\title{
Water Oxidation Catalysts: The Quest for New Oxide-Based Materials
}

\author{
Christos K. Mavrokefalos and Greta R. Patzke* \\ University of Zurich, Department of Chemistry, Winterthurerstrasse 190, CH-8057 Zurich, Switzerland; \\ christos.mavrokefalos@chem.uzh.ch \\ * Correspondence: greta.patzke@chem.uzh.ch; Tel.: +41-44-63-54693
}

Received: 22 January 2019; Accepted: 17 February 2019; Published: 26 February 2019

\begin{abstract}
The expected shortage of fossil fuels as well as the accompanying climate change are among the major challenges of the 21st century. A global shift to a sustainable energy landscape is, therefore, of utmost importance. Over the past few years, solar technologies have entered the energy market and have paved the way to replace fossil-based energy sources, in the long term. In particular, electrochemical solar-to-hydrogen technologies have attracted a lot of interest-not only in academia, but also in industry. Solar water splitting (artificial photosynthesis) is one of the most active areas in contemporary materials and catalysis research. The development of low-cost, efficient, and stable water oxidation catalysts (WOCs) remains crucial for artificial photosynthesis applications, because WOCs still represent a major economical and efficient bottleneck. In the following, we summarize recent advances in water oxidation catalysts development, with selected examples from 2016 onwards. This condensed survey demonstrates that the ongoing quest for new materials and informed catalyst design is a dynamic and rapidly developing research area.
\end{abstract}

Keywords: water oxidation catalysts; oxide materials; oxygen evolution reaction; water splitting; electrocatalysis

\section{Introduction}

Solar water splitting, namely the solar-driven splitting of water into molecular hydrogen and oxygen is one of the most promising routes to sustainably solve the issue of energy storage and transport, in the long term [1]. The overall water splitting process is schematically given as follows:

$$
2 \mathrm{H}_{2} \mathrm{O}+\text { energy } \rightarrow 2 \mathrm{H}_{2}+\mathrm{O}_{2}
$$

Typical device setups for water splitting are based on electrolysis or electrochemical water splitting cells. The involved half-cell reactions in the latter are referred to as the oxygen evolution reaction (OER) at the anode of the cell and the hydrogen evolution reaction (HER) at the cathode, which, for alkaline media, are defined as:

$$
\begin{aligned}
& \text { HER: } 4 \mathrm{H}_{2} \mathrm{O}+4 \mathrm{e}^{-} \rightarrow 2 \mathrm{H}_{2}+4 \mathrm{OH}^{-} \\
& \text {OER: } 4 \mathrm{OH}^{-} \rightarrow \mathrm{O}_{2}+2 \mathrm{H}_{2} \mathrm{O}+4 \mathrm{e}^{-}
\end{aligned}
$$

The minimum operational requirement for a water splitting system is the equilibrium voltage of $1.23 \mathrm{~V}$ at room temperature [2,3]. Nevertheless, in real systems a higher voltage, compared to the thermodynamic value, must be applied to expedite the electrochemical OER. This extra-potential is called overpotential $(\eta)$, and its minimization is a prerequisite for the development of highly active and cost-effective electrocatalysts. 
In principle, there are two main technological pathways for energy capture to drive the water splitting reaction. The first is the coupling of photovoltaics (PV) or any other grid-scale renewable energy source with electrochemical water splitting devices, i.e., electrolyzers [4]. An alternative route of solar to energy conversion are photoelectrochemical (PEC) devices [5-7]. Typically, the latter technology integrates semiconductor materials into the electrode design to directly harvest solar energy. Recently, research and development comparisons for both pathways have been subject to intense scientific debates. The first category of devices is definitely closer to large-scale technical implementations, whereas the PEC devices are at an early stage technological maturity, but provide plenty of room for flexible and off-grid setups $[8,9]$.

Given the demanding four electron transfer process involved in the water oxidation reaction, the development of efficient WOCs remains a major step towards artificial photosynthesis [10]. The past decade has witnessed great interest in the design of single and multi-metal materials and of their underlying substrates as an efficient strategy to improve the overall catalytic activity and stability of such OER catalysts [11]. Along these lines, the synergistic effects involving layered hydroxides, spinels, amorphous oxides, and other tunable oxide-based materials have resulted in an exceptional enhancement of the catalytic performance [11]. Currently, some noble metals and their oxides, such as $\mathrm{Ru}, \mathrm{Ir}, \mathrm{RuO}_{2}$, and $\mathrm{IrO}_{2}$ still remain the best catalysts for the OER, in both aqueous and acidic media. However, their high cost and low abundance are major roadblocks for their industrial application [12,13].

This review does not intend to be exhaustive, but rather aims for an update on the recent advancements in metal oxide-based OER catalysts. Hence, selected articles from 2016 to 2018 are summarized in the following sections and are rounded-off with a brief outline of the unresolved bottlenecks in this research area. The final section of the review further summarizes new research directions towards innovative composite materials.

High performance metallic WOCs are sometimes scarce, costly, and sensitive towards chemical changes, whilst many metal oxides are earth-abundant and exhibit superior durability. Metal oxides are involved in a wide range of technical processes and represent the major part of industrially applied catalyst families. Their rapid ascent traces back to the mid-1950s when they were found to catalyze a variety of oxidation and acid-base reactions. The manifold properties of oxide materials, such as electrical conductivity, lattice oxygen ion mobility, atomic or ionic diffusion among interfaces, catalytic activity, and various optical and electronic properties, are frequently associated with the presence of defects, in contrast to an ideal ionic crystal. Oxides contain different types of defects, including electron-hole pairs, excitons, vacant lattice sites, interstitial atoms, impurity atoms at interstitial or substitution locations, dislocations, and stacking faults [14]. Consequently, catalytic reactions on metal oxides are favored, due to their surface flexibility under catalytic conditions. In the following, we outline the quest for understanding and constructing new complex oxide materials and related catalyst and composite types, which still remain to be fully explored in their infinite structural variety.

\section{Recent Developments of Metal Oxide-Based WOCs}

\subsection{Ru-, Ir-, and Cu-based Metal Oxides}

In this section, the selected articles on $\mathrm{Ru}-$, Ir-, and Cu-based metal oxides received immediate recognition in the field and covered research conducted over the last three years [15-22]. Emphasis has been placed on mechanistic insights and operando techniques, as well as on the proposed Cu-based catalysts, as a possible alternative to the more costly Ru- and Ir-based WOCs. The selected studies applied the stability and onset potential required during the OER as benchmarking parameters. Generally, this focused review article places selective emphasis on progress in oxide WOC performance, as a result of new synthetic strategies (for examples of reviews containing information on operando methods $[10,23,24])$. 
All catalysts in this section are discussed and summarized below in Table 1. In the following survey tables, "durability" refers to maintenance of the catalytic performance, at constant current conditions, and "stability" refers to the resistivity of a given catalyst towards dissolution/leaching of the active metal sites. Whenever possible, the descriptions of the catalysts' stability, in the following tables, represent the exact wording as given by the authors. Exceptions are stability assessments marked with an asterisk sign $\left(^{*}\right)$; these were added by us after going through the data provided in the corresponding publications. In this review, the various metal oxide families reported in the next sections are summarized in tables according to the information on the durability and stability of catalyst performance. Unless stated otherwise, the symbol "-“ indicates that no such parameters were reported in the cited study. The Tafel values in this review are generally cited as efficiency indicators of the electrocatalytic performance. This criterion is particularly important in water electrolyzers, for instance, where high current densities, at the lowest possible operational voltages, are vital for the economic viability. Furthermore, Conway et al. clarified in a representative study, three decades ago, that Tafel slope values can provide both quantitative and mechanistic insights into electrocatalytic processes [25]. On a very fundamental level, the Tafel slope is characterized by the rate of increase of the electrode potential or polarization with the log of the current density. From a more practical point of view, along with the current density obtained at a certain overpotential, the rate of change of this current density with the overpotential is also important. Hence, low Tafel slope values are generally recognized as a key parameter indicating efficient electrocatalytic materials.

Weber et al. proposed that an exfoliation route in tetrabutylammonium hydroxide (TBAOH) solution to convert bulk IrOOH to IrOOH nanosheets could open the doors to fundamental studies and mechanistic insight. This approach might as well be of great interest for industrial applications in heterogeneous catalysis [15]. This material outperformed the state-of-the-art rutile-IrO $\mathrm{r}_{2}$ under the same conditions. The $\mathrm{IrOOH}$ nanosheets were deposited on Ti electrodes and displayed an overpotential of $344 \mathrm{mV}$ and Tafel slope of $58 \mathrm{mV} \mathrm{dec}^{-1}$, in $0.1 \mathrm{M} \mathrm{HClO}_{4}$. Chronoamperometric and XPS measurements revealed the long-lasting properties of this material. In particular, XPS showed that the trivalent species of IrOOH remained, after the OER process. Techniques for heterostructured and high quality growth of epitaxial complex oxide thin films have received increasing attention with regard to their application as water oxidation catalysts.

Seitz et al. reported on the significance of leaching in the enhancement of stability and catalytic activity [16]. In particular, they demonstrated that $\mathrm{Sr}$ leaching from $\mathrm{SrTiO}_{3}$ thin films caused surface rearrangement of $\mathrm{IrO}_{x}$ films, which led to in situ formation of an $\mathrm{IrO}_{x} / \mathrm{SrIrO}_{3}$ catalyst with only $0.27 \mathrm{~V}_{\mathrm{RHE}}$ overpotential and high stability for a long operational time of $30 \mathrm{~h}$. Figure 1 displays atomic force microscopy (AFM) maps of a smooth as-prepared surface, before electrocatalytic activity, and uniform small features after electrocatalytic tests, thus illustrating the surface rearrangement. Further evidence is provided by the XPS data in Figure 2. The signal of the Sr 3d peak was attenuated, after $30 \mathrm{~min}$ of electrocatalytic activity. The high stability and low overpotential values of 60 and $100 \mathrm{~nm} \mathrm{IrO} \mathrm{I}_{\mathrm{x}} / \mathrm{SrIrO}_{3}$ electrocatalysts, respectively, after 0 and $10 \mathrm{~min}$, as well as 2 and $30 \mathrm{~h}$ of catalytic tests are displayed in Figure 3. 
Table 1. Comparison of the electrocatalytic activity of recently reported $\mathrm{Ru}-$-, Ir-, and Cu-based catalysts ("durability" refers to maintenance of the catalytic performance at constant current conditions, while "stability" indicates the resistivity of a given catalyst towards dissolution/leaching of the active metal sites).

\begin{tabular}{|c|c|c|c|c|c|c|c|c|}
\hline Catalyst & Preparation Method & Onset Potential (V) & $\begin{array}{c}\eta(\text { at } 10 \\
\left.\mathrm{mV} / \mathrm{cm}^{2}\right)(\mathrm{V})\end{array}$ & $\begin{array}{l}\text { Tafel Slope } \\
\left(\mathrm{mV} \mathrm{dec}^{-1}\right)\end{array}$ & $\begin{array}{l}\text { Durability } \\
\text { (h) }\end{array}$ & Stability & Electrolyte & Ref. \\
\hline $\mathrm{Ru}$ and $\mathrm{Ir}$ & Sputtering \& evaporation & $\begin{array}{l}\text { Ru: } 1.20 \text { (both media), Ir: } 1.27 \& 1.43 \\
\text { (acidic \& alkaline media, respectively) }\end{array}$ & - & $30-40$ & 0.25 & Low & $\begin{array}{l}0.1 \mathrm{M} \mathrm{H}_{2} \mathrm{SO}_{4} \& \\
0.05 \mathrm{M} \mathrm{NaOH}\end{array}$ & [19] \\
\hline $\mathrm{RuO}_{2}$ and $\mathrm{IrO}_{2}$ & Sputtering \& evaporation & $\begin{array}{l}\mathrm{RuO}_{2}: 1.35 \& 1.47 \text { (acidic \& alkaline media, } \\
\quad \text { respectively), IrO } 2: 1.47 \text { (both media) }\end{array}$ & - & $30-40$ & 0.25 & Good * & $\begin{array}{c}0.1 \mathrm{M} \mathrm{H}_{2} \mathrm{SO}_{4} \& \\
0.05 \mathrm{M} \mathrm{NaOH}\end{array}$ & [19] \\
\hline $\mathrm{IrO}_{\mathrm{x}} / \mathrm{SrIrO}_{3}$ & $\begin{array}{l}\text { Pulsed laser deposition } \\
\text { (PLD) }\end{array}$ & 1.44 & 0.27 & - & 30 & Reasonable & $0.5 \mathrm{M} \mathrm{H}_{2} \mathrm{SO}_{4}$ & [16] \\
\hline $\begin{array}{c}\mathrm{Cu}, \mathrm{Cu}_{2} \mathrm{O}, \mathrm{Cu}(\mathrm{OH})_{2} \text { and } \\
\mathrm{CuO}\end{array}$ & Electrodeposition & - & 0.417 & $60-66$ & 22 & $\begin{array}{l}\mathrm{Cu} \& \mathrm{Cu}_{2} \mathrm{O} \text { : very } \\
\text { good } * \text { CuO \& } \\
\mathrm{Cu}(\mathrm{OH})_{2}: \text { poor }\end{array}$ & $0.1 \mathrm{M} \mathrm{KOH}$ & [17] \\
\hline IrOOH nanosheets & Exfoliation in $\mathrm{TBAOH}$ & - & 0.344 & 58 & 14 & Extraordinary & $0.1 \mathrm{M} \mathrm{HClO}$ & [15] \\
\hline $\mathrm{Cu}_{2} \mathrm{O} / \mathrm{ITO}$ & Electrodeposition & $<0.8$ & 0.4 & 72 & 5 & High & $\begin{array}{c}\mathrm{K}_{2} \mathrm{~B}_{4} \mathrm{O}_{8} \\
\mathrm{C}_{2} \mathrm{H}_{3} \mathrm{KO}_{2} \& \\
\mathrm{KH}_{2} \mathrm{PO}_{4}\end{array}$ & [20] \\
\hline $\begin{array}{c}\mathrm{Cu}(\mathrm{OH})_{2} @ \mathrm{CoCO}_{3}(\mathrm{OH})_{2} . \\
\mathrm{nH}_{2} \mathrm{O}\end{array}$ & Hydrothermal & - & 0.27 & 78 & 20 & Superior & $1 \mathrm{M} \mathrm{KOH}$ & [18] \\
\hline $\mathrm{RuO}_{2}(001)$ & Commercially available & - & - & - & 2 & - & $0.05 \mathrm{M} \mathrm{H}_{2} \mathrm{SO}_{4}$ & [21] \\
\hline $\mathrm{Ir}_{\mathrm{x}} \mathrm{O} / \mathrm{ATO}$ & Electrodeposition & - & 0.28 & 61.7 & 15 & High * & $0.05 \mathrm{M} \mathrm{H}_{2} \mathrm{SO}_{4}$ & [22] \\
\hline $\mathrm{TiO}_{2} / \mathrm{CuO}$ & $\begin{array}{l}\text { Spin-coating \& pulsed } \\
\text { laser deposition }\end{array}$ & - & - & - & 0.166 & Excellent & $0.1 \mathrm{M} \mathrm{NaOH}$ & [26] \\
\hline
\end{tabular}



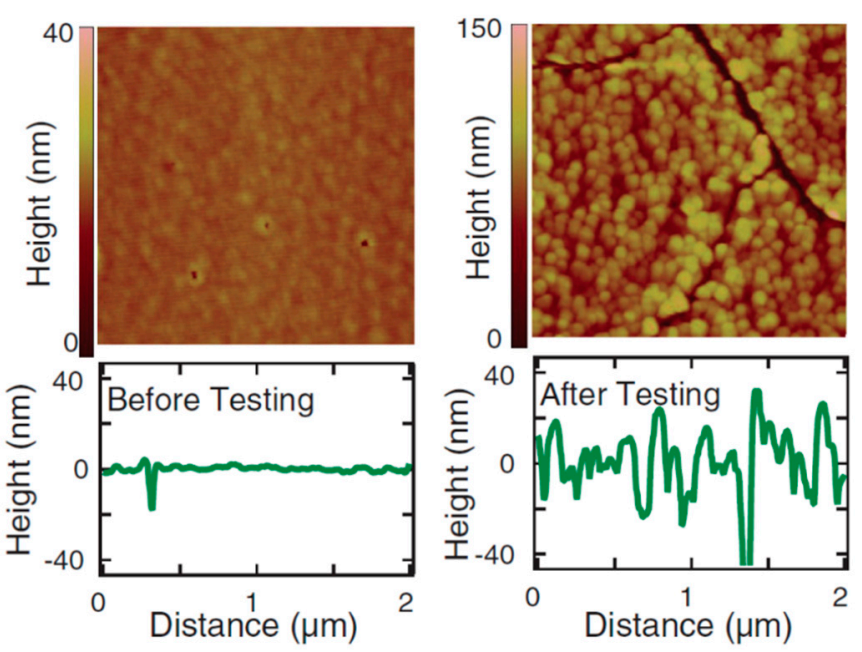

Figure 1. AFM images of $100 \mathrm{~nm} \mathrm{SrIrO}_{3}$ film before and after $30 \mathrm{~h}$ of oxygen evolution reaction (OER) performance, showing the surface rearrangement. Reproduced from [16], with permission from the American Association for the Advancement of Science, copyright 2016.
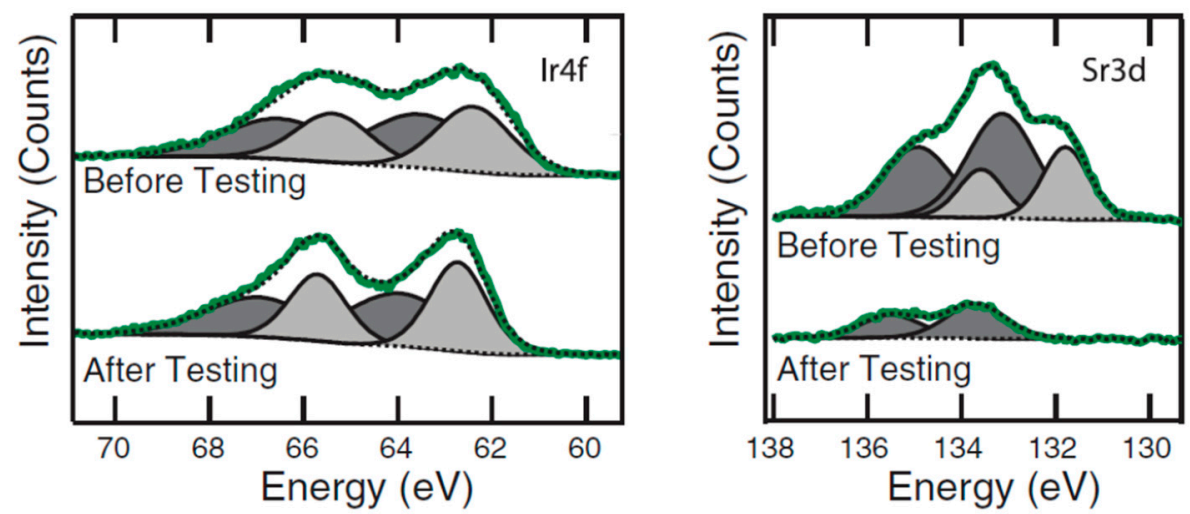

Figure 2. XPS spectra of $100 \mathrm{~nm} \mathrm{SrIrO}_{3}$ film (before and after $30 \mathrm{~min}$ of OER), showing the attenuation of the Sr 3d peak, due to leaching. Reproduced from [16], with permission from the American Association for the Advancement of Science, copyright 2016.

$\mathrm{Cu}$ and $\mathrm{Cu}$-oxide surfaces are widely known as catalysts of $\mathrm{CO}_{2}$ reduction. However, Deng et al. identified that $\mathrm{Cu}$ materials can be very promising, earth-abundant, efficient, and low-cost catalysts for the OER, when subjected to careful designing of their morphology [17]. Their work provided new progress on both $\mathrm{Cu}$ surfaces, with various oxidation states, as well as on operando monitoring techniques. In situ Raman spectroscopy of $\mathrm{Cu}, \mathrm{Cu}_{2} \mathrm{O}, \mathrm{Cu}(\mathrm{OH})_{2}$, and $\mathrm{CuO}$ on metallic copper disks was employed to study the OER in alkaline media. Different morphologies were observed, from small-pyramid-like structures to needle-shaped structures, as well as nanoparticles $<20 \mathrm{~nm}$, as shown in SEM images (Figure 4).

The corresponding Tafel slope values were in the range of $60-66 \mathrm{mV} \mathrm{dec}^{-1}$ and are comparable to those of other metal oxides in the literature. Along with the morphology of the $\mathrm{Cu}$ samples, the role of $\mathrm{Cu}$ (III) species was considered to play an important role in OER.

Cyclic voltammograms and Raman experiments were performed, showing a cathodic peak at around $1.55 \mathrm{~V}_{\text {RHE }}$ (cf. Figure 5), which was attributed to $\mathrm{Cu}$ (III) species. A Raman peak at $603 \mathrm{~cm}^{-1}$ appeared under the oxygen evolution potential and $\mathrm{Cu}(\mathrm{III})$ oxide formation was further demonstrated by in situ XANES of the Cu K-edge. Given the aforementioned information, the authors drew the conclusion that $\mathrm{Cu}$ (III) oxide species were responsible for the electrochemical water oxidation. 


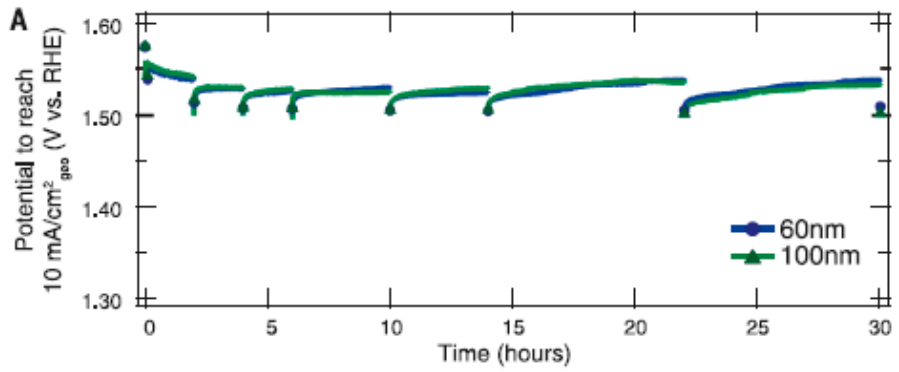

B

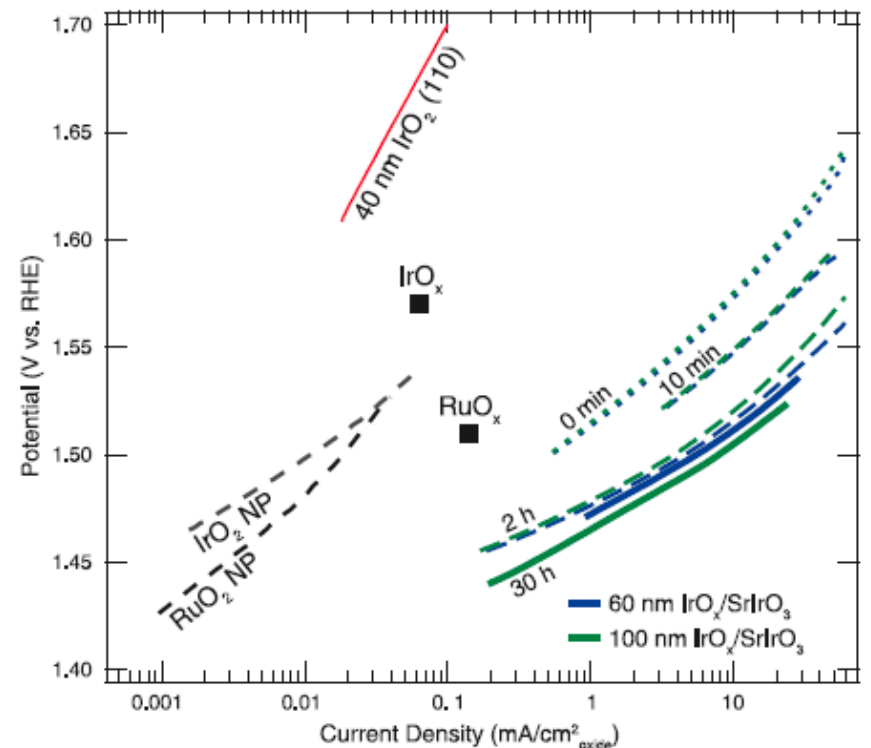

Figure 3. Performance of the $\mathrm{IrO}_{\mathrm{x}} / \mathrm{SrIrO}_{3}$ catalyst: (A) Chronopotentiometry measurements of 60 and $100 \mathrm{~nm}$ electrocatalysts, respectively, at a potential required to reach $10 \mathrm{~mA} / \mathrm{cm}^{2}$ per geometric area, for $30 \mathrm{~h}$, in $0.5 \mathrm{M} \mathrm{H}_{2} \mathrm{SO}_{4}$ electrolyte. (B) Tafel plots of 60 and $100 \mathrm{~nm}$ electrocatalysts, after 0 and $10 \mathrm{~min}$, as well as 2 and $30 \mathrm{~h}$ of catalytic tests, compared to references in $0.5 \mathrm{M} \mathrm{H}_{2} \mathrm{SO}_{4}$ electrolyte. Reproduced from [16], with permission from the American Association for the Advancement of Science, copyright 2016.

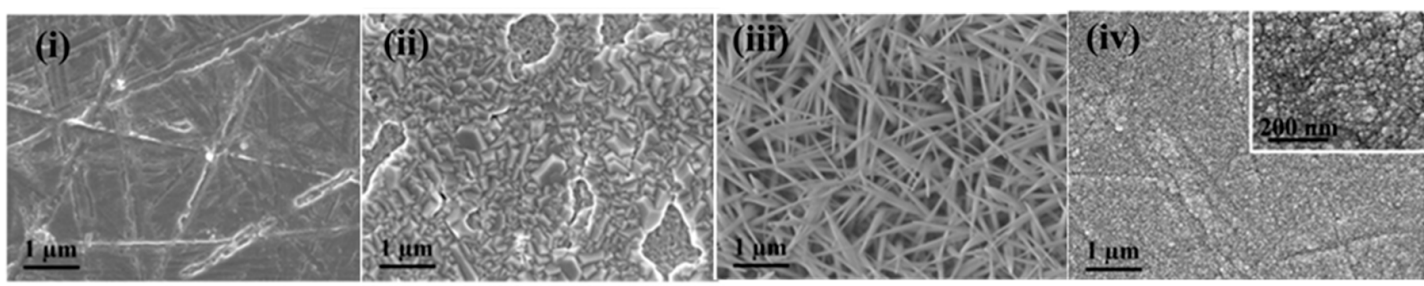

Figure 4. SEM images displaying morphology differences between as-synthesized (i) $\mathrm{Cu}$, (ii) $\mathrm{Cu}_{2} \mathrm{O} / \mathrm{Cu}$, (iii) $\mathrm{Cu}(\mathrm{OH})_{2} / \mathrm{Cu}$, and (iv) $\mathrm{CuO} / \mathrm{Cu}$ samples, respectively. Reproduced from [17], with permission from the American Chemical Society, copyright 2016.

Alternatively, a $\mathrm{Cu}(\mathrm{OH})_{2} @ \mathrm{CoCO}_{3}(\mathrm{OH})_{2} \cdot \mathrm{nH}_{2} \mathrm{O}$ core-shell structure nanowire array was proposed by Xie et al., as a catalyst for the oxygen evolution reaction [18]. The catalyst showed strong stability and could be a promising candidate for other applications as well, such as methanol electro-oxidation.

A study of Amiri et al. significantly improved the onset potential for water oxidation at a value below $0.8 \mathrm{~V}_{\mathrm{RHE}}$, by using a $\mathrm{Cu}_{2} \mathrm{O}$ thin film on indium tin oxide (ITO) electrodes [20]. Another aspect of their work is the facile electrodeposition method using copper perchlorate, various diamines, and 1,4-bis(2-carboxyaldehyde phenoxy)butane precursors. The stability of the catalyst was high. The electrode could be used for multiple OER experiments, without loss of its activity in various electrolytes from potassium borate to potassium acetate and potassium phosphate, as observed by the authors. 


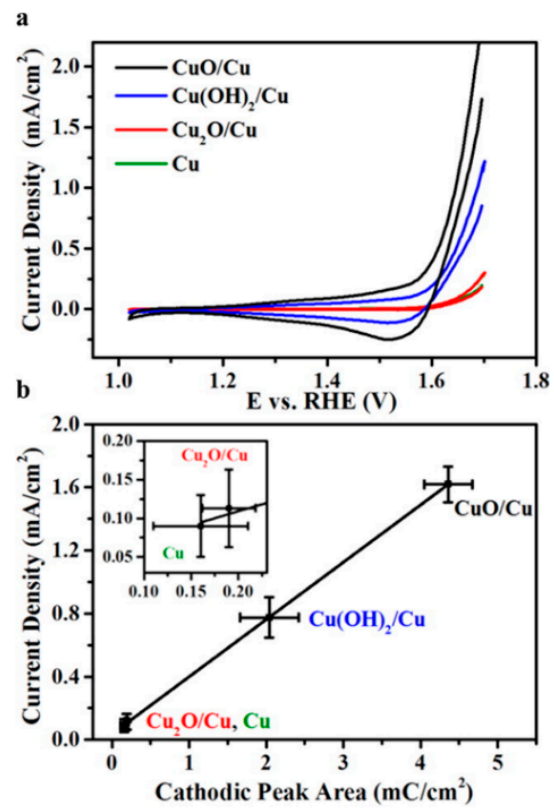

Figure 5. Performance evaluation of $\mathrm{Cu}$-based OER-catalysts: (a) Cyclic voltammograms of $\mathrm{Cu}$, $\mathrm{CuO} / \mathrm{Cu}, \mathrm{Cu}(\mathrm{OH})_{2} / \mathrm{Cu}$, and $\mathrm{Cu}_{2} \mathrm{O} / \mathrm{Cu}$, after chronoamperometry at $0.7 \mathrm{~V}_{\mathrm{RHE}}$ (scan rate $0.01 \mathrm{~V} / \mathrm{s}$ in 0.1 $\mathrm{M} \mathrm{KOH}) ; \mathrm{CVs}$ were scanned cathodically, at first. (b) Plot of the current densities as a function of charge of the reduction peaks at $1.55 \mathrm{~V}_{\mathrm{RHE}}$ (inset: enlarged view of $\mathrm{Cu}_{2} \mathrm{O} / \mathrm{Cu}$ and $\mathrm{Cu}$ results). Reproduced from [17], with permission from the American Chemical Society, copyright 2016.

The work of Roy et al. showed the importance of different facets of a catalyst, not only for the OER activity, but also for corrosion [21]. The authors investigated how oxygen evolution and corrosion levels arising from different sites influence future catalyst engineering. Evidence was provided that there is no direct correlation between OER activity and stability of the various facets of the catalyst and commercial nanoparticles. Well-defined, oriented, thin films of rutile $\mathrm{RuO}_{2}$ (i.e., 001, 101, and 111) were studied in acidic solution and were found to be more active towards OER, compared to (110) single crystalline and commercial $\mathrm{RuO}_{2}$ particles. More precisely, potentiostatic experiments over $2 \mathrm{~h}$ on $\mathrm{RuO}_{2}$ thin film (001) orientations showed steady state currents, at around $150 \mu \mathrm{A} \mathrm{cm}^{-2}$, at the applied potential of $1.6 \mathrm{~V}_{\mathrm{RHE}}$, whilst the (101) and (111) orientations provided currents around 90 and $40 \mu \mathrm{A} \mathrm{cm}^{-2}$, respectively. Moreover, the $\mathrm{RuO}_{2}$ (110) surface gave a higher steady state current density at around $50 \mu \mathrm{A} \mathrm{cm}^{-2}$, compared to the commercial $\mathrm{RuO}_{2}$ particles, which showed the lowest steady state current density, at approximately $20 \mu \mathrm{A} \mathrm{cm}{ }^{-2}$. Spectrometric measurements revealed that higher amounts of $\mathrm{Ru}$ on all of the aforementioned oriented thin films dissolved in the acidic electrolyte, compared to the (110) single crystal and particle references, where the amounts of dissolved Ru were found to be much smaller after $2 \mathrm{~h}$ of electrocatalytic tests. More precisely, $225 \mathrm{ng} \mathrm{Ru} \mathrm{cm}{ }^{-2}$ of the $\mathrm{RuO}_{2}$ (001) oriented thin films was dissolved after $2 \mathrm{~h}$ of electrocatalytic experiments, compared to 190, 150, 13, and $10 \mathrm{ng} \mathrm{Ru} \mathrm{cm}{ }^{-2}$ of the $\mathrm{RuO}_{2}$ (101), (111), (110), and commercial particles, respectively.

In related lines, Suk $\mathrm{Oh}$ et al. studied the role of various electrode supports towards the OER activity and electrochemical stability of pure $\mathrm{IrO}_{\mathrm{x}}$ nanoparticles, $\mathrm{IrO}_{\mathrm{x}}$-supported on carbon $\left(\mathrm{IrO}_{\mathrm{x}} / \mathrm{C}\right)$, and $\mathrm{IrO}_{\mathrm{x}}$-modified commercial and non-commercial antimony-doped tin oxide $\left(\mathrm{IrO}_{\mathrm{x}} / \mathrm{comm}\right.$. ATO and $\mathrm{IrO}_{x} /$ ATO, respectively) [22]. The motivation of their study was based on the ability of catalyst-supports to reduce the overall metal-loading, without lowering the durability of the electrode. Outcomes of their study showed a much higher stability and corrosion-resistance of the $\mathrm{IrO}_{\mathrm{x}}$ nanoparticles on the metal/metal oxide supports, compared to carbon, as well as high charge-transfer kinetics. The faradaic efficiency of the $\mathrm{IrO}_{\mathrm{x}} / \mathrm{ATO}$ catalysts was found to be $100 \%$, for OER, which showed their high selectivity towards water oxidation. Furthermore, the oxidation state of the $\mathrm{IrO}_{\mathrm{x}} /$ ATO was reduced to $3.2+$, compared to the unsupported $\mathrm{IrO}_{\mathrm{x}}$ nanoparticles 
(4+), after long-term electrochemical experiments revealing the metal/metal oxide support effects. Furthermore, voltammetric characterizations were performed and it was found that the electroactive species of $\mathrm{IrO}_{x}$-supported ATO nanoparticles were decreased by only $30 \%$ after electrocatalytic activity of $15 \mathrm{~h}$, whereas $\mathrm{IrO}_{\mathrm{x}}$ loading on $\mathrm{C}$ decreased by $99.7 \%$, under the same conditions.

\subsection{Noble Metal-Free Oxide-Related WOCs}

\subsubsection{Layered Hydroxides and Related Ni-Fe-Based Materials}

Layer double hydroxides (LDHs) are a class of layered materials, which are also known as anionic clays. Their characteristic structural feature is the generic layer sequence $[A c B Z A c B]_{n}$, where $c$ represents layers of metal cations, $A$ and $B$ are layers of hydroxide $\left(\mathrm{HO}^{-}\right)$anions, and $Z$ are layers of other anions and neutral molecules [27]. Nowadays, LDHs find widespread application in dye-sensitized solar cells, photocatalytic water oxidation, chemical sensors, and supercapacitors, thanks to their open structures and chemical versatility [28]. Recently, several layer double hydroxide catalysts have been developed for OER catalysis [29-33].

Presently, NiFe-LDH catalysts are among the leading LDH-based WOC materials. Even though water oxidation on nickel hydroxide has been studied since the 1960s, the clear-cut assignment of $\mathrm{Ni}$ as the active site remains under debate for mixed metal LDHs. Some recent studies proposed that the incorporation of Fe into Ni-LDH structures provides more active sites as a potential for the enhanced OER activity $[34,35]$. This behavior has been further supported by Nocera et al., who argued that the enhanced OER activity is promoted by the Lewis acidity of $\mathrm{Fe}(\mathrm{IIII})$ [36]. The group of Duan et al. demonstrated that a charge imbalance in the $\mathrm{M}(\mathrm{OH})_{6}$ layers is caused by the redox-active $\mathrm{Fe}(\mathrm{III})$ ions, which is then compensated by interlayer anions [37]. All of the representative layered hydroxide OER catalysts discussed below and summarized in Table 2 covered research of the last three years. The maximum performing NiFe-LDH-based catalyst to date is a NiFe-LDH array, which is also specified in Table 2 [37]. The following selected studies contributed to new catalyst architectures and designs with improved stability. Furthermore, considerable efforts were made over the past few years to replace Fe with other transition metals.

$\mathrm{Wu}$ et al. reported on ultrathin CoNi double hydroxide/CoO nanosheets, via an in situ reduction and interface-directed assembly method in air, as shown in the schematic illustration of Figure 6 [29]. Interfacial tension resulted in the strong extrusion of hydrated metal-oxide clusters, which led to the formation of the $\mathrm{CoNi} \mathrm{LDH} / \mathrm{CoO}$ nanosheets. The current density for OER was determined as $150 \mathrm{~mA} \mathrm{~cm}{ }^{-2}$ at $0.3 \mathrm{~V}_{\mathrm{RHE}}$, i.e., 1.5 times greater than that for $\mathrm{RuO}_{2}$. The durability of the catalyst was also tested and the current density remained stable for $10 \mathrm{~h}$. The obtained CoNi LDH/CoO nanosheets exhibited high turnover frequencies (TOFs) of $1.4 \mathrm{~s}^{-1}$ at the overpotential of $0.4 \mathrm{~V}_{\mathrm{RHE}}$. The authors argued that the performance of their catalysts was mainly related to the higher +3 valence of the Co and $\mathrm{Ni}$ centers, as well as to the low crystallinity, which gave rise to a number of exposed defects and active sites. Furthermore, the functionalization of the surface with $\mathrm{OH}^{-}$groups and the $\mathrm{OH}^{-} / \mathrm{O}_{2}$ adsorption and transport in the porous structure contributed to the high OER activity.

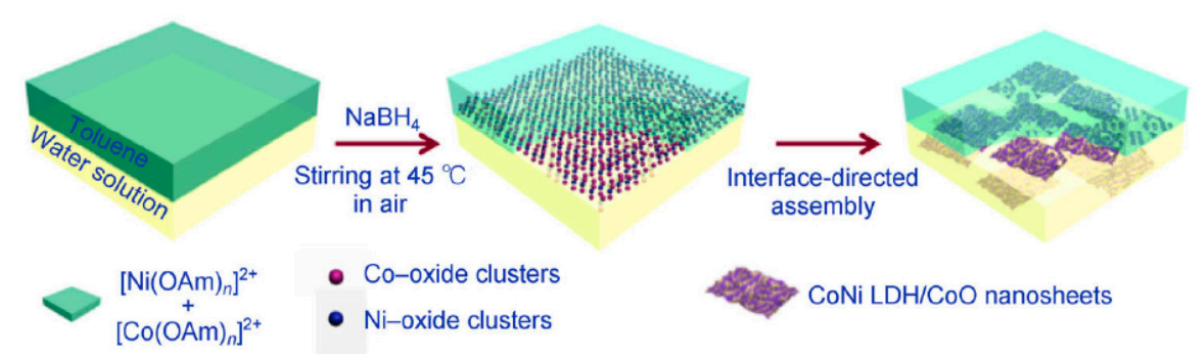

Figure 6. Formation scheme for $\mathrm{CoNi}-\mathrm{LDH} / \mathrm{CoO}$ nanosheets via an in situ reduction approach, followed by assembly at the toluene/water interface. Reproduced from [29], with permission from Springer Nature, copyright 2016. 
Table 2. Comparison of the electrocatalytic activity of noble metal-free LDH and related Ni-Fe catalysts (cf. Table 1 for definitions of "durability" and "stability").

\begin{tabular}{|c|c|c|c|c|c|c|c|c|}
\hline Catalyst & Preparation Method & $\begin{array}{c}\text { Onset } \\
\text { Potential (V) }\end{array}$ & $\begin{array}{c}\eta(\text { at } 10 \\
\left.\mathrm{mV} / \mathrm{cm}^{2}\right)(\mathrm{V})\end{array}$ & $\begin{array}{l}\text { Tafel Slope } \\
\left(\mathrm{mV} \mathrm{dec}^{-1}\right)\end{array}$ & $\begin{array}{l}\text { Durability } \\
\text { (h) }\end{array}$ & Stability & Electrolyte & Ref. \\
\hline $\begin{array}{c}\mathrm{CoNi}-\mathrm{LDH} / \mathrm{CoO} \\
\text { nanosheets }\end{array}$ & $\begin{array}{l}\text { In situ reduction \& } \\
\text { interface-directed assembly in air }\end{array}$ & 1.48 & 0.3 & 123 & 10 & Good & $1 \mathrm{M} \mathrm{KOH}$ & [29] \\
\hline $\mathrm{CoAl} \& \mathrm{CoFe} \mathrm{LDH}$ & Co-precipitation & 1.58 & $0.36 \& 0.37$ & $39 \& 49$ & 50 & Excellent & $0.1 \mathrm{M} \mathrm{KOH}$ & [30] \\
\hline Co-Fe LDH nanosheets & Electrodeposition & - & 0.42 & 131 & 50 & Superior & $0.1 \mathrm{M} \mathrm{K}_{2} \mathrm{~B}_{4} \mathrm{O}_{8}$ & [31] \\
\hline $\begin{array}{l}\mathrm{Ni}_{0.75}-\mathrm{V}_{0.25} \mathrm{LDH} \text { narrow } \\
\text { nanosheets }\end{array}$ & Hydrothermal & - & 0.35 & 50 & 25 & Considerable & $1 \mathrm{M} \mathrm{KOH}$ & [32] \\
\hline $\begin{array}{l}\text { CoAl-LDH on 3D } \\
\text { graphene network }\end{array}$ & Hydrothermal & - & 0.28 & 36 & 30 & Excellent & $1 \mathrm{M} \mathrm{KOH}$ & [33] \\
\hline NiFe LDHs-MoO & Hydrothermal & - & 0.276 & 55 & 12 & Good & $1 \mathrm{M} \mathrm{KOH}$ & [38] \\
\hline NiFe-LDH array & Electrodeposition & 1.43 & 0.224 & 52.5 & 50 & Superior & $1 \mathrm{M} \mathrm{KOH}$ & [37] \\
\hline Fe-doped $\mathrm{Ni}(\mathrm{OH})_{2}$ films & Precipitation & - & 0.25 to 0.35 & - & 2 & Good* & $1 \mathrm{M} \mathrm{KOH}$ & [36] \\
\hline $\mathrm{Ni}-\mathrm{FeO}(\mathrm{OH})$ & $\begin{array}{l}\text { Microwave-assisted autoclave } \\
\text { synthesis under solvothermal } \\
\text { conditions }\end{array}$ & - & 0.29 & 40 & $>20$ & Good & $0.1 \mathrm{M} \mathrm{KOH}$ & [39] \\
\hline $\begin{array}{l}\mathrm{Fe}_{2} \mathrm{O}_{3}-\mathrm{Ni}(\mathrm{OH})_{2} \text { to } \\
\mathrm{NiFe}_{2} \mathrm{O}_{4}-\mathrm{NiOOH}\end{array}$ & Hydrothermal \& anodization & - & 0.24 & 55 & 1 & High & $1 \mathrm{M} \mathrm{KOH}$ & [40] \\
\hline $\mathrm{Ni}-\mathrm{Fe}-\mathrm{OH} @ \mathrm{Ni}_{3} \mathrm{~S}_{2}$ & Two-step synthesis & - & 0.479 & 124 & 50 & Excellent & $1 \mathrm{M} \mathrm{KOH}$ & [41] \\
\hline $\mathrm{Ni} / \mathrm{NiFe}-\mathrm{OH}$ & Multi-step electrodeposition & - & 0.205 & 53 & 12 & Excellent & $1 \mathrm{M} \mathrm{KOH}$ & [42] \\
\hline NiFe-LDH nanosheets & Pulsed laser ablation in liquids & - & $0.27-0.45$ & & 3.5 & Remarkable & $1 \mathrm{M} \mathrm{KOH}$ & [43] \\
\hline NiFe LDH-NS@DG & Co-precipitation & 1.41 & 0.21 & 52 & 10 & Robust & $1 \mathrm{M} \mathrm{KOH}$ & [44] \\
\hline
\end{tabular}


Ping et al. introduced a CoAl-LDH nanosheets catalyst on a 3D graphene network [33]. In their study, a porous catalyst was prepared by self-assembly of the exfoliated single-layer CoAl nanosheets onto 3D graphene, via electrostatic interaction as illustrated in Figure 7. Prior to the exfoliation, the CoAl-LDH $\left(\mathrm{CO}_{3}{ }^{2-}\right)$ was fabricated through a hydrothermal process, based on urea hydrolysis, and subjected to anion exchange. The resulting catalyst outperformed an $\mathrm{IrO}_{2}$ reference, by exhibiting a very low overpotential of $0.28 \mathrm{~V}_{\mathrm{RHE}}$ and a Tafel slope value of $36 \mathrm{mV} / \mathrm{dec}$. The TOF values of the 3DGN/CoAl-NS were found to be $\sim 0.6 \mathrm{~s}^{-1}$ and $\sim 1.2 \mathrm{~s}^{-1}$ at overpotentials of 0.3 and $0.35 \mathrm{~V}_{\mathrm{RHE}}$, respectively. Furthermore, about $22.5 \mu \mathrm{mol}$ of $\mathrm{O}_{2}$ was produced at a constant current of $1 \mathrm{~mA} \mathrm{~cm}{ }^{-2}$. Chronoamperometry and chronopotentiometry experiments were carried out and indicated excellent electrochemical stability for $30 \mathrm{~h}$ (Figure 8). The electrocatalytic efficiency of the catalyst was ascribed to the fast electron/charge transfer, during the OER, and acceleration of the reaction kinetics thanks to the uniform coating of the single layer CoAl nanosheets onto 3D graphene.

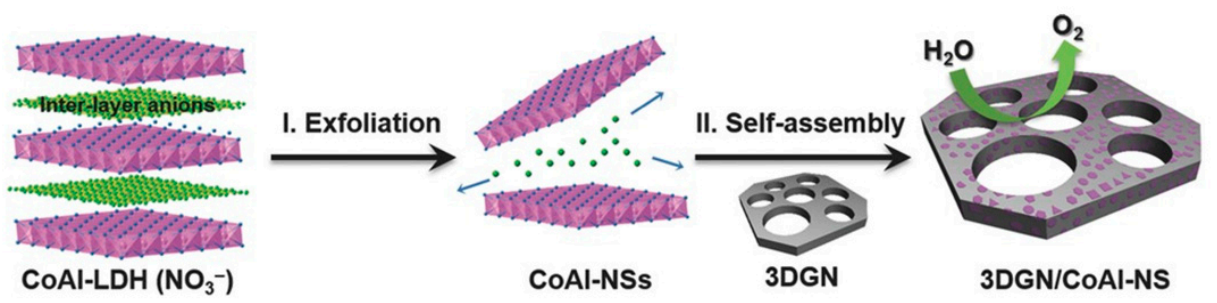

Figure 7. 3D graphene assisted formation of the porous electrocatalyst 3DGN/CoAl-NS. Reproduced from [33], with permission from John Wiley and Sons, copyright 2016.

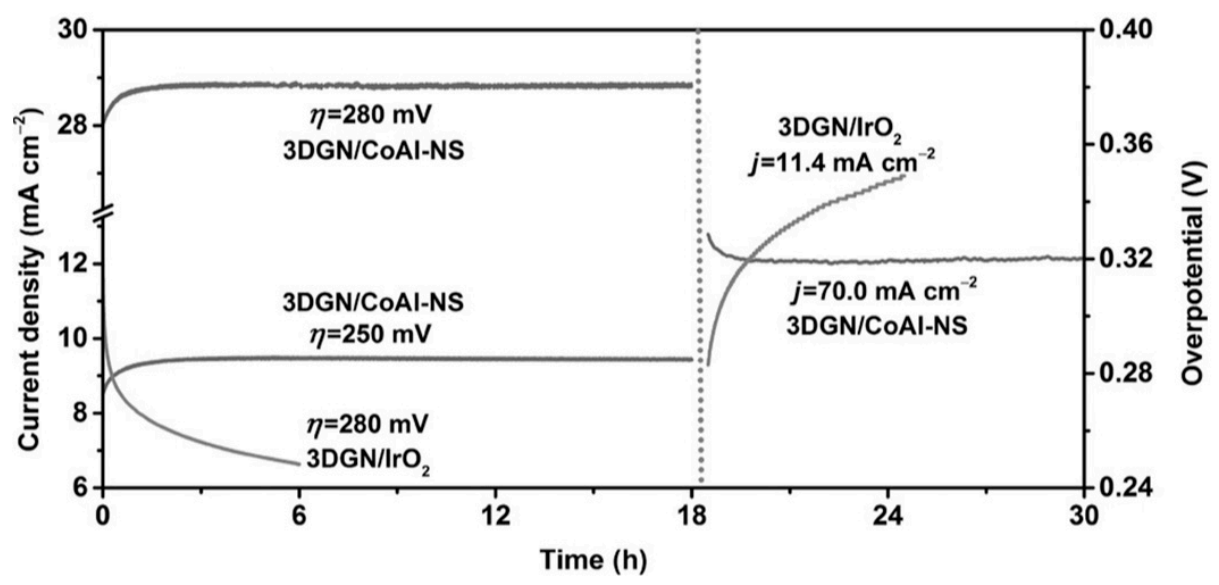

Figure 8. Chronoamperometric measurements of $3 \mathrm{DGN} / \mathrm{CoAl}-\mathrm{NS}$ and $3 \mathrm{DGN} / \mathrm{IrO}_{2}$ in $1 \mathrm{M} \mathrm{KOH}$. Left plot: 3DGN $/$ CoAl-NS at $\eta=0.25$ and $0.28 \mathrm{~V}$ RHE, and $3 \mathrm{DGN} / \mathrm{IrO}_{2}$ at $\eta=0.28 \mathrm{~V}$ RHE. Right plot: 3DGN/CoAl-NS at $j=70 \mathrm{~mA} \mathrm{~cm}{ }^{-2}$, and 3DGN $/ \mathrm{IrO}_{2}$ at $j=11.4 \mathrm{~mA} \mathrm{~cm}{ }^{-2}$. Reproduced from [33], with permission from John Wiley and Sons, copyright 2016.

Yang et al. demonstrated the effect of $\mathrm{Fe}$ and $\mathrm{Al}$ contents in Co-Fe LDH catalysts on the OER activity [30]. A co-precipitation method with $\mathrm{Al}^{3+}$ or $\mathrm{Fe}^{3+}$ ions in the range of 15 to 45 at $\%$ was applied. The optimal Fe content was reported at 35 at \%, which resulted in a synergistic effect on the Co-Fe LDH catalyst. The role of both ions as trivalent species was essential for the stabilization of the LDH structure. The OER activity was enhanced when the optimal Fe content was incorporated, whereas the oxygen evolution was suppressed in the presence of $\mathrm{Al}^{3+}$ species. The onset potential and overpotential of the optimized $\mathrm{Co}_{0.65} \mathrm{Fe}_{0.35}(\mathrm{OH})_{2}$ catalyst were observed at $1.58 \mathrm{~V}_{\mathrm{RHE}}$ and $0.36 \mathrm{~V}_{\mathrm{RHE}}$, respectively. The catalyst showed a very good stability in aqueous alkaline electrolyte, for $48 \mathrm{~h}$, with a small Tafel slope of $49 \mathrm{mV} \mathrm{dec}^{-1}$.

An alternative LDH catalyst was introduced by You et al. [31]. An electrodeposition method was employed to fabricate a CoFe-LDH nanosheet array coated with an ultrathin CoFe-borate layer 
supported on Ti mesh. The electrocatalytic performance of the 3D catalyst electrode was evaluated in near neutral $\mathrm{pH}$ in $0.1 \mathrm{M} \mathrm{K}_{2} \mathrm{~B}_{4} \mathrm{O}_{7}$ solution. The CoFe- $\mathrm{B}_{\mathrm{i}} @ \mathrm{CoFe}-\mathrm{LDH}$ NA/TM displayed a high catalytic OER activity, with a small overpotential of $0.42 \mathrm{~V}_{\text {RHE }}$. HRTEM images depicted the formation of an ultrathin amorphous layer $\left(\mathrm{CoFe}-\mathrm{B}_{\mathrm{i}}\right)$, with a thickness between 5 and $8 \mathrm{~nm}$ and a nanoarray feature of the catalyst was, furthermore, observed during morphological characterizations (Figure 9) and retained after electrocatalytic activity for $50 \mathrm{~h}$. The TOF was calculated at $0.482 \mathrm{~mol} \mathrm{O}_{2} \mathrm{~s}^{-1}$ at the overpotential of $0.6 \mathrm{~V}_{\mathrm{RHE}}$.
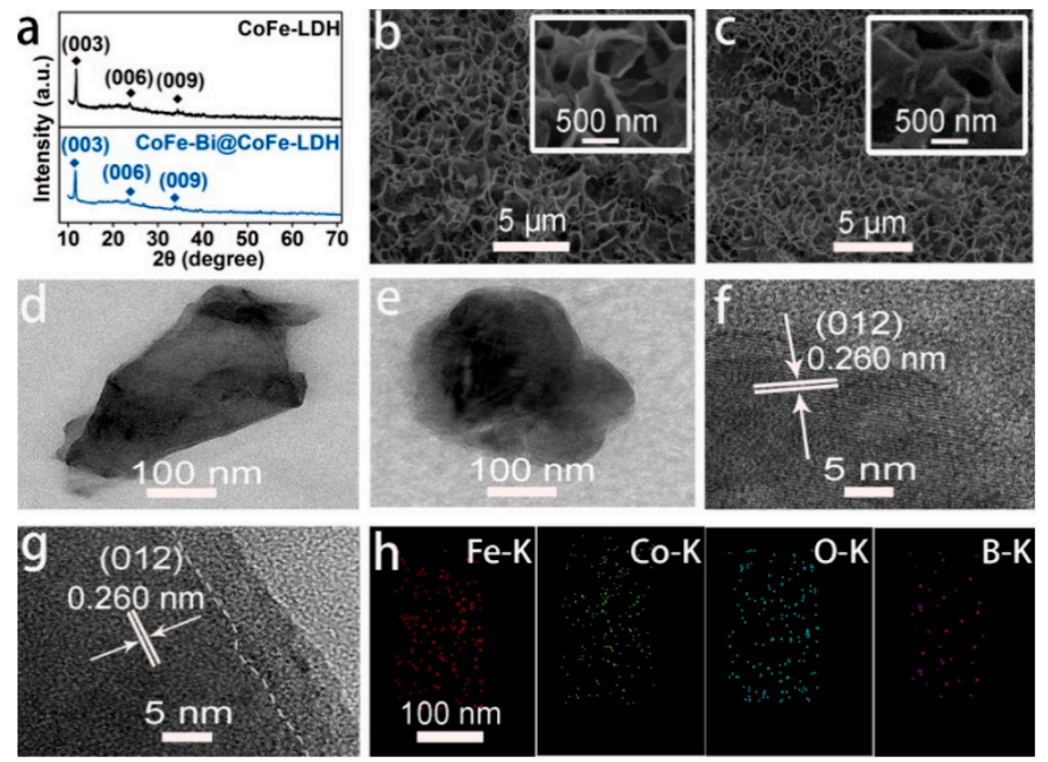

Figure 9. Structural and morphological characterization of CoFe-LDH and CoFe- $\mathrm{B}_{\mathrm{i}} @ \mathrm{CoFe}-\mathrm{LDH}$ : (a) XRD patterns, SEM images of (b) CoFe-LDH NA/TM and (c) CoFe- $\mathrm{B}_{\mathrm{i}} @ \mathrm{CoFe}-\mathrm{LDH}$ NA/TM. TEM images of (d) CoFe-LDH, and (e) CoFe- $\mathrm{B}_{\mathrm{i}} @ \mathrm{CoFe}-\mathrm{LDH}$. HRTEM images of (f) CoFe-LDH and (g) CoFe- $\mathrm{B}_{\mathrm{i}} @ \mathrm{CoFe}-\mathrm{LDH}$. (h) Elemental mapping images of CoFe- $\mathrm{B}_{\mathrm{i}} @ \mathrm{CoFe}-\mathrm{LDH}$. Reproduced from [31], with permission from the American Chemical Society, copyright 2018.

Xie et al. reduced $\mathrm{MoO}_{4}{ }^{2-}$ intercalated nickel-iron LDHs and obtained a NiFe-MoO nanosheets catalyst [38]. In terms of water oxidation, the authors obtained comparable results to $\mathrm{RuO}_{2}$. These results were ascribed to the high surface area, porosity, and surface electronic structure of the new LDH material. Their strategy led to an increase of active sites and an electronic modification of the NiFe alloy surface. The TOF for this catalyst was estimated at $0.19 \mathrm{~s}^{-1}$ at the overpotential of $0.3 \mathrm{~V}_{\mathrm{RHE}}$ and a faradaic efficiency around $95 \%$ for OER was determined.

Furthermore, a Ni-V monolayer double hydroxide was introduced by Fan and co-workers [32], applying a hydrothermal method to synthesize the bulk LDHs. The performance of this material is comparable to the best-performing NiFe-LDHs to date in the literature. In particular, the $\mathrm{Ni}_{0.75}-\mathrm{V}_{0.25}$ $\mathrm{LDH}$ gave a current density of $57 \mathrm{~mA} \mathrm{~cm}^{-2}$, at an overpotential of $0.35 \mathrm{~V}_{\mathrm{RHE}}$, for the OER. Experimental $\mathrm{O}_{2}$ evolution was evaluated by gas chromatography, where the $\mathrm{Ni}_{0.75}-\mathrm{V}_{0.25} \mathrm{LDH}$ exhibited a TOF of $0.05 \mathrm{~s}^{-1}$ at $0.35 \mathrm{~V}_{\mathrm{RHE}}$ overpotential. The abundance of the active sites in the LDH structure was identified as the main reason for the high performance of $\mathrm{Ni}_{0.75}-\mathrm{V}_{0.25}-\mathrm{LDH}$. Typical TEM images of $\alpha-\mathrm{Ni}(\mathrm{OH})_{2}$ and $\mathrm{Ni}_{0.75}-\mathrm{V}_{0.25} \mathrm{LDH}$ show the 2D nanosheet nature of the former (Figure 10a,b), whereas a three-dimensional morphology assembly of ultrathin nanosheets was observed upon incorporation of vanadium (Figure 10c,d).

$\mathrm{Li}$ et al. reported a new view of the significance of iron doping in a Ni hydroxide catalyst, which promoted the formation of $\mathrm{Ni}^{4+}$ and, therefore, played an important role in the water oxidation [36]. The strong Lewis acidity of $\mathrm{Fe}^{3+}$ was identified as a crucial factor to increase the $\mathrm{Ni}$ valence and, thereby, to promote the oxyl character of the intermediates during the $\mathrm{O}-\mathrm{O}$ bond formation. 

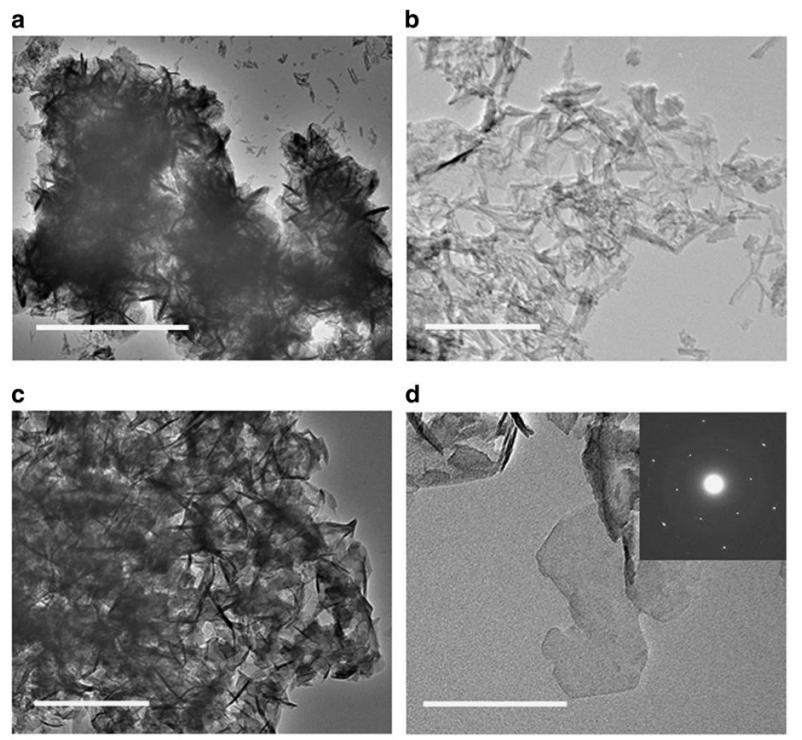

Figure 10. Morphological characterization of TEM images of $\alpha-\mathrm{Ni}(\mathrm{OH})_{2}$, compared to $\mathrm{Ni}_{0.75}-\mathrm{V}_{0.25}$ LDH: $(\mathbf{a}, \mathbf{b}) \alpha-\mathrm{Ni}(\mathrm{OH})_{2}$ (scale bar $=1 \mu \mathrm{m}$ for $(\mathbf{a})$ and $200 \mathrm{~nm}$ for $(\mathbf{b})$ ), (c,d) $\mathrm{Ni}_{0.75}-\mathrm{V}_{0.25} \mathrm{LDH}$ (inset of (d): SAED pattern (scale bar $=200 \mathrm{~nm}$ for $(\mathbf{c})$ and $100 \mathrm{~nm}$ for $(\mathbf{d})$ ). Reproduced from [32], with permission from Nature Communications, copyright 2016.

Görlin et al. discussed the importance of high-surface area conductive supports and of the electrolyte $\mathrm{pH}$ [39]. A microwave-assisted autoclave synthesis under solvothermal conditions was applied for the synthesis of a $\mathrm{NiFeO}(\mathrm{OH})$ catalyst. Catalyst support and $\mathrm{pH}>13$ resulted in enhanced catalytic activity, and higher particle dispersion allowed more metal centers to be accessible and to be electrochemically active. The highest TOFs were determined at 0.1 and $0.2 \mathrm{~s}^{-1}$, respectively, in $0.1 \mathrm{M} \mathrm{KOH}$. The $\mathrm{O}_{2}$ levels were found to be close to $100 \%$ of the faradaic efficiency after online gas chromatography-mass spectrometry (GC-MS) measurements. The role of Fe centers in the metal redox activity was, furthermore, discussed in new detail, based on the UV-vis monitoring data.

A $\mathrm{NiFe}_{2} \mathrm{O}_{4}-\mathrm{NiOOH}$ catalyst was prepared through a simple anodization method by Zhang et al. [40]. The catalyst afforded currents up to $30 \mathrm{~mA} \mathrm{~cm}^{-2}$ at an overpotential of $0.24 \mathrm{~V}_{\mathrm{RHE}}$ and only required $0.41 \mathrm{~V}_{\mathrm{RHE}}$ to achieve a very high current density of $3000 \mathrm{~mA} \mathrm{~cm}^{-2}$. The faradaic efficiency of $\mathrm{O}_{2}$ evolution was close to $100 \%$. In this study, it was stated that the excellent OER performance arose from the integration of amorphous $\mathrm{NiFe}_{2} \mathrm{O}_{4}$ and $\mathrm{NiOOH}$. Finally, an ultrafast synthetic approach of only $5 \mathrm{~s}$ was reported by Zou and co-workers for the fabrication of a Ni-Fe-OH@Ni $\mathrm{Ni}_{2} / \mathrm{NF}$ electrode material [41]. A schematic illustration of this ultrafast method is displayed in Figure 11. The catalyst gave currents up to $1000 \mathrm{~mA} \mathrm{~cm}^{-2}$ at $0.469 \mathrm{~V}_{\mathrm{RHE}}$ and displayed excellent catalytic stability for $50 \mathrm{~h}$ at the applied potential of $1.6 \mathrm{~V}_{\mathrm{RHE}}$, at the current density of $1000 \mathrm{~mA} \mathrm{~cm}{ }^{-2}$ in alkaline media. Furthermore, the faradaic yield of $\mathrm{O}_{2}$ was found to be up to $95 \%$.

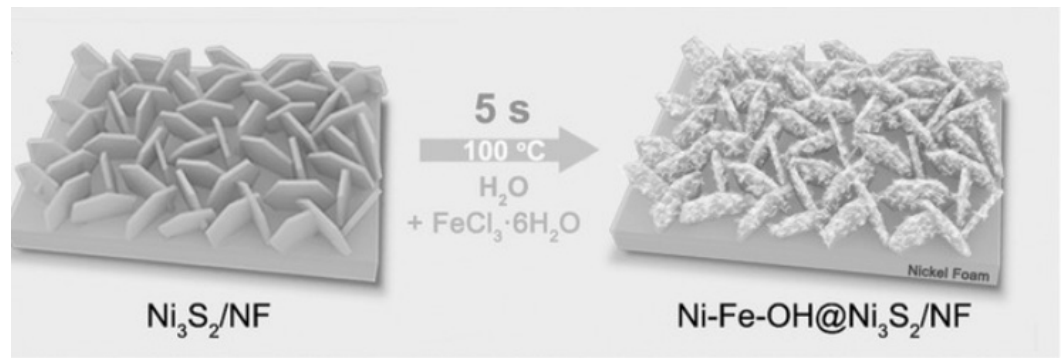

Figure 11. Ultrafast $\mathrm{Ni}-\mathrm{Fe}-\mathrm{OH} @ \mathrm{Ni}_{3} \mathrm{~S}_{2} / \mathrm{NF}$ preparation at $100{ }^{\circ} \mathrm{C}$ by a $5 \mathrm{sec}$ immersion of $\mathrm{Ni}_{3} \mathrm{~S}_{2} / \mathrm{NF}$ in a preheated aqueous solution with $\mathrm{Fe}^{3+}$. Reproduced from [41], with permission from John Wiley and Sons, copyright 2017. 
$\mathrm{Wu}$ et al. highlighted the importance of designing well-controlled and aligned structures to enhance the catalytic capabilities of electrocatalysts for high-performance electrodes. Starting from this main incentive, for the first time, they fabricated unique hierarchical hollow Ni/NiFe (oxy)hydroxide heterostructured nanotubes radially aligned on a Ni foam, as seen in Figure 12 [42].
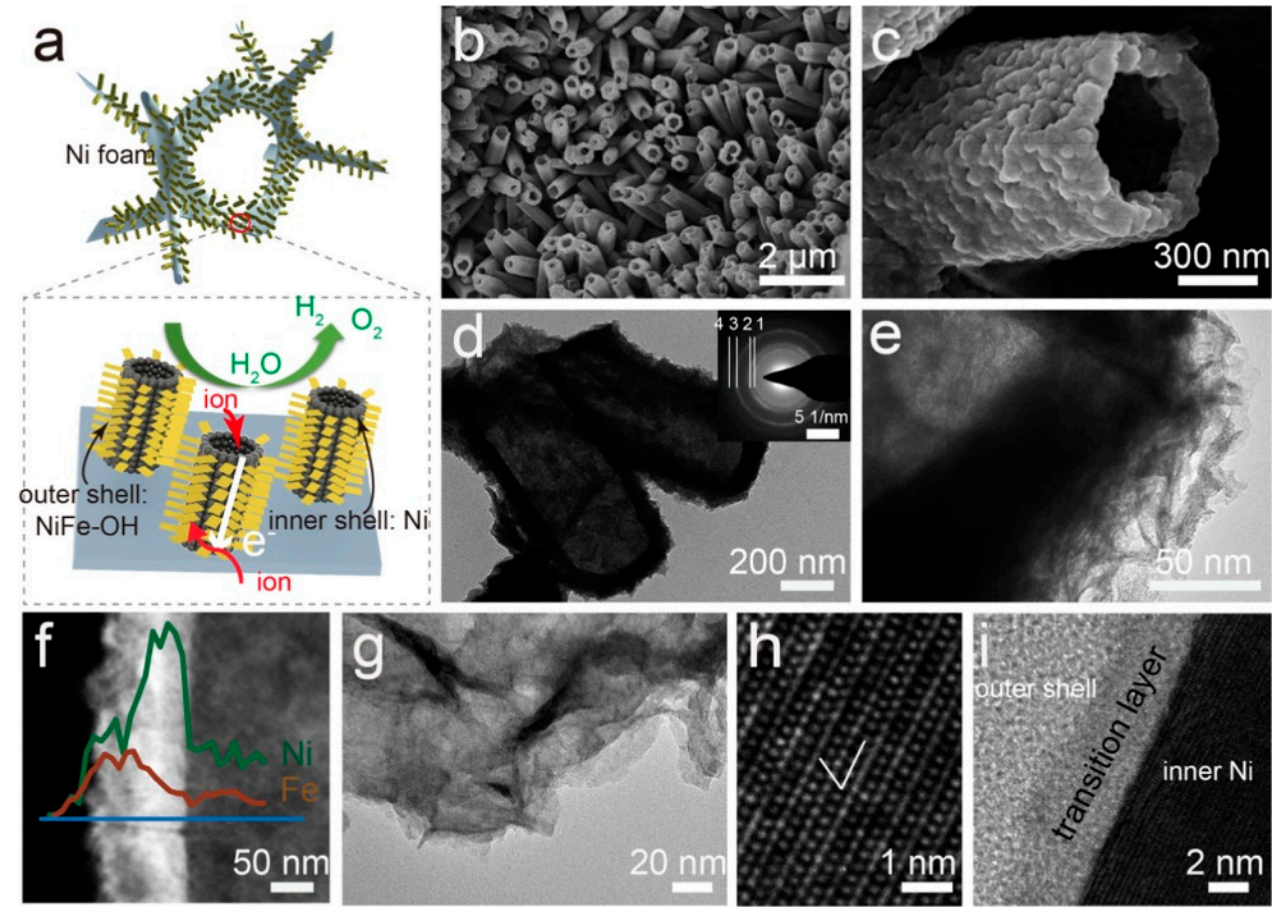

Figure 12. EM images of hierarchical hollow Ni/NiFe (oxy)hydroxide. (a) Scheme of radially aligned heterostructured nanotubes on the Ni foam. $(\mathbf{b}, \mathbf{c})$ SEM and $(\mathbf{d}, \mathbf{e})$ TEM images of the nanotubes. Inset in (d): corresponding SAED pattern. (f) HAADF scanning TEM image and elemental line scanning at the wall-edge region, and (g-i) close-up TEM of NiFe (oxy)hydroxide, crystalline Ni, and the interface area. Reproduced from [42], with permission from the American Chemical Society, copyright 2018.

The material was used in a home-made electrochemical cell driven by a single battery of $1.5 \mathrm{~V}$ and showed excellent stability and overpotential at around $0.2 \mathrm{~V}_{\mathrm{RHE}}$, outperforming the state-of-the-art noble metals $\mathrm{Ru}$ and $\mathrm{Pt}$. Hunter et al. employed a pulsed laser ablation technique in liquid media and prepared $\mathrm{NiFe}-\mathrm{LDH}$ nanosheets with different interlayer anions (i.e., $\mathrm{CO}_{3}{ }^{2-}, \mathrm{SO}_{4}{ }^{2-}, \mathrm{OH}^{-}, \mathrm{F}^{-}, \mathrm{Cl}^{-}$ and $\mathrm{I}^{-}$) to probe their role in water oxidation catalysis [43]. The anion binding was evaluated by XPS and DFT calculations. Outcomes of their study revealed a relationship of water oxidation activity with the $\mathrm{pK}_{\mathrm{a}}$ value of the interlayer anions and suggested that Bronsted or Lewis basicity of the anions was a key parameter for the water oxidation mechanism.

Furthermore, the authors found that nitrite species bound to edge-site Fe centers were correlated with high water oxidation activity, thus, pointing out the active role of the latter in the water oxidation process. The NiFe-LDH nanosheets showed remarkable stability for $3.5 \mathrm{~h}$ in $1 \mathrm{M} \mathrm{KOH}$. The overpotential values varied between $0.27 \mathrm{~V}_{\mathrm{RHE}}$ and $0.45 \mathrm{~V}_{\mathrm{RHE}}$, depending on the various interlayer anions. Jia et al. synthesized a highly active heterostructured NiFe-LDH nanosheet on defective graphene, via a co-precipitation method [44]. DFT calculations suggested that the high electrocatalytic activity of the NiFe LDH-NS@DG catalyst towards water oxidation arose from the interaction of exposed 3d-transition metal atoms with carbon defects. This synergism was also found to cause the robust stability of the catalyst for $10 \mathrm{~h}$, in $1 \mathrm{M} \mathrm{KOH}$. The catalyst showed current densities above $50 \mathrm{~mA} \mathrm{~cm}^{-2}$ at the applied potential of $1.5 \mathrm{~V}_{\mathrm{RHE}}$. The overpotential at the current density of $10 \mathrm{~mA}$ $\mathrm{cm}^{-2}$ was found to be $0.21 \mathrm{~V}_{\text {RHE}}$. A small Tafel slope value of $52 \mathrm{mV} \mathrm{dec}^{-1}$ was also found between the range of 0.1 and $0.15 \mathrm{~V}_{\mathrm{RHE}}$ of applied potential. The onset potential of the NiFe LDH-NS@DG 
catalyst was observed at $1.41 \mathrm{~V}_{\mathrm{RHE}}$ and the faradaic efficiency of $\mathrm{O}_{2}$ levels was $97.5 \%$, after $5 \mathrm{~h}$ of chronoamperometric tests, at the current density of $100 \mathrm{~mA} \mathrm{~cm}^{-2}$.

\subsubsection{Spinels}

Complex spinel-type oxides have attracted a lot of research interest as water oxidation catalysts, over the last years, due to their favorable structural properties, giving rise to tunability, high conductivity, and robust operational stability. Spinel oxides adopt the general formula $\mathrm{AB}_{2} \mathrm{X}_{4}$, where $A$ and $B$ are cations occupying the octahedral and tetrahedral sites in the anionic sublattice (with $X$ representing anions, typically oxygen or less often chalcogens/halogenides). $\mathrm{Co}_{3} \mathrm{O}_{4}$ is a well-known example of a binary, spinel-type WOC. Ternary spinel-type cobaltites exhibit similar structural and electronic properties to $\mathrm{Co}_{3} \mathrm{O}_{4}$ with the general composition $\mathrm{MCo}_{2} \mathrm{O}_{4}(\mathrm{M}=\mathrm{Zn}, \mathrm{Ni}, \mathrm{Cu}, \mathrm{Mn}$, etc.).

The gold standard of Co-oxide WOCs, over the past years, has been the amorphous $\mathrm{CoP}_{\mathrm{i}}$ catalyst introduced by Nocera et al. [5,45]. The selection of articles below was taken from the most cited and hot papers in the field, reflecting the progress in WOC understanding and performance, over the last three years. A comparison of the electrocatalytic performance of the selected WOC materials is given in Table 3.

Recently, various synthetic strategies were employed to access $\mathrm{Co}_{3} \mathrm{O}_{4}$ spinels [46-49]. Wang and co-workers used a sol-gel method to synthesize regular cobalt spinels, comprised of $\mathrm{Co}^{2+}$ on the tetrahedral site and two $\mathrm{Co}^{3+}$ ions on the octahedral site [47]. Their work was focused on the investigation of site-dependent OER activity, by substituting $\mathrm{Co}^{2+}$ and $\mathrm{Co}^{3+}$ with inactive $\mathrm{Zn}^{2+}$ $\left(\mathrm{ZnCo}_{2} \mathrm{O}_{4}, \mathrm{Co}^{3+}\right.$ octahedral $)$ and $\mathrm{Al}^{3+}\left(\mathrm{CoAl}_{2} \mathrm{O}_{4}, \mathrm{Co}^{2+}\right.$ tetrahedral), respectively. The electrochemical performance was tested by cyclic voltammetry, and interestingly the redox reaction was found to occur only at the $\mathrm{Co}^{2+}$ tetrahedral sites, as shown in the voltammogram in Figure 13. The Tafel slope value was found to be smaller in the case of $\mathrm{Co}_{3} \mathrm{O}_{4}$, which suggested a different rate-determining step. This study also pointed out the importance of operando investigations in such systems. From operando extended X-ray absorption fine structure (EXAFS) and electrochemical impedance spectroscopy (EIS) studies, the conclusion was drawn that cobalt oxyhydroxide $(\mathrm{CoOOH})$ was formed and acted as a reactive center for the oxygen evolution reaction. In contrast, the $\mathrm{ZnCo}_{2} \mathrm{O}_{4}$ catalyst was negatively affected by the strongly bonded -OH groups on the surface, and so, its electrocatalytic activity was limited compared to its counterparts. The larger Tafel slope supported the latter observation, where the OER process is rate limited due to these strong - $\mathrm{OH}$ bonds.
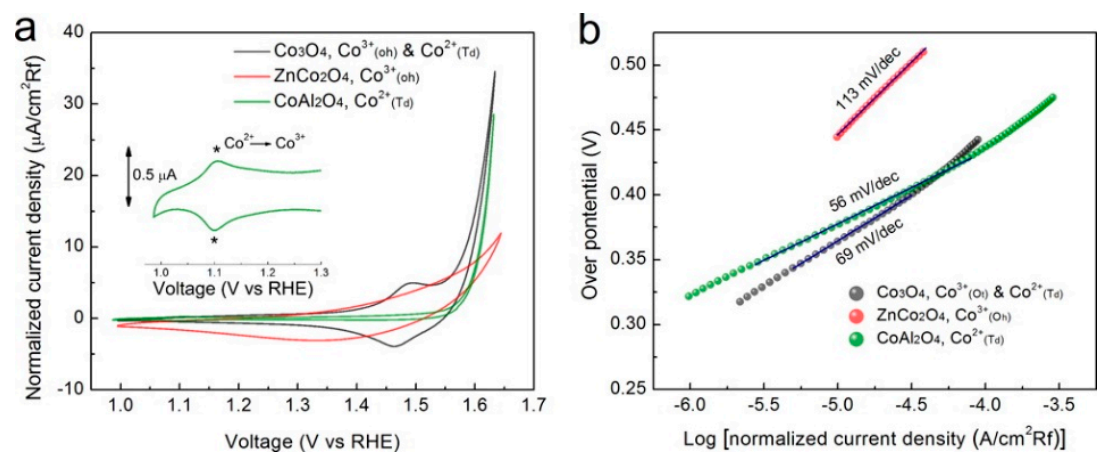

Figure 13. Electrochemical characterization of $\mathrm{Co}_{3} \mathrm{O}_{4}, \mathrm{ZnCo}_{2} \mathrm{O}_{4}$, and $\mathrm{ZnAl}_{2} \mathrm{O}_{4}$ : (a) Normalized cyclic voltammograms and (b) corresponding Tafel slopes. Reproduced from [47], with permission from the American Chemical Society, copyright 2016. 
Table 3. Comparison of the electrocatalytic activity of spinel catalysts (cf. Table 1 for definitions of "durability" and "stability")

\begin{tabular}{|c|c|c|c|c|c|c|c|c|}
\hline Catalyst & Preparation Method & $\begin{array}{c}\text { Onset } \\
\text { Potential (V) }\end{array}$ & $\begin{array}{c}\eta(\text { at } 10 \\
\left.\mathrm{mV} / \mathrm{cm}^{2}\right)(\mathrm{V})\end{array}$ & $\begin{array}{l}\text { Tafel Slope } \\
\left(\mathrm{mV} \mathrm{dec}^{-1}\right)\end{array}$ & $\begin{array}{l}\text { Durability } \\
\text { (h) }\end{array}$ & Stability & Electrolyte & Ref. \\
\hline $\mathrm{Co}_{3} \mathrm{O}_{4} / \mathrm{N}$-graphene & Hydrothermal & 1.49 & 0.96 & 121.8 & 4 & Good * & $0.1 \mathrm{M} \mathrm{KOH}$ & [50] \\
\hline $\begin{array}{c}\mathrm{Co}_{3} \mathrm{O}_{4} \text { assembled } \\
\text { hollow spheres }\end{array}$ & Solvothermal \& calcination & 1.43 & 0.29 & 86 & 10 & Prominent & $1 \mathrm{M} \mathrm{KOH}$ & [46] \\
\hline $\begin{array}{c}\mathrm{Co}_{3} \mathrm{O}_{4}, \mathrm{ZnCo}_{2} \mathrm{O}_{4} \& \\
\mathrm{CoAl}_{2} \mathrm{O}_{4}\end{array}$ & Sol-gel & - & - & $69,113 \& 56$ & - & - & $0.1 \mathrm{M} \mathrm{KOH}$ & [47] \\
\hline $\mathrm{Co} @ \mathrm{Co}_{3} \mathrm{O}_{4} / \mathrm{N}-\mathrm{CNT}$ & $\begin{array}{l}\text { Pyrolysis in } \mathrm{H}_{2} \text { atm. \& } \\
\text { oxidative calcination }\end{array}$ & 1.62 & 0.39 & 54.3 & 45 & Good * & $0.1 \mathrm{M} \mathrm{KOH}$ & [51] \\
\hline $\begin{array}{l}\text { Hollow } \mathrm{Co}_{3} \mathrm{O}_{4} \\
\text { microtube arrays }\end{array}$ & $\begin{array}{l}\text { Hydrothermal \& } \\
\text { electrochemical treatment }\end{array}$ & 1.52 & 0.151 & 84 & 12 & High & $1 \mathrm{M} \mathrm{KOH}$ & [33] \\
\hline $\mathrm{ZnCo}_{2} \mathrm{O}_{4}$ QDs/N-CNT & Hydrothermal & 1.56 & 0.43 & 70.6 & 10 & High & $0.1 \mathrm{M} \mathrm{KOH}$ & [52] \\
\hline $\mathrm{NiFe} / \mathrm{Ni} \mathrm{Co}_{2} \mathrm{O}_{4}$ & $\begin{array}{l}\text { Hydrothermal \& } \\
\text { electrodeposition }\end{array}$ & 1.47 & 0.34 & 38.8 & 10 & Excellent & $1 \mathrm{M} \mathrm{KOH}$ & [53] \\
\hline $\mathrm{NiCO}_{2} \mathrm{O}_{4} \mathrm{NPs}$ & Two-step solution method & 1.49 & 0.157 & 75 & 20 & Excellent & $1 \mathrm{M} \mathrm{KOH}$ & [54] \\
\hline $\begin{array}{c}\mathrm{CoFeO}_{x}, \mathrm{CoFeNiO}_{x} \& \\
\mathrm{FeNiO}_{x}\end{array}$ & Electrodeposition & 1.43 & 0.24 & 37 & - & - & $1 \mathrm{M} \mathrm{KOH}$ & [55] \\
\hline $\mathrm{CoFe}_{2} \mathrm{O}_{4} @ \mathrm{Co}-\mathrm{Fe}-\mathrm{B}_{\mathrm{i}}$ & Hydrothermal & - & 0.46 & 127 & 20 & Good & $0.1 \mathrm{M} \mathrm{K}_{2} \mathrm{~B}_{4} \mathrm{O}_{8}$ & [56] \\
\hline $\mathrm{Co}_{3} \mathrm{O}_{4}$ & Hydrothermal & 143 & 0.35 & 69 & - & - & $1 \mathrm{M} \mathrm{KOH}$ & [57] \\
\hline
\end{tabular}


An electrochemical sacrificial strategy was applied by Zhu et al. for the fabrication of hollow $\mathrm{Co}_{3} \mathrm{O}_{4}$ microtube arrays [48], which is schematically represented in Figure 14. More precisely, the $\mathrm{CoHPO}_{4}$ microrods were immersed in $1 \mathrm{M} \mathrm{NaOH}$ and a constant potential was applied. Upon the anodic bias application, the microrods' surface became rough and nanoplates were formed. The protonated $\mathrm{CoHPO}_{4}$ was dissolved in the $\mathrm{NaOH}$ solution and $\mathrm{Co}^{2+}$ species acted as source of cobalt oxides to be generated. The nanoporous nature of the cobalt oxide shells provided transport pathways for the $\mathrm{OH}^{-}$and $\mathrm{Co}^{2+}$ diffusion. The fully converted $\mathrm{CoHPO}_{4}$ resulted in $\mathrm{Co}_{3} \mathrm{O}_{4}$ spinel. These micro/nanostructures were found to be competitive with $\mathrm{IrO}_{2}$ and Pt references as OER catalysts. The authors proposed that such design and engineering of micro/nanostructures (Figure 15) can be an efficient pathway for the enhancement of catalytic activity through the facilitation of mass transport by exposing more electroactive sites. During the water oxidation reaction, the catalyst showed impressive performance with current densities at around $300 \mathrm{~mA} \mathrm{~cm}^{-2}$, almost two times greater, compared to $\mathrm{IrO}_{2}$. The Tafel slope value was found to be $84 \mathrm{mV} \mathrm{dec}^{-1}$, and the catalyst showed high stability during an operational time of $12 \mathrm{~h}$. The corresponding voltammograms and Tafel slopes are displayed in Figure 16. The catalyst, furthermore, exhibited a high faradaic efficiency of $96.3 \%$ for OER.

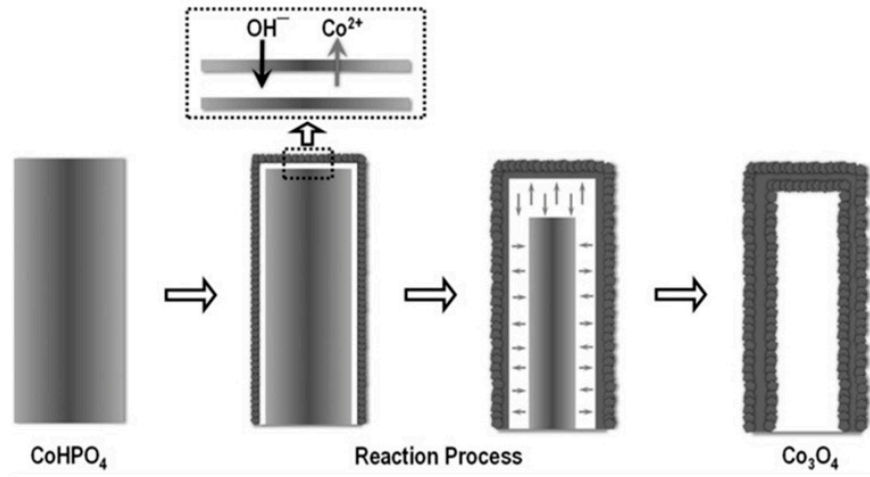

Figure 14. $\mathrm{Co}_{3} \mathrm{O}_{4}-\mathrm{MTA}$ formation scheme from the $\mathrm{CoHPO}_{4}$ precursor. Reproduced from [48], with permission from John Wiley and Sons, copyright 2017.
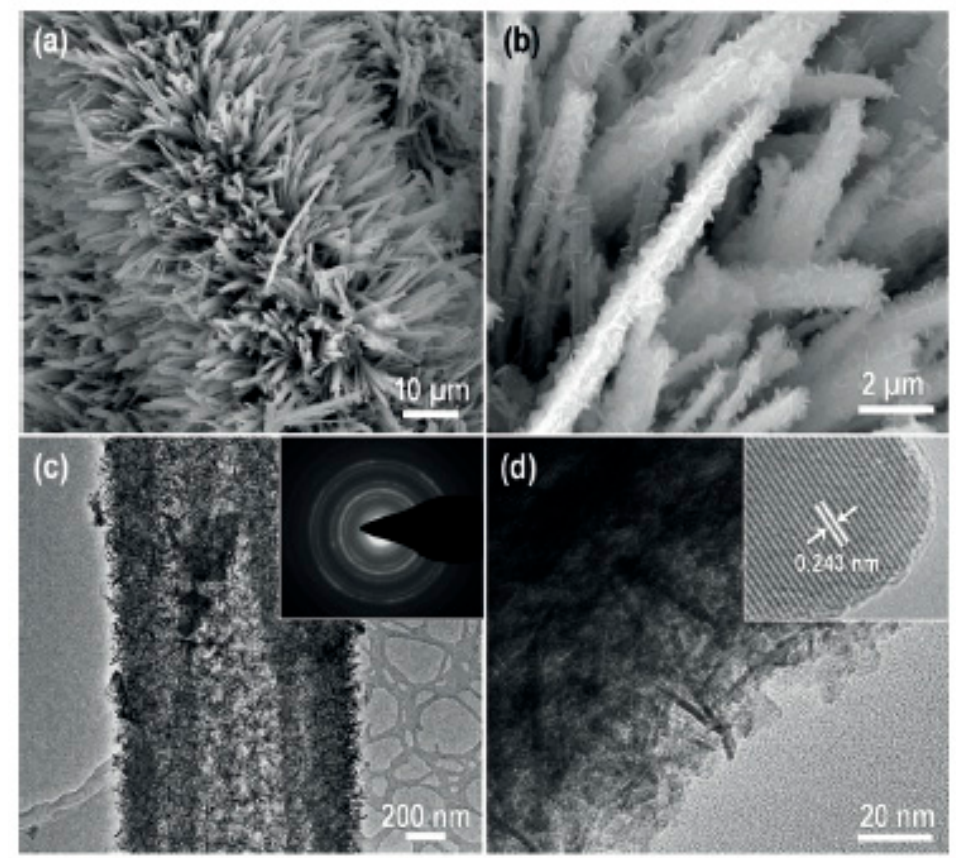

Figure 15. Morphological features of $\mathrm{Co}_{3} \mathrm{O}_{4}$-MTA: (a,b) SEM and (c,d) TEM images. Reproduced from [48], with permission from John Wiley and Sons, copyright 2017. 

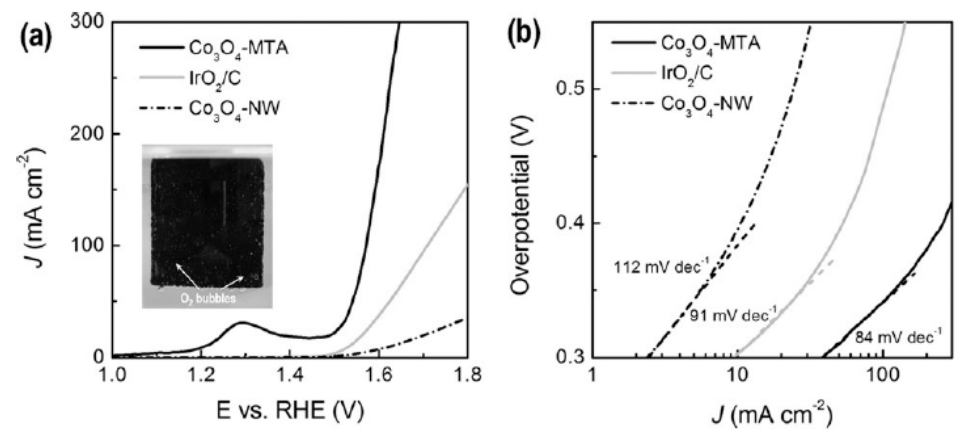

Figure 16. Electrochemical characterization of $\mathrm{Co}_{3} \mathrm{O}_{4}$-MTA: (a) Linear sweep voltammograms and (b) Tafel slopes, compared to $\mathrm{IrO}_{2} / \mathrm{C}$ and $\mathrm{Co}_{3} \mathrm{O}_{4}-\mathrm{NW}$, respectively. Reproduced from [48], with permission from John Wiley and Sons, copyright 2017.

Hollow spheres assembled by $\alpha-\mathrm{Co}(\mathrm{OH})_{2}$ nanosheets were developed by Xie and co-workers via a solvothermal method followed by further calcinations, which led to mesoporous $\mathrm{Co}_{3} \mathrm{O}_{4}$ nanostructures [46]. By tuning the amount of polyvinylpyrrolidone (PVP) different samples were synthesized as shown in Figure 17. The obtained monodisperse hierarchical structure exhibited a low onset potential at around $1.44 \mathrm{~V}_{\mathrm{RHE}}$, with low overpotential $\left(0.29 \mathrm{~V}_{\mathrm{RHE}}\right)$ and relatively small Tafel slopes, in the range of 86 and $97 \mathrm{mV} \mathrm{dec}^{-1}$. The samples indicated an excellent stability in alkaline media which renders them promising for further energy conversion as well as storage applications.
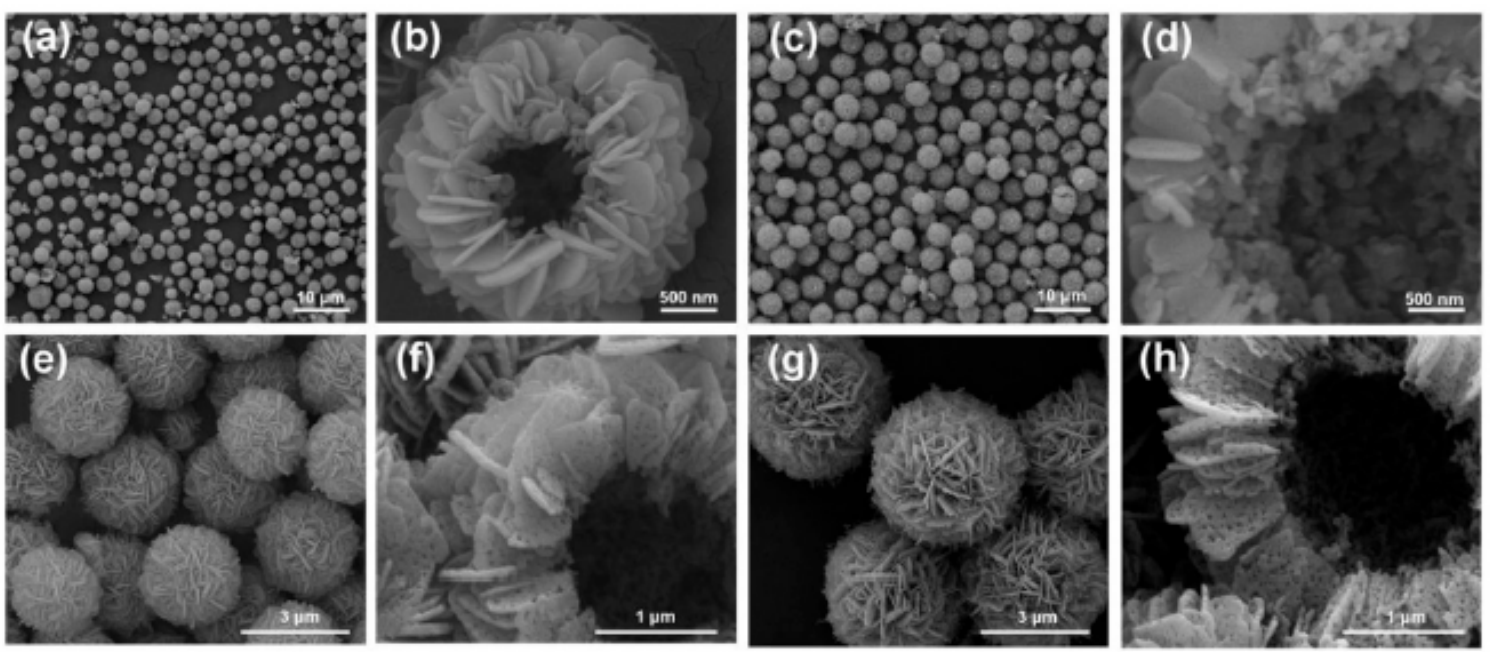

Figure 17. SEM images illustrating the strategy to hollow sphere assemblies of $\alpha-\mathrm{Co}(\mathrm{OH})_{2}$ nanosheets: $(\mathbf{a}, \mathbf{b})$ Precursor $\alpha-\mathrm{Co}(\mathrm{OH})_{2}-\mathrm{PVP}-L o w,(\mathbf{c}, \mathbf{d})$ precursor $\alpha-\mathrm{Co}(\mathrm{OH})_{2}-\mathrm{PVP}-H i g h,(\mathbf{e}, \mathbf{f}) \mathrm{Co}_{3} \mathrm{O}_{4}$-PVP-Low, and $(\mathbf{g}, \mathbf{h}) \mathrm{Co}_{3} \mathrm{O}_{4}$-PVP-High. Reproduced from [46], with permission from Elsevier, copyright 2018.

A subcategory of spinels are the above-mentioned cobaltites, which have been used as OER catalysts due to their increased conductivity and versatile electrochemically active sites compared to monometallic oxide catalysts. A two-step solution method was reported by Guan et al. as a way of utilizing metal-organic frameworks (MOFs), for the development of hollow $\mathrm{NiCo}_{2} \mathrm{O}_{4}$ nanowall arrays on carbon cloth, as shown in Figure 18 [54]. A uniform coverage of the Co-MOF on carbon cloth and the Co-based nanowalls was first obtained, and after annealing in air in the final step, the nanoarray structure of $\mathrm{NiCo}_{2} \mathrm{O}_{4}$ was maintained. The catalyst displayed high stability for $20 \mathrm{~h}$ and low overpotential of around $0.16 \mathrm{~V}_{\mathrm{RHE}}$ in alkaline media, which was ascribed to its hollow nature. The material was proposed for other applications besides water oxidation, such as in supercapacitors. 


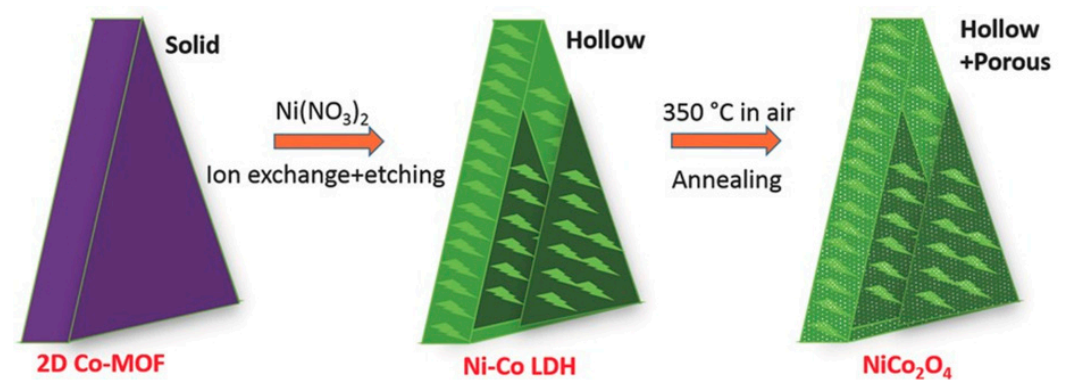

Figure 18. Route to uniform hollow $\mathrm{NiCo}_{2} \mathrm{O}_{4}$ nanostructure from 2D Co-MOF solid nanowall precursors. Reproduced from [54], with permission from John Wiley and Sons, copyright 2017.

Xiao et al. proposed a 3D hierarchical porous catalyst architecture consisting of $\mathrm{NiFe} / \mathrm{NiCo}_{2} \mathrm{O}_{4} / \mathrm{Ni}$ foam [53]. The synthesis procedure of this material is displayed in Figure 19. The catalyst reached very high current densities in the range of $1200 \mathrm{~mA} \mathrm{~cm}^{-2}$ at an overpotential of $0.34 \mathrm{~V}_{\mathrm{RHE}}$ and onset potential at $1.47 \mathrm{~V}_{\mathrm{RHE}}$ in $1 \mathrm{M} \mathrm{KOH}$ at $\mathrm{pH} 14$. The stability and durability of this material was evaluated through cyclic voltammetry and the current density remained stable, over an operational time of $10 \mathrm{~h}$.

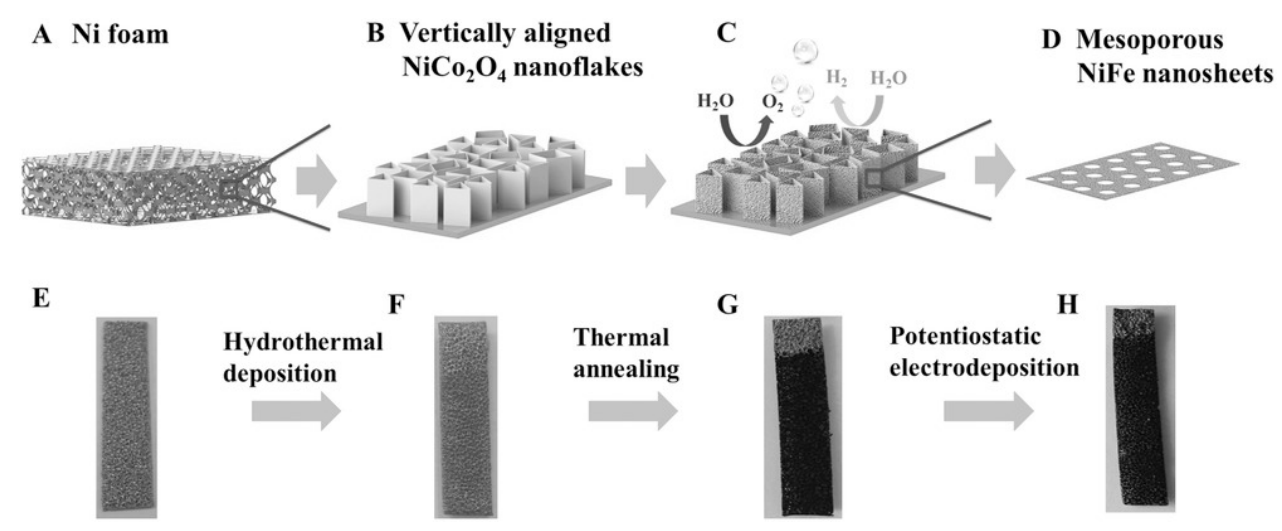

Figure 19. Formation process of porous $\mathrm{NiFe} / \mathrm{NiCo}_{2} \mathrm{O}_{4} / \mathrm{NF}$ composite electrodes: Scheme (A-D) and corresponding photos (E-H). Reproduced from [53], with permission from John Wiley and Sons, copyright 2016.

Morales-Guio et al. classified a variety of oxidatively electrodeposited thin films, according to their electrocatalytic activity into the following three categories [55]. Single-metal oxides falling into the first category, such as $\mathrm{NiO}_{\mathrm{x}}, \mathrm{MnO}_{\mathrm{x}}$, and $\mathrm{FeO}_{\mathrm{x}}$, showed the lowest performance. The second category included $\mathrm{CoO}_{x}$ and $\mathrm{CoNiO}_{x}$, which showed a medium activity. Finally, the third category consisted of the most active catalysts, namely $\mathrm{FeNiO}_{x}, \mathrm{CoFeO}_{x}$, and $\mathrm{CoFeNiO}_{x}$, which revealed high electrocatalytic performance, due to their synergistic effects. Their efficiency towards water oxidation reached currents up to $100 \mathrm{~mA} \mathrm{~cm}^{-2}$, at overpotentials of around $0.24 \mathrm{~V}_{\mathrm{RHE}}$ in $1 \mathrm{M} \mathrm{KOH}$, at $\mathrm{pH} 14$. The TOF values as a function of catalyst loading were also evaluated at the overpotential of $0.35 \mathrm{~V}_{\mathrm{RHE}}$. In particular, at the relatively low loading of $5 \mu \mathrm{g} \mathrm{cm}{ }^{-2}$, the TOF values of the more active $\mathrm{FeNiO}_{\mathrm{x}}$, $\mathrm{CoFeO}_{x}$, and $\mathrm{CoFeNiO}_{x}$ catalysts were found to be around $0.5,5$, and $4 \mathrm{~s}^{-1}$, respectively. The calculated faradaic efficiency of $\mathrm{O}_{2}$ was also close to $100 \%$.

Ji et al., on the other hand, used a complex core-shell $\mathrm{CoFe}_{2} \mathrm{O}_{4} @ \mathrm{Co}-\mathrm{Fe}-\mathrm{B}_{\mathrm{i}}$ nanoarray architecture in a potassium borate ( $\mathrm{pH}$ 9.2) electrolyte and the catalyst showed a superior long-term stability, for at least $20 \mathrm{~h}$, along with a high faradaic efficiency of $96 \%$ of $\mathrm{O}_{2}$ evolution [56].

Regarding the operational behavior of cobalt oxides, Zhang et al. monitored the chemical transformation of multiwall carbon nanotubes supported with hydrothermally prepared $\mathrm{Co}_{3} \mathrm{O}_{4}$ nanoparticles $\left(\mathrm{Co}_{3} \mathrm{O}_{4}\right.$-MWCNTs) to $\mathrm{CoO}(\mathrm{OH})$, via ambient pressure $\mathrm{X}$-ray photoelectron spectroscopy (APXPS) [57]. The aforementioned transformation was only observed upon a potential application, 
during operando conditions. When the potential was removed, the catalyst was converted to its as-synthesized form, namely $\mathrm{Co}_{3} \mathrm{O}_{4}$. It was suggested that this rapid operando conversion was caused by proton concentration gradients in the presence of water vapor in the local environment, close to the solid/liquid interface. The electrocatalyst afforded current densities up to $100 \mathrm{~mA} \mathrm{~cm}^{-2}$, at an applied potential of $1.65 \mathrm{~V}_{\text {RHE. }}$. The overpotential at the current density of $10 \mathrm{~mA} \mathrm{~cm}^{-2}$ was observed at $0.35 \mathrm{~V}_{\mathrm{RHE}}$ in $1 \mathrm{M} \mathrm{KOH}$. The onset potential was observed at $1.43 \mathrm{~V}_{\mathrm{RHE}}$ and the Tafel slope value was calculated at $69 \mathrm{mV} \mathrm{dec}^{-1}$.

Recently, in one of our studies, we have synthesized cobalt oxide spinel $\left(\mathrm{Co}_{3} \mathrm{O}_{4}\right)$ nanocrystals via a hydrothermal method. Our work provided deeper insight into the control parameters of hydrothermal WOC formation processes, through a combination of mechanistic in situ and ex situ analytical methods. This comprehensive study provided guidelines about how the WOC performance of binary oxides can be improved through an empirical understanding of their growth mechanisms [58].

\subsubsection{Perovskite-Based WOCs}

Perovskite oxides display the general formula $\mathrm{ABO}_{3}$, where the A-site ion on the corners of the elemental cell is usually an alkaline earth or rare-earth element, with a coordination number of 12. On the other hand, the octahedrally coordinated B-site ions in the center of the elemental cell are mainly $3 \mathrm{~d}, 4 \mathrm{~d}$, and $5 \mathrm{~d}$ transition metals. Ever since pioneering works of the 1970s [59], numerous studies on the structure and properties of perovskites have been reported in the literature. More recently, perovskite oxides were proposed as efficient electrocatalysts for the oxygen evolution reaction [59-65]. The following studies contributed to the development of new perovskite representatives, which significantly improved their activity and stability as water oxidation catalysts. A comparison of the electrocatalytic performance of the materials of this category is summarized in Table 4 and covers research of the last three years.

An electrospinning method was employed by Zhao et al. for the development of $\operatorname{PrBa}_{0.5} \mathrm{Sr}_{0.5} \mathrm{Co}_{1.5} \mathrm{Fe}_{0.5} \mathrm{O}_{5+\delta}$ nanofibers [61]. The intrinsic activity and mass activity of this material were increased 4.7 and 20 times, respectively, compared to $\mathrm{IrO}_{2}$, while the diameter of the particles was reduced to $20 \mathrm{~nm}$. The aforementioned characteristics led to a high stability for $12 \mathrm{~h}$, at a lower overpotential of 0.37 $\mathrm{V}_{\mathrm{RHE}}$, compared to $\mathrm{IrO}_{2}$. The importance of the morphology and electronic properties of the structure resulted in an enhanced water oxidation, showing the optimization potential of these parameters. Furthermore, Zhu et al. used an electrospinning method to fabricate $\mathrm{SrNb}_{0.1} \mathrm{Co}_{0.7} \mathrm{Fe}_{0.2} \mathrm{O}_{3-\delta}$ perovskite nanorods, which displayed an excellent stability and activity in alkaline media [64]. A representative scheme of the synthesis protocol is shown in Figure 20. The results were compared with the-state-of the-art $\mathrm{IrO}_{2}$ and showed seven times higher current densities at $0.4 \mathrm{~V}_{\mathrm{RHE}}$, combined with a lower Tafel slope. The material displayed an excellent stability for $30 \mathrm{~h}$. The structural properties led to an increase of both charge transfer as well as of the electrochemically active surface, which boosted the water oxidation performance.

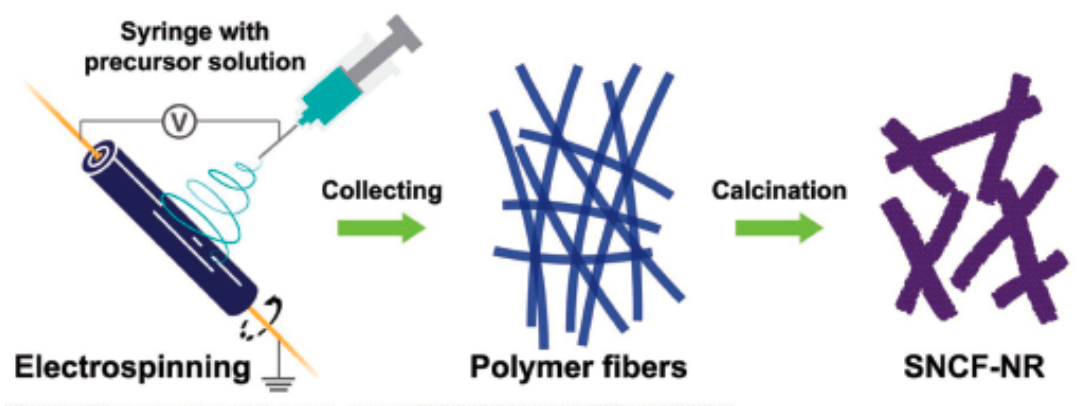

Figure 20. Preparative route to $\mathrm{SrNb}_{0.1} \mathrm{Co}_{0.7} \mathrm{Fe}_{0.2} \mathrm{O}_{3-\delta}$ perovskite nanorods by electrospinning. Reproduced from [64], with permission from John Wiley and Sons, copyright 2017. 
Table 4. Comparison of the electrocatalytic activity of perovskite oxide catalysts (cf. Table 1 for definitions of "durability" and "stability").

\begin{tabular}{|c|c|c|c|c|c|c|c|c|}
\hline Catalyst & Preparation Method & $\begin{array}{c}\text { Onset } \\
\text { Potential (V) }\end{array}$ & $\begin{array}{c}\eta(\text { at } 10 \\
\left.\mathrm{mV} / \mathrm{cm}^{2}\right)(\mathrm{V})\end{array}$ & 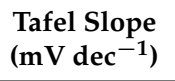 & $\begin{array}{l}\text { Durability } \\
\text { (h) }\end{array}$ & Stability & Electrolyte & Ref. \\
\hline $\mathrm{PrBa}_{0.5} \mathrm{Sr}_{0.5} \mathrm{Co}_{1.5} \mathrm{Fe}_{0.5} \mathrm{O}_{5+\delta}$ & Electrospinning & - & 0.37 & 52 & 12 & High & $0.1 \mathrm{M} \mathrm{KOH}$ & [61] \\
\hline $\mathrm{SrNb}_{0.1} \mathrm{Co}_{0.7} \mathrm{Fe}_{0.2} \mathrm{O}_{3-\delta}$ nanorods & Electrospinning & 1.52 & 0.37 & 61 & 30 & Remarkable & $1 \mathrm{M} \mathrm{KOH}$ & [60] \\
\hline $\begin{array}{c}\mathrm{BaCo}_{0.7} \mathrm{Sn}_{0.3} \mathrm{O}_{3-\delta} \& \\
\mathrm{BaCo}_{0.7} \mathrm{Fe}_{0.1} \mathrm{Sn}_{0.2} \mathrm{O}_{3-\delta}\end{array}$ & Ball milling-assisted solid-state reaction & 1.53 & 0.45 & 68 & 2 & Good & $0.1 \mathrm{M} \mathrm{KOH}$ & [63] \\
\hline $\mathrm{La}_{0.95} \mathrm{FeO}_{3-\delta}$ & Sol-gel & 1.55 & 0.41 & 82 & - & - & $0.1 \mathrm{M} \mathrm{KOH}$ & [64] \\
\hline $\mathrm{La}_{1-x} \mathrm{Sr}_{x} \mathrm{CoO}_{3-\delta}$ & Reverse-phase hydrolysis & - & 0.4 & 31 & 24 & High & $0.1 \mathrm{M} \mathrm{KOH}$ & [65] \\
\hline $\mathrm{BaNiO}_{3} \& \mathrm{BaNi}_{0.83} \mathrm{O}_{2.5}$ & Flux mediated crystal growth & - & - & - & 20 & Very good * & $0.1 \mathrm{M} \mathrm{KOH}$ & [66] \\
\hline
\end{tabular}


A ball-milling-assisted solid-state reaction was used by $\mathrm{Xu}$ and co-workers for the development of $\mathrm{BaCo}_{0.7} \mathrm{Sn}_{0.3} \mathrm{O}_{3-\delta}$ and $\mathrm{BaCo}_{0.7} \mathrm{Fe}_{0.1} \mathrm{Sn}_{0.2} \mathrm{O}_{3-\delta}$ perovskite oxides, respectively [63]. They demonstrated that the electrocatalytic activity of the catalysts can be easily tuned by modifying the dopant concentration. This example highlights the importance of doping strategies to enhance the conductivity in a wide range of materials, which in turn, increases their electrocatalytic activity towards OER. In parallel, the work of Zhu et al. focused on a sol-gel preparation method and by tuning the cation deficiency enhanced OER activity was accomplished [60]. In particular, a $\mathrm{La}_{0.95} \mathrm{FeO}_{3-\delta}$ perovskite was developed; Figure 21 shows how the significant change in OER activity is related to the formation of oxygen vacancies and $\mathrm{Fe}^{4+}$, in the A-site of the perovskite.

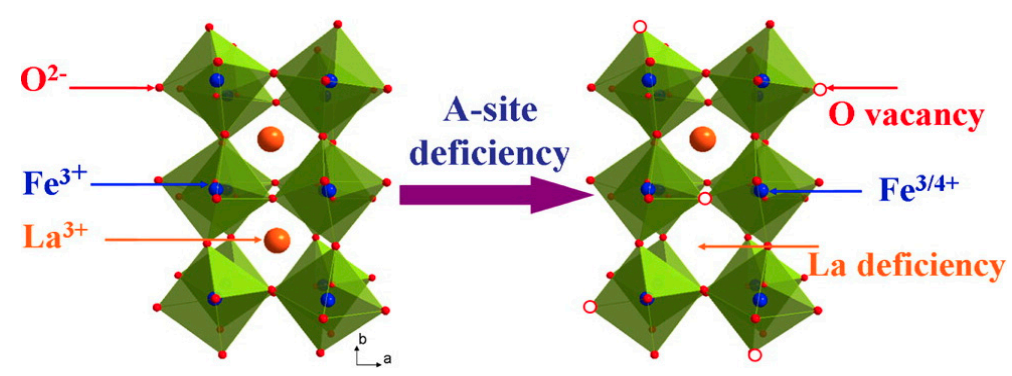

Figure 21. Formation of oxygen vacancies and $\mathrm{Fe}^{4+}$ in enhancing the $\mathrm{OER}$ activity in A-site-deficient $\mathrm{La}_{0.95} \mathrm{FeO}_{3-\delta}$ perovskites. Reproduced from [60], with permission from the American Chemical Society, copyright 2016.

Mefford et al. proposed a reverse-phase hydrolysis method for the synthesis of $\mathrm{La}_{1-x} \mathrm{Sr}_{x} \mathrm{CoO}_{3-\delta}$ [65]. Their mechanistic study provided further evidence of how oxygen vacancies become a crucial parameter for improving the electrocatalytic activity of metal oxides. Briefly, it was stated that the controlled substitution of $\mathrm{Sr}^{2+}$ for $\mathrm{La}^{3+}$, across the full-phase width, while maintaining the perovskite structure, allowed the effects of covalence, vacancy defects, and oxygen exchange to be probed. Lee et al. reported for the first time a hexagonal perovskite, $\mathrm{BaNiO}_{3}$, as water oxidation catalyst in alkaline media and demonstrated that this new family of perovskites outperformed $\mathrm{IrO}_{2}$, by at least $19 \mathrm{~mA} \mathrm{~cm}{ }^{-2}$ during the first cycle of OER [66]. The study of Black et al., first investigated quaternary hafnium oxynitrides with a reduced band gap and showed the potential of these compounds for photoelectrochemical water splitting devices [67]. The new $\mathrm{RHfO}_{2} \mathrm{~N}$ perovskites, with $\mathrm{R}=\mathrm{La}, \mathrm{Nd}$, and $\mathrm{Sm}$, display structures resembling the $\mathrm{GdFeO}_{3}$-type. The $\mathrm{LaHfO}_{2} \mathrm{~N}$ and $\mathrm{NdHfO}_{2} \mathrm{~N}$ compounds, in particular, showed increased resistance towards photocorrosion, compared to the $\mathrm{SmHfO}_{2} \mathrm{~N}$ photocatalyst.

\subsubsection{Mixed Oxides}

Mixed oxides frequently excel through their increased stability and synergistic effects, in a wide range of properties and applications $[55,56,68-73]$. Table 5 summarizes progress in the performance of mixed oxide water oxidation catalysts, over the last three years.

Gholamrezaei and co-workers proposed a new $\mathrm{SrMnO}_{3}$ nanostructure for chemical water oxidation [74]. Various preparation methods were chosen and compared by the authors, and sonochemical synthesis was found to afford the best results, with respect to morphology and nanoparticle size. Electrocatalytic water oxidation was carried out in a $\left(\mathrm{NH}_{4}\right)_{2} \mathrm{Ce}\left(\mathrm{NO}_{3}\right)_{6}$ solution, where the effect of the $\mathrm{Ce}(\mathrm{IV})$ concentration was studied. $\mathrm{O}_{2}$ evolution was increased with higher amounts of cerium. The results suggested that changes in the synthesis method and reaction conditions altered the morphology of the catalyst, as well as the size and the uniformity of the particles. The overall efficiency of the catalyst was enhanced along with the high uniformity of the particles. 
Table 5. Comparison of the electrocatalytic activity of mixed oxide catalysts (cf. Table 1 for definitions of "durability" and "stability").

\begin{tabular}{|c|c|c|c|c|c|c|c|c|}
\hline Catalyst & Preparation Method & Onset Potential (V) & $\begin{array}{c}\eta(\text { at } 10 \\
\left.\mathrm{mV} / \mathrm{cm}^{2}\right)(\mathrm{V})\end{array}$ & $\begin{array}{c}\text { Tafel Slope (mV } \\
\left.\operatorname{dec}^{-1}\right)\end{array}$ & $\begin{array}{l}\text { Durability } \\
\text { (h) }\end{array}$ & Stability & Electrolyte & Ref. \\
\hline $\mathrm{NiCeO}_{\mathrm{x}}$ & Electrodeposition & - & 0.27 & - & $>24$ & Excellent & $1 \mathrm{M} \mathrm{KOH}$ & [68] \\
\hline $\mathrm{Sn}-\mathrm{Fe}_{2} \mathrm{O}_{3} \mathrm{NWs}$ & Hydrothermal & 0.1 & - & - & 10 & Excellent & $1 \mathrm{M} \mathrm{KOH}$ & [69] \\
\hline $\begin{array}{c}\mathrm{Ni}-\mathrm{FeO}_{x} \& \\
\mathrm{Ni}-\mathrm{Fe}-\mathrm{CoO}_{x} \mathrm{NPs}\end{array}$ & $\begin{array}{l}\text { Impregnation in the } \\
\text { presence of aniline }\end{array}$ & - & 0.2 & - & 1 & Good * & $0.1 \mathrm{M} \mathrm{KOH}$ & [70] \\
\hline $\mathrm{CoNiO}_{x} / \mathrm{rGO}$ & Precipitation & - & 0.28 & 45 & 20 & Advanced & $\begin{array}{c}0.1 \mathrm{M} \& 1 \mathrm{M} \\
\mathrm{KOH}\end{array}$ & [71] \\
\hline $\mathrm{Fe}_{x} \mathrm{Co}_{\mathrm{y}} \mathrm{O}$ & Precipitation & - & 0.35 & 36.8 & 2.5 & Good & $0.1 \mathrm{M} \mathrm{KOH}$ & [72] \\
\hline $\begin{array}{c}\mathrm{Fe}_{3} \mathrm{O}_{4}-\mathrm{Co}_{9} \mathrm{~S}_{8} \\
\mathrm{NPs} / \mathrm{rGO}\end{array}$ & Two solvothermal steps & 1.48 & 0.34 & 82.8 & 6 & High & $0.1 \mathrm{M} \mathrm{KOH}$ & [75] \\
\hline $\mathrm{Na}_{1-\mathrm{x}} \mathrm{Ni}_{\mathrm{y}} \mathrm{Fe}_{1-\mathrm{y}} \mathrm{O}_{2}$ & Hydrothermal & 1.35 & 0.26 & 44 & 12 & Excellent & $1 \mathrm{M} \mathrm{KOH}$ & [76] \\
\hline $\begin{array}{c}\mathrm{CoNiO}, \mathrm{MnNiO} \& \\
\mathrm{FeNiO}\end{array}$ & $\begin{array}{l}\text { Precipitation reaction } \\
\text { with urea }\end{array}$ & $\begin{array}{l}\text { CoNiO: 1.60, MnNiO: } \\
\text { 1.61 \& FeNiO: } 1.54\end{array}$ & - & $\begin{array}{l}\text { CoNiO: 39, MnNiO: } \\
\quad 43 \text { \& FeNiO: } 18\end{array}$ & - & - & $0.1 \mathrm{M} \mathrm{KOH}$ & [77] \\
\hline $\mathrm{Fe}_{2-x} \mathrm{Cr}_{\mathrm{x}} \mathrm{O}_{3}$ & Coprecipitation & $<1.3$ & 0.45 & - & 1.5 & Good * & $100 \mathrm{mM}$ PBS & [78] \\
\hline $\mathrm{MnVO}_{\mathrm{x}} @ \mathrm{~N}-\mathrm{rGO}$ & Hydrothermal & 1.32 & 0.39 & 271 & 4 & Excellent & $0.1 \mathrm{M} \mathrm{KOH}$ & [79] \\
\hline $\mathrm{MnOx} / \mathrm{N}-\mathrm{CNT}$ & Hydrothermal & ca. 1.4 & 0.36 & 75 & 2 & $\begin{array}{l}\text { Catalyst } \\
\text { detachment }\end{array}$ & $1 \mathrm{M} \mathrm{KOH}$ & [80] \\
\hline $\mathrm{Mn}_{x} \mathrm{Sb}_{1-x} \mathrm{O}_{x}$ & $\begin{array}{l}\text { Physical Vapor } \\
\text { Deposition (PVD) }\end{array}$ & 1.5 & 0.3 & 75 & 25 & High * & $1 \mathrm{M} \mathrm{H}_{2} \mathrm{SO}_{4}$ & [81] \\
\hline $\mathrm{Ho}_{2} \mathrm{O}_{3} / \mathrm{MnO}_{\mathrm{x}}$ & Hydrothermal & $\begin{array}{l}\text { Varied according to } \\
\text { calcination }\end{array}$ & - & - & 0.5 & High & $\begin{array}{l}0.25 \mathrm{M} \\
\mathrm{LiClO}_{4}\end{array}$ & [82] \\
\hline
\end{tabular}


The study of Desmond-Ng et al. was focused on a theoretical model and experimental considerations aiming for the engineering of catalytic systems that are competitive with the best water oxidation electrocatalysts to date [68]. To this end, the authors synthesized a $\mathrm{NiCeO}_{x}-\mathrm{Au}$ catalyst, with an outstanding OER activity in alkaline media. A highlight of this approach was the new combination of electronic, geometric, and catalyst support effects. The TOF of $\mathrm{NiCeO}_{\mathrm{x}}-\mathrm{Au}$ catalyst at $0.28 \mathrm{~V}_{\mathrm{RHE}}$ overpotential was determined as $0.08 \mathrm{~s}^{-1}$.

$\mathrm{Li}$ et al. proposed $\mathrm{Sn}$ as a dopant in hematite nanowire photoanodes [69]. The morphology was considered the key factor leading to the high performance of the Sn-doped hematite, which was furthermore coated with a cobalt oxide catalyst for enhanced photocurrent densities. A schematic illustration of the catalyst preparation is shown in Figure 22. In this paper, the importance of retaining the concentration and uniformity of dopants along the nanowire growth was highlighted as another crucial parameter that is essential for high catalyst activity. The authors applied a silica encapsulation method, which retained the morphology of the hematite nanowire and further provided tuned nanowire lengths for maximum light absorption.

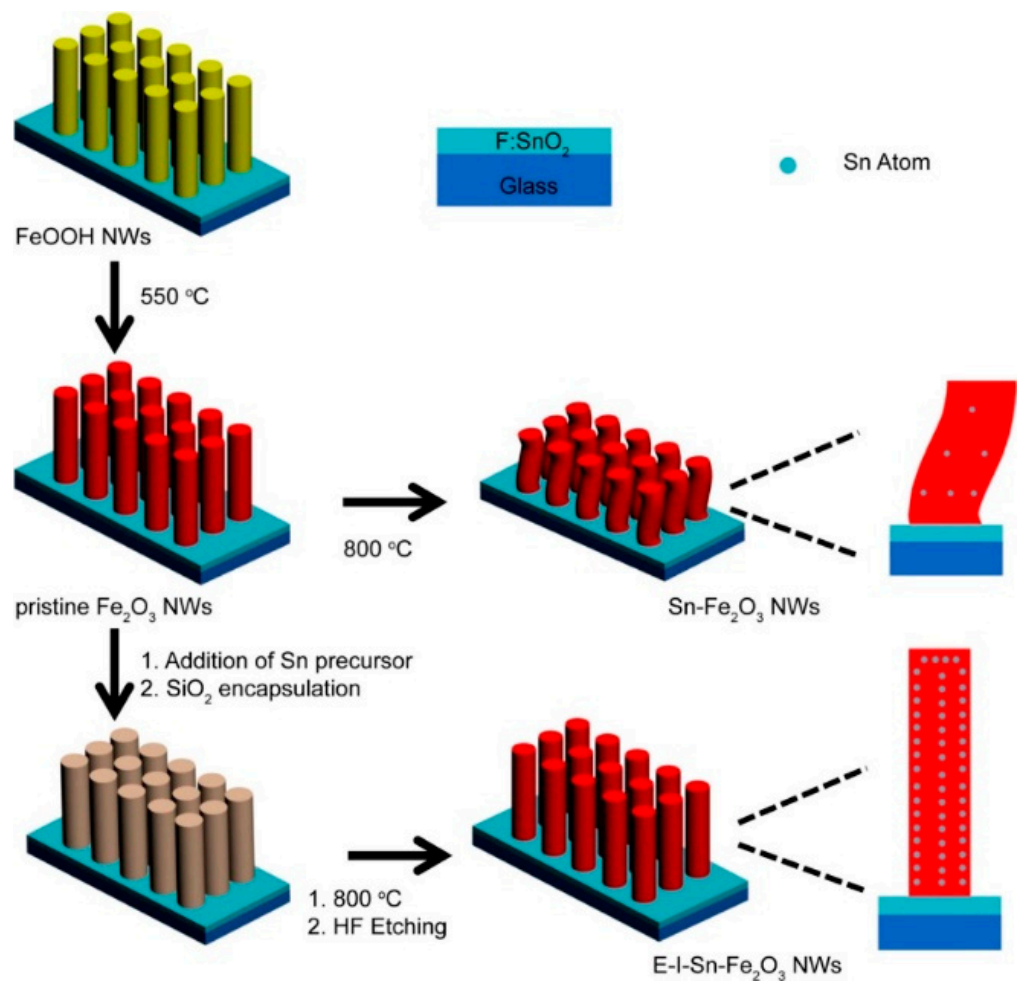

Figure 22. Synthetic protocol for $\mathrm{Sn}-\mathrm{Fe}_{2} \mathrm{O}_{3} \mathrm{NWs}$ and E-I-Sn- $\mathrm{Fe}_{2} \mathrm{O}_{3} \mathrm{NWs}$ for further decoration with cobalt oxides (not shown). Reproduced from [69], with permission from the American Chemical Society, copyright 2017.

Bates et al. proposed a different way of increasing the electrocatalytic efficiency of a Ni-Fe-Co mixed metal oxide (MMO) catalyst. The morphology was optimized by addition of aniline as a capping agent, in order to generate a high surface area [70]. Charge-transfer effects contributed to a higher conductivity among the Ni-Co sites and, therefore, increased their catalytic activity in water oxidation.

A promising strategy towards the development of OER electrocatalysts was proposed by Li et al., where a $\mathrm{CoNiO}_{x}$ nanocomposite was deposited onto a reduced graphene oxide [71]. The exceptional performance of this nanocomposite in water oxidation was ascribed to the hierarchical sheet-on-sheet structure, affording a high surface area and high porosity. The catalyst showed a low overpotential at $0.28 \mathrm{~V}_{\mathrm{RHE}}$ and a Tafel slope of $45 \mathrm{mV} \mathrm{dec}^{-1}$. Proposing that all metal sites are active during the electrochemical reaction, the TOF value was estimated at $0.03 \mathrm{~s}^{-1}$, at the overpotential of $0.35 \mathrm{~V}$ RHE. 
Zhuang et al. fabricated a high surface area catalyst consisting of $\mathrm{Fe}_{\mathrm{x}} \mathrm{Co}_{\mathrm{y}}-\mathrm{O}$ nanosheets $\left(261.1 \mathrm{~m}^{2} \mathrm{~g}^{-1}\right)$, with an ultrathin thickness of $1.2 \mathrm{~nm}$ [72]. These features led to a superior activity, compared to commercial $\mathrm{RuO}_{2}$, with an overpotential at $0.35 \mathrm{~V}_{\mathrm{RHE}}$ and a Tafel slope at $36.8 \mathrm{mV}$ $\mathrm{dec}^{-1}$. The TOF value at the overpotential of $0.35 \mathrm{~V}_{\mathrm{RHE}}$ was calculated at $0.02 \mathrm{~s}^{-1}$. This outstanding performance of the catalyst was ascribed to the large number of oxygen vacancies in the sheets, which further acted as active centers. The proposed OER mechanism of a $\mathrm{Co}^{3+}$ active site, near an oxygen vacancy, is illustrated in Figure 23.

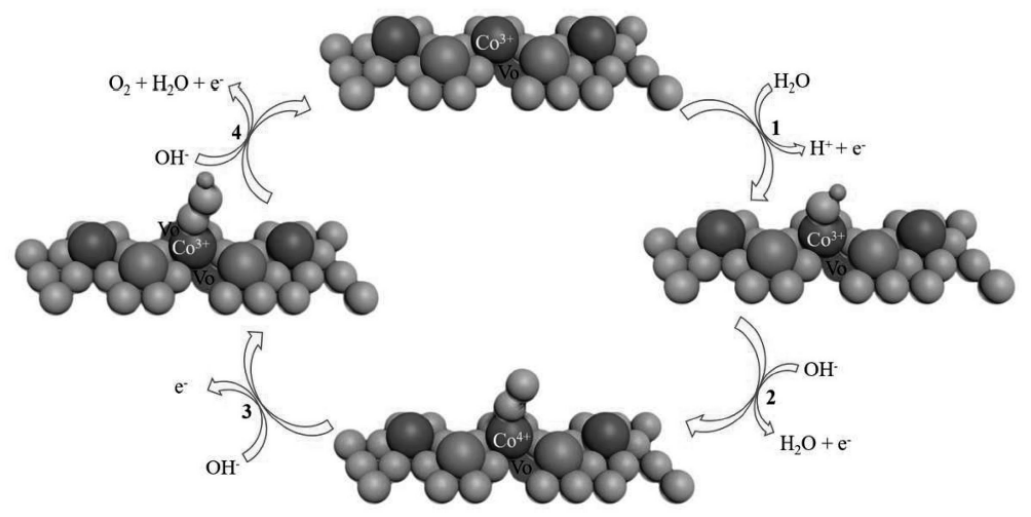

Figure 23. Proposed OER mechanism of a $\mathrm{Co}^{3+}$ active site, near an oxygen vacancy in $\mathrm{Fe}_{x} \mathrm{Co}_{\mathrm{y}}-\mathrm{O}$ nanosheets. Reproduced from [72], with permission from John Wiley and Sons, copyright 2017.

Applying a two-step solvothermal method, Yang et al. fabricated $\mathrm{Fe}_{3} \mathrm{O}_{4}$-decorated $\mathrm{Co}_{9} \mathrm{~S}_{8}$ nanoparticles on reduced graphene oxide [75]. The composite catalyst gave an excellent stability and catalytic activity. This was ascribed to electron transfer from the Fe species to $\mathrm{Co}_{9} \mathrm{~S}_{8}$, which promoted the cleavage of the $\mathrm{Co}-\mathrm{O}$ bond in the stable configuration of the $\mathrm{Co}-\mathrm{O}-\mathrm{O}$ superoxo group.

A layered $\mathrm{Na}_{1-x} \mathrm{Ni}_{\mathrm{y}} \mathrm{Fe}_{1-y} \mathrm{O}_{2}$ double oxide was reported by Weng and co-workers with excellent stability and electrocatalytic activity, compared to the state-of-the-art $\mathrm{RuO}_{2}$ and $\mathrm{IrO}_{2}$ [76]. As a result of $\mathrm{Na}$ extraction, the valence states of $\mathrm{Ni}$ and $\mathrm{Fe}$ were raised and the catalyst exhibited excellent OER activity. This catalyst was also integrated in a perovskite solar cell, which delivered a solar-to-hydrogen efficiency of around $11.2 \%$.

A new catalytic material comprising $\mathrm{Fe}_{2-x} \mathrm{Cr}_{x} \mathrm{O}_{3}$ particles is under investigation by Kanazawa et al. and is proposed for both photoelectrochemical and electrochemical water oxidation [78]. Findings of their study revealed that $\mathrm{Cr}$-substitution resulted in a five-fold enhancement of the electrochemical water oxidation performance, compared to $\alpha-\mathrm{Fe}_{2} \mathrm{O}_{3}$, as well as lowered charge transfer resistance, giving rise to an improved OER activity, with nearly a 100\% faradaic efficiency.

Mn oxides are cost-effective, environment-friendly, and redox active. The $\left\{\mathrm{CaMn}_{4} \mathrm{O}_{5}\right\}$ oxygen evolving center of photosystem II is a constant source for bio-inspired approaches, in many fields of catalysis. Due to their versatility, Mn oxides have even been referred to as "Swiss army knife" [83]. In the following, selected recent studies on mixed oxide catalysts, based on manganese are summarized.

Xing et al. proposed a new class of composite catalysts comprising $\mathrm{MnVO}_{\mathrm{x}}$ on $\mathrm{N}$-doped reduced graphene oxide [79]. A hydrothermal method was applied, starting from a $\left[\mathrm{Mn}_{4} \mathrm{~V}_{4} \mathrm{O}_{17}(\mathrm{OAc})_{3}\right]^{3-}$ polyoxometalate precursor. The authors showed that the precursor was successfully deposited on carbon and then converted to WOCs, with recorded OER current densities of $80 \mathrm{~mA} \mathrm{~cm}{ }^{-2}$, at the applied potential of $1.67 \mathrm{~V}_{\text {RHE }}$. The overpotential of the $\mathrm{MnVO}_{\mathrm{x}} / \mathrm{N}-\mathrm{rGO}$ electrocatalyst was determined as $0.39 \mathrm{~V}_{\mathrm{RHE}}$, at $10 \mathrm{~mA} \mathrm{~cm}{ }^{-2}$ current density, with a Tafel slope of $271 \mathrm{mV} \mathrm{dec}{ }^{-1}$. The synthesis method provided nanoparticulate $\mathrm{Mn}-\mathrm{V}$ oxides with excellent stability, which can be further used for a variety of technological applications.

Antoni and co-workers employed high surface area N-functionalized CNTs for the oxidative deposition of $\mathrm{MnO}_{\mathrm{x}}$ under reflux and mild hydrothermal conditions [80]. The synthesis was carried 
out in the presence of $\mathrm{CsMnO}_{4}$ and $\mathrm{KMnO}_{4}$ as manganese sources, which gave mainly rise to the formation of crystalline birnessite manganese oxides. The $\mathrm{MnO}_{\mathrm{x}}$-modified $\mathrm{N}$-CNTs catalysts afforded higher current densities, at around $20 \mathrm{~mA} \mathrm{~cm}^{-2}$, compared to the unmodified N-CNTs in alkaline electrolyte. The overpotential of the catalyst was recorded as $0.36 \mathrm{~V}_{\mathrm{RHE}}$ at $10 \mathrm{~mA} \mathrm{~cm}{ }^{-2}$ current density and the reported Tafel slope was $75 \mathrm{mV} \mathrm{dec}^{-1}$. The faradaic efficiency was also increased from $75 \%$ to $90 \%$ towards the OER, after $10 \mathrm{~min}$ of electrocatalytic tests, and this was attributed to the oxidation of manganese.

A physical vapor deposition approach via reactive radio frequency magnetron co-sputtering of $\mathrm{Mn}$ and $\mathrm{Sb}$ was employed by Zhou et al., for the synthesis of rutile-type solid solutions, $\mathrm{Mn}_{\mathrm{x}} \mathrm{Sb}_{1-\mathrm{x}} \mathrm{O}_{\mathrm{x}}$, with OER activity in strong acidic conditions [81]. The mixed oxides showed current densities above $50 \mathrm{~mA} \mathrm{~cm}^{-2}$, at the applied potential of $1.79 \mathrm{~V}_{\mathrm{RHE}}$. The overpotential at the current density of $10 \mathrm{~mA}$ $\mathrm{cm}^{-2}$ was found to be $0.58 \mathrm{~V}_{\mathrm{RHE}}$, with a Tafel slope value of $75 \mathrm{mV} \mathrm{dec}^{-1}$. Notably, the fraction of $\mathrm{Mn}^{3+}$ increased with the overall amount of $\mathrm{Mn}$ in the mixed oxides. This was corroborated by XAS, AP-XPS, and computational investigations and linked to the overall increase in OER activity. Likewise, Morgan Chan et al. showed via spectroscopic and computational studies that the enhancement of $\mathrm{MnO}_{2}$ oxygen evolution catalyst is related to the introduction of $\mathrm{Mn}^{3+}$ species, and the suppression of $\mathrm{Mn}^{3+}$ oxidation to $\mathrm{Mn}^{4+}$, due to structural restrictions, was considered crucial for higher activity [84].

Najafpour and co-workers proposed and hydrothermally fabricated a new manganese oxide supported on holmium oxide for OER [82]. Their catalyst was very stable, recoverable, and it could be used for long operational OER. The observed self-healing properties were explained with the presence of $\mathrm{Ce}(\mathrm{IV})$ species. $\mathrm{O}_{2}$ was produced from water in the presence of Mn oxides and Ce(IV) and water, and $\mathrm{MnO}_{4}{ }^{-}$was further formed from the oxidation of intermediate $\mathrm{Mn}$ (II) ions by Ce(IV). These $\mathrm{MnO}_{4}{ }^{-}$ions were eventually converted back to Mn oxide, resulting in self repair of the catalyst.

\subsubsection{Other Hydroxides and (Oxy)hydroxides}

Commercial water electrolyzers require efficient electrocatalysts with high current densities, usually above $500 \mathrm{~mA} \mathrm{~cm}^{-2}$, with long-term stability, at overpotentials below $0.3 \mathrm{~V}_{\mathrm{RHE}}$. To this end, metal hydroxides and (oxy)hydroxides have attracted a lot of research attention as target structures, to fabricate catalysts with the aforementioned characteristics [18,36,39-41,85-92]. Table 6 summarizes progress in the electrocatalytic activity of hydroxide and (oxy)hydroxide catalysts, over the last three years. In addition to noble metal oxides, such as $\mathrm{RuO}_{2}$ and $\mathrm{IrO}_{2}$, which have been established as the best OER catalysts to date, Fe-doped $\mathrm{NiOOH}$ ranks among the best, noble metal-free catalysts.

Recently, Shin et al. investigated new dopants using a density functional theory approach, in order to determine the atomistic mechanism for the OER of $\mathrm{Ni}_{1-x} \mathrm{Fe}_{x} \mathrm{OOH}$ [93]. In their study, 17 transition metals were considered to replace Fe. They found out that the most promising materials were $\mathrm{Co}, \mathrm{Rh}$, and $\mathrm{Ir}$, and the resulting overpotentials were estimated to be $0.27,0.15$, and $0.02 \mathrm{~V}_{\mathrm{RHE}}$, respectively. The authors concluded that $\mathrm{Fe}^{4+}$ and $\mathrm{Ni}^{4+}$ species played an essential role in the OER. The promotion of a radical environment on the metal-oxo bond was also found to be a key prerequisite for high OER activity.

Liang et al. used a $\mathrm{PH}_{3}$ plasma-assisted method developed by their group, to fully convert a NiFe hydroxide into porous NiFeP, as shown in Figure 24 [85]. This method facilitated the rapid synthesis of phosphides, at around $15 \mathrm{~min}$, at low temperatures of approximately $200{ }^{\circ} \mathrm{C}$. The catalyst showed high geometric current densities of $300 \mathrm{~mA} \mathrm{~cm}^{-2}$ at the corresponding overpotential of $0.2 \mathrm{~V}_{\mathrm{RHE}}$, a low overpotential of $0.258 \mathrm{~V}_{\text {RHE }}$ at $10 \mathrm{~mA} \mathrm{~cm}^{-2}$, and a small Tafel slope of $39 \mathrm{mV} \mathrm{dec}^{-1}$. The low overpotential of $0.25 \mathrm{~V}_{\mathrm{RHE}}$ corresponded to $0.036 \mathrm{~s}^{-1} \mathrm{TOF}$, as calculated by the authors. The high activity was ascribed to the morphological architecture and the electronic interaction between the $\alpha-\mathrm{NiFe}-\mathrm{OH}$ and $\mathrm{NiFeP}$, respectively. 
Table 6. Comparison of the electrocatalytic activity of hydroxide and (oxy)hydroxide catalysts (cf. Table 1 for definitions of "durability" and "stability").

\begin{tabular}{|c|c|c|c|c|c|c|c|c|}
\hline Catalyst & Preparation Method & $\begin{array}{c}\text { Onset } \\
\text { Potential (V) }\end{array}$ & $\begin{array}{c}\eta(\text { at } 10 \\
\left.\mathrm{mV} / \mathrm{cm}^{2}\right)(\mathrm{V})\end{array}$ & $\begin{array}{c}\text { Tafel Slope (mV } \\
\left.\operatorname{dec}^{-1}\right)\end{array}$ & $\begin{array}{l}\text { Durability } \\
\text { (h) }\end{array}$ & Stability & Electrolyte & Ref. \\
\hline $\mathrm{NiFeOH} / \mathrm{NiFeP}$ & $\begin{array}{l}\text { Hydrothermal \& } \mathrm{PH}_{3} \text { plasma } \\
\text { treatment \& electrodeposition }\end{array}$ & - & 0.258 & 39 & 24 & High * & $1 \mathrm{M} \mathrm{KOH}$ & [85] \\
\hline $\mathrm{NiFe}-\mathrm{OH}$ & Stepwise electrodeposition & - & 0.24 & 38.9 & 5 & Good * & $1 \mathrm{M} \mathrm{KOH}$ & [86] \\
\hline $\mathrm{W}_{0.5} \mathrm{Co}_{0.4} \mathrm{Fe}_{0.1}$ oxyhydroxide coralloids & Hydrothermal & 1.53 & 0.25 & 32 & $>500$ & Superior & $1 \mathrm{M} \mathrm{KOH}$ & [87] \\
\hline CoFe-H hydroxide \& CoFe-H/BiVO 4 & Electrodeposition & 0.23 & 0.28 & 28 & 45 & High * & $1 \mathrm{M} \mathrm{KOH}$ & [88] \\
\hline $\mathrm{CeO}_{2} / \mathrm{FeOOH}$ & Electrodeposition & 0.21 & 0.25 & 32 & 50 & High & $1 \mathrm{M} \mathrm{NaOH}$ & [89] \\
\hline $\mathrm{FeOOH} / \mathrm{Co} / \mathrm{FeOOH}$ & Electrodeposition & 0.22 & 0.25 & 32 & 50 & High & $1 \mathrm{M} \mathrm{NaOH}$ & {$[90]$} \\
\hline FeCoW oxyhydroxides & Modified sol-gel & - & 0.191 & 37 & 550 & High & $1 \mathrm{M} \mathrm{KOH}$ & [91] \\
\hline $\mathrm{NiFe}(\mathrm{OH}) / \mathrm{NiFe}: \mathrm{Pi}$ & $\begin{array}{l}\text { Electrodeposition \& } \\
\text { phosphorylation }\end{array}$ & 1.43 & 0.29 & 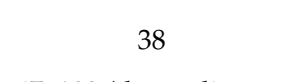 & 10 & Excellent & $1 \mathrm{M} \mathrm{KOH}$ & [92] \\
\hline Ag-decorated $\mathrm{Co}(\mathrm{OH})_{2}$ & Selective reduction-oxidation & - & 0.27 & $\begin{array}{l}67-109 \text { (depending on } \\
\text { the amount of Ag) }\end{array}$ & 10 & Good & $1 \mathrm{M} \mathrm{KOH}$ & [94] \\
\hline $\mathrm{NiFeOOH} / \mathrm{TiO}_{2}$ core-shell & Hydrothermal & & 0.273 & 86.9 & 24 & High * & $\begin{array}{c}0.01 \mathrm{M} \\
\mathrm{Na}_{2} \mathrm{SO}_{4}\end{array}$ & [95] \\
\hline$\alpha-\mathrm{NiCo}(\mathrm{OH})_{2}$ & Electrodeposition & 1.43 & 0.26 & $25-30$ & 6 & High * & $1 \mathrm{M} \mathrm{KOH}$ & [96] \\
\hline $\mathrm{NiPS}_{3} @ \mathrm{NiOOH}$ & $\begin{array}{c}\text { Chemical vapor transport \& } \\
\text { liquid exfoliation }\end{array}$ & 1.48 & 0.35 & 80 & $>160$ & Excellent & $0.1 \mathrm{M} \mathrm{KOH}$ & [97] \\
\hline
\end{tabular}




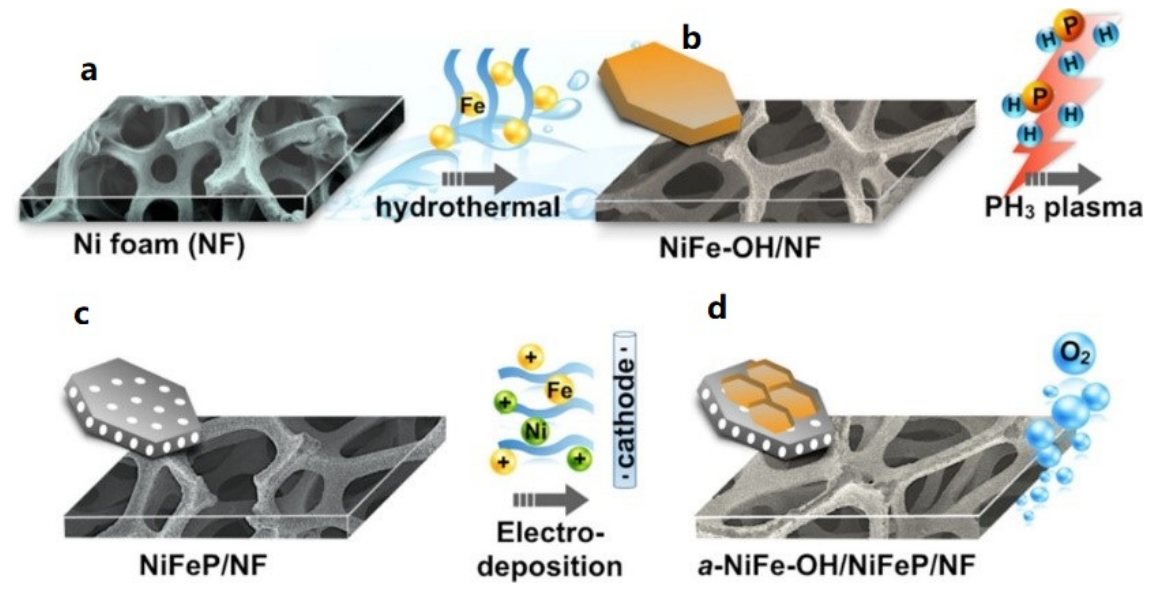

Figure 24. Plasma-assisted strategy to hierarchical $\alpha-\mathrm{NiFe}-\mathrm{OH} / \mathrm{NiFeP} / \mathrm{NF}$ electrocatalysts for water oxidation: (a) Ni foam substrate, (b) NiFe-DH nanoplates hydrothermally grown on $\mathrm{Ni}$ foam, (c) conversion of $\mathrm{NiFe}-\mathrm{DH}$ to porous $\mathrm{NiFeP}$ nanoplates, using $\mathrm{PH}_{3}$ plasma, and (d) electrodeposition of amorphous NiFe-OH nanosheet layer onto NiFeP. Reproduced from [85], with permission from John Wiley and Sons, copyright 2017.

Electrodeposition was employed by many groups, in order to synthesize catalysts using $\mathrm{FeOH}$ or $\mathrm{FeOOH}$-coupled with other co-catalyst metals or metal oxides, such as $\mathrm{Ni}, \mathrm{CeO}_{2}$, and $\mathrm{BiVO}_{4}[86,87,89,90,92]$. Of note is the work by Li et al., which dealt with the surface wettability [92]; the authors employed electrodeposition and phosphorylation methods to deposit an $\alpha-\mathrm{NiFe}-\mathrm{OH}$ nanosheet layer onto a NiFe: $\mathrm{P}_{\mathrm{i}} 3 \mathrm{D}$ hierarchical nanostructure. From the results, the authors concluded that surface wettability is a key parameter for controlling the morphology, while it is also capable of modifying the chemical properties of a catalyst. The catalyst showed a low overpotential of $0.29 \mathrm{~V}_{\mathrm{RHE}}$ at $10 \mathrm{~mA} \mathrm{~cm}^{-2}$ and an excellent stability in the aqueous media. The faradaic efficiency was found to be $98.2 \%$, which suggested that the main product evolved on the catalyst was $\mathrm{O}_{2}$. Furthermore, the phosphorylation assisted the enhancement of the surface area, which provided more catalytic active sites for water adsorption and oxidation.

A trimetallic $\mathrm{W}_{0.5} \mathrm{Co}_{0.4} \mathrm{Fe}_{0.1}$ oxyhydroxide corraloid was introduced by Pi et al.; this exhibited a superior stability and durability in alkaline media, for 21 days [87]. Their catalyst outperformed most of the reported Co-based nanomaterials and showed continuous electrolysis currents with imperceptible decay after more than $500 \mathrm{~h}$. The authors followed a wet-chemical method to synthesize corraloid-like trimetallic oxyhydroxides on nickel foam and carbon nanotubes. The preparative route and the electron microscopy characterization of the catalyst are displayed in Figure 25. The images showed disintegrated and twisted nanosheets and the selected area electron diffraction data revealed the high crystallinity of the oxyhydroxides. The special structure of this catalyst went hand-in-hand with a low overpotential of $0.25 \mathrm{~V}_{\mathrm{RHE}}$, at the current density of $10 \mathrm{~mA} \mathrm{~cm}^{-2}$ and a small Tafel slope of $32 \mathrm{mV} \mathrm{dec}^{-1}$. XPS data showed that an optimized amount of Fe went hand in hand with the optimization of the binding energy of oxygen intermediates, which led to a high OER activity.

A similar trimetallic catalyst consisting of FeCoW oxyhydroxides was synthesized via a modified sol-gel method by Zhang and co-workers [91]. These gelled FeCoW oxyhydroxides exhibited superior durability for $550 \mathrm{~h}$, i.e., approximately 23 days, with a very low overpotential of $0.191 \mathrm{~V}_{\mathrm{RHE}}$ at 10 $\mathrm{mA} \mathrm{cm}{ }^{-2}$, in alkaline media. The intrinsic activity of gelled-FeCoW oxyhydroxides was quantified by determining the TOF value, which was found to be $0.46 \mathrm{~s}^{-1}$, at an overpotential of $0.3 \mathrm{~V}_{\text {RHE }}$. The faradaic efficiency of $\mathrm{O}_{2}$ evolution recorded on the catalyst was calculated to be close to $100 \%$. The synergistic effects between the three metals produced a favorable local coordination environment, which, along with their electronic interaction, significantly enhanced the OER activity. 


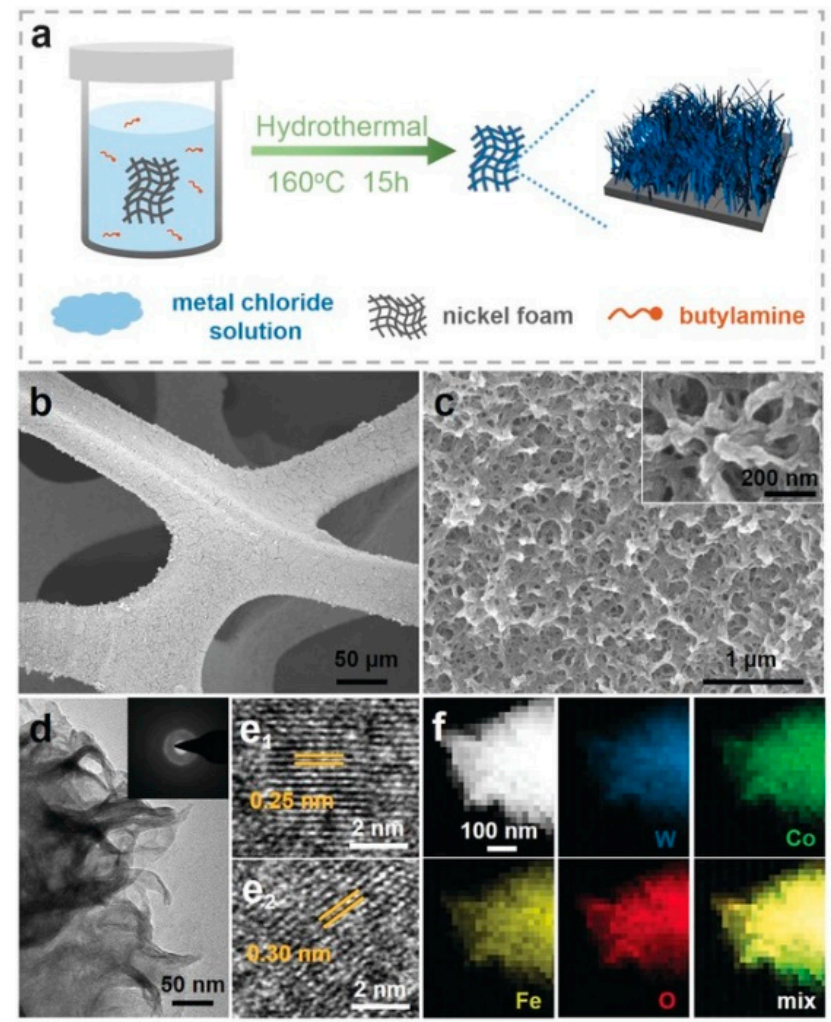

Figure 25. Preparative route (a) and morphological characterization of oxyhydroxides on nickel foam (NF): (b,c) SEM, (d) TEM and $\left(\mathbf{e}_{1}, \mathbf{e}_{2}\right)$ HRTEM images of oxyhydroxide $\mathrm{W}_{0.5} \mathrm{Co}_{0.4} \mathrm{Fe}_{0.1} / \mathrm{NF}$ (inset: corresponding SAED pattern). (f) HAADF-STEM image and STEM-EDS mapping of $\mathrm{W}_{0.5} \mathrm{Co}_{0.4} \mathrm{Fe}_{0.1} / \mathrm{NF}(\mathrm{Co}=$ green, $\mathrm{Fe}=$ yellow, $\mathrm{O}=$ red $)$. Reproduced from [87], with permission from John Wiley and Sons, copyright 2017.

Electrodeposited amorphous $\alpha$-phase $\mathrm{Ni}-\mathrm{Co}(\mathrm{OH})_{2}$ nanodendrite forests were synthesized on a stainless steel foil by Balram and co-workers [96]. The key parameter for the formation of nanodendritic structures was the addition of small amounts of water to the deposition bath. A limited water electrolysis and hydrogen bubble production occurred near the electrode interface with the electrolyte, which caused highly localized $\mathrm{pH}$ gradients, resulting in the aforementioned three-dimensional structure. The electrocatalyst afforded current densities higher than $50 \mathrm{~mA} \mathrm{~cm}{ }^{-2}$, at the applied potential of $1.6 \mathrm{~V}_{\text {RHE. }}$. The overpotential at the current density of $10 \mathrm{~mA} \mathrm{~cm}^{-2}$ was found at $0.25 \mathrm{~V}_{\mathrm{RHE}}$ and the Ni-Co(OH $)_{2}$ material showed an excellent stability during the operational time of $6 \mathrm{~h}$.

Konkena and co-workers employed a chemical vapor transport and liquid exfoliation method, in order to fabricate an $\mathrm{NiPS}_{3} @ \mathrm{NiOOH}$ core-shell structure [97]. Ni(III)-based (NiOOH) species of the shell structure enhanced the overall OER, as shown by a combination of spectroscopic and computational analyses. Additionally, the high OER activity was attributed to the highly active metal-edge sites. The catalyst excelled through a low-onset potential at $1.48 \mathrm{~V}_{\mathrm{RHE}}$, as well as an overpotential value of $0.35 \mathrm{~V}_{\text {RHE }}$ at the current density of $10 \mathrm{~mA} \mathrm{~cm}^{-2}$. The Tafel slope was recorded as $80 \mathrm{mV} \mathrm{dec}^{-1}$ and the catalyst showed a high stability after $6 \mathrm{~h}$ of electrocatalytic tests.

\section{Brief Discussion of the Unresolved Bottlenecks}

The development of a highly efficient and low-cost water oxidation catalysts remains of utmost importance for commercial artificial photosynthesis applications. Notwithstanding the recent advances in this field, fundamental improvement strategies and issues need to be further addressed. Focusing efforts on mechanistic studies is essential for a deeper understanding of how a more efficient and long-lasting water oxidation catalyst can be engineered. Furthermore, these advanced engineering 
efforts for a promising oxidation catalyst need to be coupled with convenient and applicable benchmarking protocols. These protocols will allow us to easily compare our systems on all levels and to unambiguously identify candidates for a technological scale-up. Given that such generally accepted standard test procedures are still pending, here, we refrained from further performance comparisons between the different material types. The wide variation of preparative and experimental parameters between the selected studies still renders such comparisons far from unambiguous. Another unresolved bottleneck in the field is the need for widely available in situ/operando monitoring techniques, under real catalytic conditions. Monitoring structural changes during catalysis, under various concentrations, $\mathrm{pH}$, and temperature parameters, provides indispensable first-hand information for selecting the most efficient optimization parameters.

\section{Directions to New Composite Materials}

In this section, an outlook is given on new composite materials for OER catalysis. Kuang et al. introduced a superior carbon material as a booster additive for water oxidation catalysts, namely graphdiyne (GDY), which comprises assembled layers of $\mathrm{sp}$ and $\mathrm{sp}^{2}$ hybridized carbon atoms [98]. Graphdiyne has been proposed as a new and the most stable carbon allotrope, with a high $\pi$-connectivity, uniformly distributed triangular pores, and tunable electronic properties [99]. The geometrical structure of this material is illustrated in Figure 26. More specifically, Kuang and co-workers fabricated a GDY/NiFe-LDH electrocatalysts, via a hydrothermal method. Morphological characterizations of the material, as well as elemental mapping data are displayed in Figure 27. The electrocatalyst exhibited outstanding catalytic activity towards water oxidation, at a low overpotential of $260 \mathrm{mV}$ in an alkaline electrolyte. Density functional theory calculations were also performed and demonstrated strong interactions between $-\mathrm{C} \equiv \mathrm{C}-\mathrm{C} \equiv \mathrm{C}-$ and the transition metal atoms, which further contributed to the fast electron transfer and long operational stability.
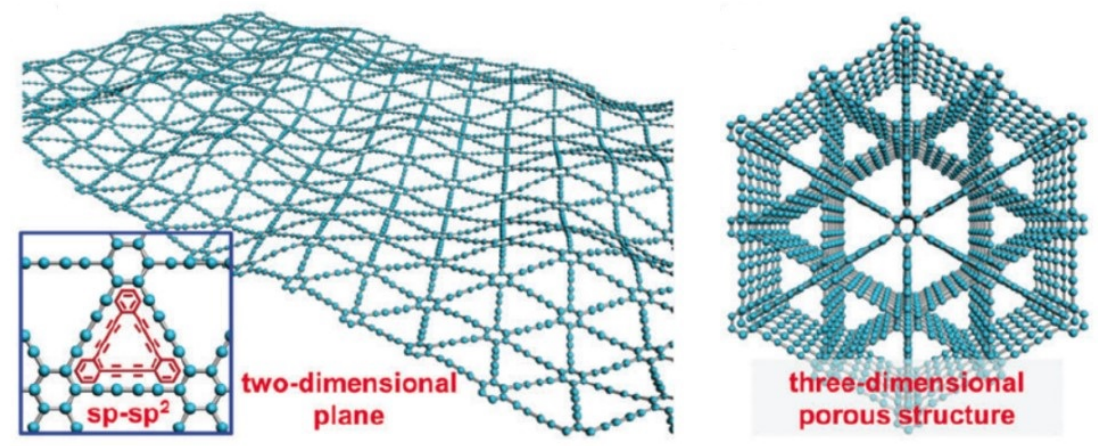

Figure 26. Structural features of graphdiyne (GDY). Reproduced from [98], with permission from the Royal Society of Chemistry, copyright 2018.

Chen and co-workers synthesized an emerging type of carbon, the giant carbon tubes (GCTs), with outstanding water oxidation properties, and a unique physicochemical structure [100]. Regarding the formation protocol, quartz wool was employed as a template for the CVD growth of the giant carbon tubes. The material was placed in a quartz tube and heated to different temperatures-between 950 and $1050{ }^{\circ} \mathrm{C}$-in a mixed $\mathrm{H}_{2}$ and $\mathrm{CH}_{4}$ gas stream.

The nitridation of the GNTs (N-GNTs) was also carried out by further heating of the sample in a furnace, under an $\mathrm{NH}_{3}$ flow. SEM and TEM images of the material are shown in Figure 28. The GNTs and N-GNTs showed an overpotential of $0.44 \mathrm{~V}_{\mathrm{RHE}}$, at the current density of $10 \mathrm{~mA} \mathrm{~cm}^{-2}$ and Tafel slope values of 46 and $48 \mathrm{mV} \mathrm{dec}^{-1}$, respectively, which were significantly lower than those of other carbon-based WOCs. The authors also ran chronoamperometric studies of the catalyst for almost $30 \mathrm{~min}$, and the current densities showed a time-dependent upward trend. 


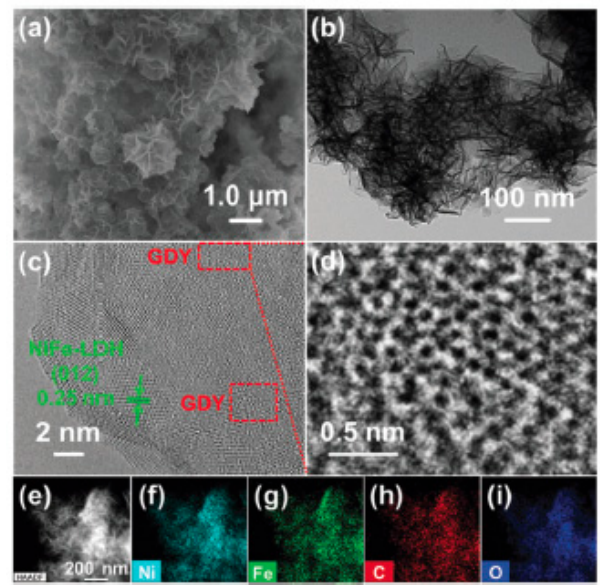

Figure 27. Morphological features and composition of GDY/NiFe-LDH composite: (a) SEM image, (b) ACTEM image, (c,d) HRTEM images, and (e-i) HAADF and EDS mapping. Reproduced from [98], with permission from the Royal Society of Chemistry, copyright 2018.

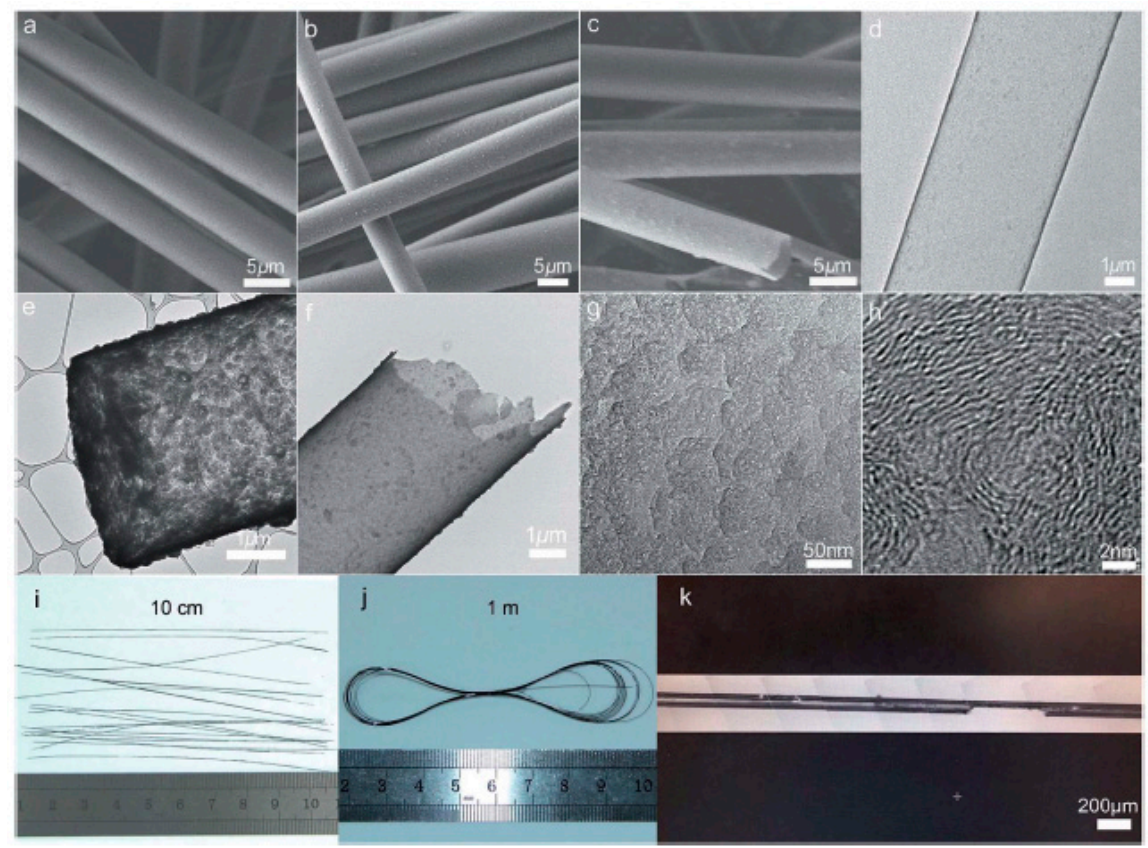

Figure 28. FESEM images of (a) quartz wires (b) quartz wire@carbon, (c) giant carbon tubes (GCTs), and $(\mathbf{d}-\mathbf{h})$ TEM and HRTEM characterizations of GCTs. Optical images of carbon tubes growing on quartz wire (125 $\mu \mathrm{m}$ in wire diameter) of (i) $10 \mathrm{~cm}$ and (j) ultralong $1 \mathrm{~m}$ species. (k) An Infinite Focus Microscopy (IFM) image of a GCT, with an inner diameter up to $125 \mu \mathrm{m}$. Reproduced from [100], with permission from the Royal Society of Chemistry, copyright 2018.

Heterojunction structures are of current interest for solar water splitting, as proposed recently by Wei et al. [101]. In particular, the authors employed a hydrothermal method to synthesize $\mathrm{SrTiO}_{3} / \mathrm{TiO}_{2}$ heterogeneous hollow multi-shelled structures (HoMSs), via a hydrothermal crystallization of $\mathrm{SrTiO}_{3}$ on the surface of the $\mathrm{TiO}_{2}$. The preparation route towards the $\mathrm{SrTiO}_{3} / \mathrm{TiO}_{2}$ heterojunctions is illustrated in Figure 29. Morphological characterizations (cf. Figure 30) showed the full coverage of the $\mathrm{TiO}_{2}$ surface with $\mathrm{SrTiO}_{3}$. The heterogeneous hollow multi-shelled structures increased the ability of the $\mathrm{SrTiO}_{3} / \mathrm{TiO}_{2}$ photocatalyst to absorb light and subsequently augmented their charge carrier separation efficiency. The $\mathrm{SrTiO}_{3} / \mathrm{TiO}_{2}$ photocatalyst retained its catalytic activity, without any evident decrease, after $20 \mathrm{~h}$ of overall water splitting reaction. 


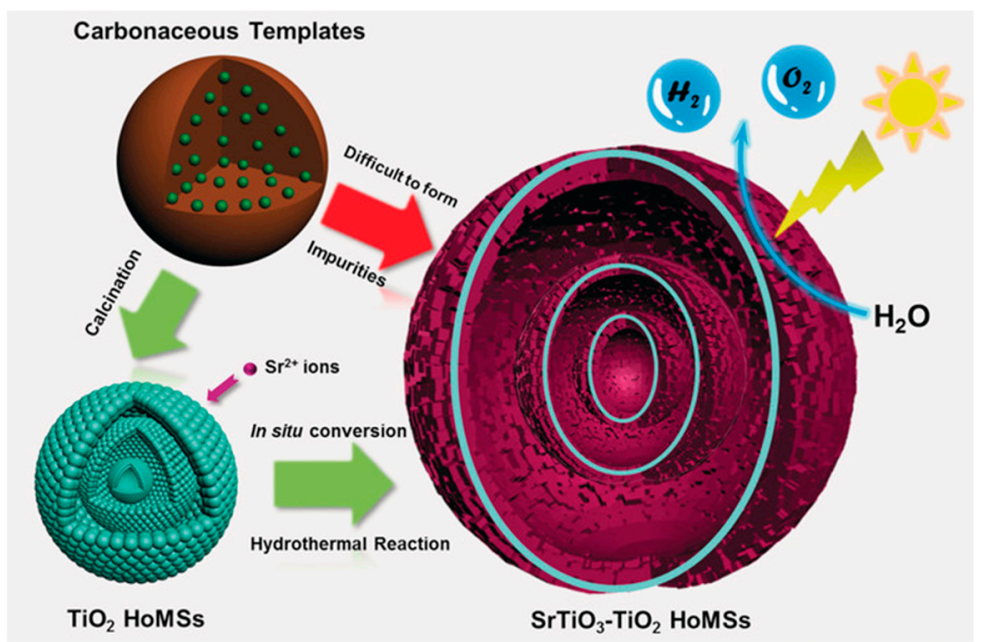

Figure 29. Preparative route of the $\mathrm{SrTiO}_{3}-\mathrm{TiO}_{2}$ hollow multi-shelled structures (HoMSs), via a hydrothermal method. Reproduced from [101], with permission from John Wiley and Sons, copyright 2019.
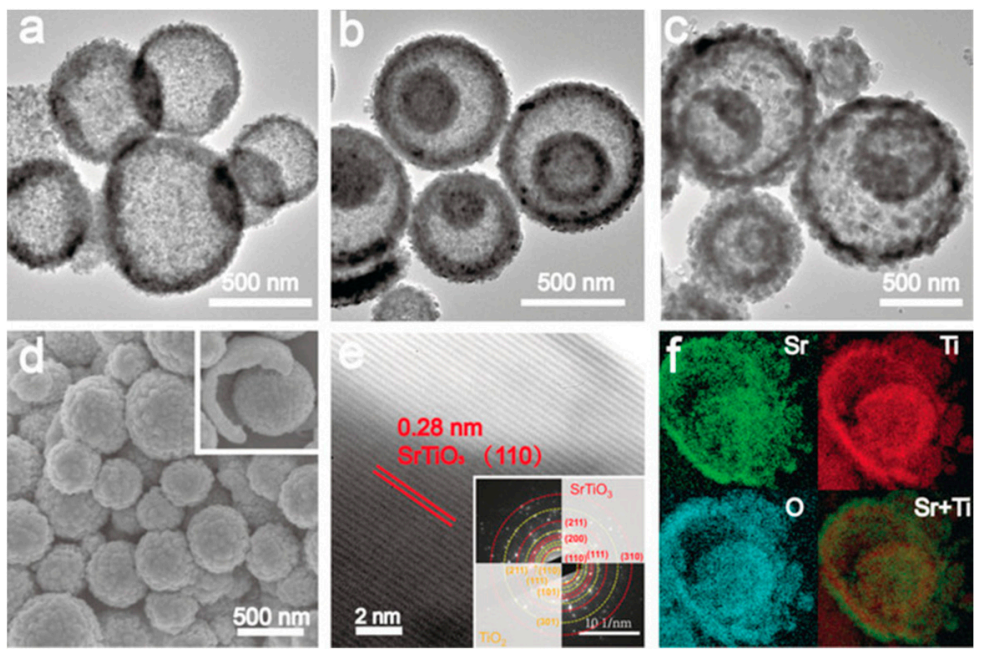

Figure 30. Morphological characterization of hollow multi-shelled structures (HoMSs): TEM images of (a) single (1S-), (b) double (2S-), and (c) triple (3S-) shelled structures. (d) SEM image of 3S-HoMSs (inset: broken sphere). (e) HRTEM image of SAED of S-HoMSs (S-HoMSs). (f) Elemental mapping of a slice of S-HoMSs, after $12 \mathrm{~h}$ of hydrothermal reaction. Reproduced from [101], with permission from John Wiley and Sons, copyright 2019.

\section{Conclusions and Perspectives}

Water splitting as means of a clean and sustainable hydrogen energy production is of utmost importance, in order to meet our worldwide present and future energy needs. Electrochemical processes involving the oxygen evolution reaction are an essential part of this technology. As a result, the development of efficient electrocatalysts has become critical and, as a consequence, this research field has attracted increasing attention over the past years. To this end, an electrocatalyst for commercial electrolyzers should generally reach current densities of at least $500 \mathrm{~mA} \mathrm{~cm}^{-2}$, with long-term stability, as well as overpotentials below $0.3 \mathrm{~V}_{\mathrm{RHE}}$.

It is important to point out that different lines of research emerge from electrolyzer optimization for photovoltaic-driven electrolysis devices (PV-PEC) and from photoelectrochemical systems (PEC). Concerning PV-PEC, increased production levels in the electrolyzer industry require comparable cost levels to the PV sector, to couple these technologies both economically and operationally. 
Therefore, the optimization of porous transport layers in electrolyzers is an essential task, with regard to costs, stability, and efficiency. Furthermore, improvements of the performance and stability of catalyst layers and membranes are indispensable. On the mass production scale, the use of earth-abundant electrocatalysts with similar characteristics to that of noble-metal electrocatalysts, will become inevitable. In addition, membrane-free systems are highly desirable, due to their low upfront capital costs. Another low-cost strategy will be the reduction of the ionic resistance of the membrane to significantly enhance the electrocatalyst activity and to minimize the mass transport limitations. In addition to the need for earth-abundant and low cost materials, the interfacial interactions between the absorbers, electrocatalysts, and electrolytes need to be further and more deeply understood.

While the technology readiness for the PV-PEC devices is at an advanced level, the technological maturity of PEC devices is at a rather early stage, with an estimated time horizon for applications of approximately 10 years. Consequently, progress in PEC technology is of high scientific significance to (and complements) PV-driven electrolysis devices with flexible setups.

Keeping the present situation in mind, this review presents an overview on the recent advances in water oxidation catalysts, focusing on highly visible studies in the field, between 2016 and 2018, to set research directions for the future. The selected works identify a wide range of influential parameters, such as morphology control, choice of operational media, catalyst stability and mechanisms, as well as synthesis methods, including doping strategies, which are just beginning to be fully explored for performance optimization. The complexity of these parameter interactions, furthermore, increases the need for fundamental mechanistic understanding, going hand in hand with the development of new in situ/operando monitoring techniques. In addition, computational studies provide valuable guidelines for the informed use of such new analytical and synthetic techniques. The quest for true catalysts is more important than ever, given the increasing number of yet unexplored new oxide materials, let alone the manifold emerging oxide clusters. The need for new and more efficient materials is pressing to both enhance the performance and commercialization of electrolyzers and to leverage the full potential of complementary and direct, off-grid photoelectrochemical devices.

Funding: This work was funded by the University of Zurich Research Priority Program (URPP) for Solar Light to Chemical Energy Conversion (LightChEC) and by the Swiss National Science Foundation (Sinergia Grant No. CRSII2_160801/1).

Acknowledgments: We thank the University of Zurich Research Priority Program (URPP) for Solar Light to Chemical Energy Conversion (LightChEC) as well as the Swiss National Science Foundation for their support.

Conflicts of Interest: The authors declare no conflict of interest.

\section{References}

1. Takanabe, K. Photocatalytic Water Splitting: Quantitative Approaches toward Photocatalyst by Design. ACS Catal. 2017, 7, 8006-8022. [CrossRef]

2. Roger, I.; Shipman, M.A.; Symes, M.D. Earth-abundant catalysts for electrochemical and photoelectrochemical water splitting. Nat. Rev. Chem. 2017, 1, 3. [CrossRef]

3. Doyle, R.L.; Lyons, M.E.G. The Oxygen Evolution Reaction: Mechanistic Concepts and Catalyst Design. In Photoelectrochemical Solar Fuel Production; Giménez, S., Bisquert, J., Eds.; Springer International Publishing: Cham, Switzerland, 2016; pp. 41-104.

4. Turner, J. Sustainable hydrogen production. Science 2004, 305, 973-974. [CrossRef] [PubMed]

5. Nocera, D.G. The artificial leaf. Acc. Chem. Res. 2012, 45, 767-776. [CrossRef] [PubMed]

6. Joya, K.S.; Joya, Y.F.; Ocakoglu, K.; van de Krol, R. Water-splitting catalysis and solar fuel devices: Artificial leaves on the move. Angew. Chem. 2013, 52, 10426-10437. [CrossRef] [PubMed]

7. Si, W.; Pergolesi, D.; Haydous, F.; Fluri, A.; Wokaun, A.; Lippert, T. Investigating the behavior of various cocatalysts on $\mathrm{LaTaON}_{2}$ photoanode for visible light water splitting. Phys. Chem. Chem. Phys. 2016, 19, 656-662. [CrossRef] [PubMed] 
8. Ardo, S.; Fernandez Rivas, D.; Modestino, M.A.; Schulze Greiving, V.; Abdi, F.F.; Alarcon Llado, E.; Artero, V.; Ayers, K.; Battaglia, C.; Becker, J.-P.; et al. Pathways to electrochemical solar-hydrogen technologies. Energy Environ. Sci. 2018, 103, 15729. [CrossRef]

9. Turan, B.; Becker, J.-P.; Urbain, F.; Finger, F.; Rau, U.; Haas, S. Upscaling of integrated photoelectrochemical water-splitting devices to large areas. Nat. Commun. 2016, 7, 12681. [CrossRef] [PubMed]

10. Li, J.; Güttinger, R.; Moré, R.; Song, F.; Wan, W.; Patzke, G.R. Frontiers of water oxidation: The quest for true catalysts. Chem. Soc. Rev. 2017, 46, 6124-6147. [CrossRef] [PubMed]

11. Wang, Z.; Wang, L. Photoelectrodes for water splitting: Materials, fabrication and characterization. Sci. China Mater. 2018, 61, 806-821. [CrossRef]

12. Lee, Y.; Suntivich, J.; May, K.J.; Perry, E.E.; Shao-Horn, Y. Synthesis and Activities of Rutile $\mathrm{IrO}_{2} \mathrm{and} \mathrm{RuO}_{2}$ Nanoparticles for Oxygen Evolution in Acid and Alkaline Solutions. J. Phys. Chem. Lett. 2012, 3, 399-404. [CrossRef] [PubMed]

13. Walter, M.G.; Warren, E.L.; McKone, J.R.; Boettcher, S.W.; Mi, Q.; Santori, E.A.; Lewis, N.S. Solar water splitting cells. Chem. Rev. 2010, 110, 6446-6473. [CrossRef] [PubMed]

14. Védrine, J. Heterogeneous Catalysis on Metal Oxides. Catalysts 2017, 7, 341. [CrossRef]

15. Weber, D.; Schoop, L.M.; Wurmbrand, D.; Laha, S.; Duppel, V.; Podjaski, F.; Mueller, K.; Starke, U.; Lotsch, B.V. $\mathrm{IrOOH}$ nanosheets as acid stable electrocatalysts for the oxygen evolution reaction. J. Mater. Chem. A 2018. [CrossRef]

16. Seitz, L.C.; Dickens, C.F.; Nishio, K.; Hikita, Y.; Montoya, J.; Doyle, A.; Kirk, C.; Vojvodic, A.; Hwang, H.Y.; Norskov, J.K.; et al. A highly active and stable $\mathrm{IrO}_{\mathrm{x}} / \mathrm{SrIrO}_{3}$ catalyst for the oxygen evolution reaction. Science 2016, 353, 1011-1014. [CrossRef] [PubMed]

17. Deng, Y.; Handoko, A.D.; Du, Y.; Xi, S.; Yeo, B.S. In Situ Raman Spectroscopy of Copper and Copper Oxide Surfaces during Electrochemical Oxygen Evolution Reaction: Identification of $\mathrm{Cu}(\mathrm{III})$ Oxides as Catalytically Active Species. ACS Catal. 2016, 6, 2473-2481. [CrossRef]

18. Xie, L.; Tang, C.; Wang, K.; Du, G.; Asiri, A.M.; Sun, X. $\mathrm{Cu}(\mathrm{OH})_{2} @ \mathrm{CoCO}_{3}(\mathrm{OH})_{2} \cdot n \mathrm{H}_{2} \mathrm{O}$ Core-Shell Heterostructure Nanowire Array: An Efficient 3D Anodic Catalyst for Oxygen Evolution and Methanol Electrooxidation. Small 2017, 13. [CrossRef] [PubMed]

19. Cherevko, S.; Geiger, S.; Kasian, O.; Kulyk, N.; Grote, J.-P.; Savan, A.; Shrestha, B.R.; Merzlikin, S.; Breitbach, B.; Ludwig, A.; et al. Oxygen and hydrogen evolution reactions on $\mathrm{Ru}, \mathrm{RuO}_{2}$, $\mathrm{Ir}$, and $\mathrm{IrO}_{2}$ thin film electrodes in acidic and alkaline electrolytes: A comparative study on activity and stability. Catal. Today 2016, 262, 170-180. [CrossRef]

20. Amiri, M.; Fallahi, M.; Bezaatpour, A.; Jijie, R.; Nozari-asbmarz, M.; Rouhi, M.; Boukherroub, R.; Szunerits, S. Solution Processable $\mathrm{Cu}(\mathrm{II})$ macrocycle for the Formation of $\mathrm{Cu}_{2} \mathrm{O}$ Thin Film on Indium Tin Oxide and Its Application for Water Oxidation. J. Phys. Chem. C 2018, 122, 16510-16518. [CrossRef]

21. Roy, C.; Rao, R.R.; Stoerzinger, K.A.; Hwang, J.; Rossmeisl, J.; Chorkendorff, I.; Shao-Horn, Y.; Stephens, I.E.L. Trends in Activity and Dissolution on $\mathrm{RuO}_{2}$ under Oxygen Evolution Conditions: Particles versus Well-Defined Extended Surfaces. ACS Energy Lett. 2018, 3, 2045-2051. [CrossRef]

22. Oh, H.-S.; Nong, H.N.; Reier, T.; Bergmann, A.; Gliech, M.; Ferreira de Araújo, J.; Willinger, E.; Schlögl, R.; Teschner, D.; Strasser, P. Electrochemical Catalyst-Support Effects and Their Stabilizing Role for $\mathrm{IrO}_{\mathrm{x}}$ Nanoparticle Catalysts during the Oxygen Evolution Reaction. J. Am. Chem. Soc. 2016, 138, 12552-12563. [CrossRef] [PubMed]

23. Wu, Y.T.; Liu, N. Visualising Battery Reactions and Processes by Using In Situ and In Operando Microscopies. Chem 2018, 4, 438-465. [CrossRef]

24. Zhang, M.; Frei, H. Water Oxidation Mechanisms of Metal Oxide Catalysts by Vibrational Spectroscopy of Transient Intermediates. Annu. Rev. Phys. Chem. 2017, 68, 209-231. [CrossRef] [PubMed]

25. Conway, B.E.; Bai, L.; Sattar, M.A. Role of the transfer coefficient in electrocatalysis: Applications to the $\mathrm{H}_{2}$ and $\mathrm{O}_{2}$ evolution reactions and the characterization of participating adsorbed intermediates. Int. J. Hydrogen Energy 1987, 12, 607-621. [CrossRef]

26. Atabaev, T.S.; Lee, D.H.; Hong, N.H. Fabrication of $\mathrm{TiO}_{2} / \mathrm{CuO}$ photoelectrode with enhanced solar water splitting activity. Funct. Mater. Lett. 2017, 10, 1750084. [CrossRef]

27. Mishra, G.; Dash, B.; Pandey, S. Layered double hydroxides: A brief review from fundamentals to application as evolving biomaterials. Appl. Clay Sci. 2018, 153, 172-186. [CrossRef] 
28. Han, L.; Dong, S.; Wang, E. Transition-Metal (Co, Ni, and Fe)-Based Electrocatalysts for the Water Oxidation Reaction. Adv. Mater. 2016, 28, 9266-9291. [CrossRef] [PubMed]

29. Wu, J.; Ren, Z.; Du, S.; Kong, L.; Liu, B.; Xi, W.; Zhu, J.; Fu, H. A highly active oxygen evolution electrocatalyst: Ultrathin CoNi double hydroxide/CoO nanosheets synthesized via interface-directed assembly. Nano Res. 2016, 9, 713-725. [CrossRef]

30. Yang, F.; Sliozberg, K.; Sinev, I.; Antoni, H.; Bähr, A.; Ollegott, K.; Xia, W.; Masa, J.; Grünert, W.; Cuenya, B.R.; et al. Synergistic Effect of Cobalt and Iron in Layered Double Hydroxide Catalysts for the Oxygen Evolution Reaction. ChemSusChem 2017, 10, 156-165. [CrossRef] [PubMed]

31. You, C.; Ji, Y.; Liu, Z.; Xiong, X.; Sun, X. Ultrathin CoFe-Borate Layer Coated CoFe-Layered Double Hydroxide Nanosheets Array: A Non-Noble-Metal 3D Catalyst Electrode for Efficient and Durable Water Oxidation in Potassium Borate. ACS Sustain. Chem. Eng. 2018, 6, 1527-1531. [CrossRef]

32. Fan, K.; Chen, H.; Ji, Y.; Huang, H.; Claesson, P.M.; Daniel, Q.; Philippe, B.; Rensmo, H.; Li, F.; Luo, Y.; et al. Nickel-vanadium monolayer double hydroxide for efficient electrochemical water oxidation. Nat. Commun. 2016, 7, 11981. [CrossRef] [PubMed]

33. Ping, J.; Wang, Y.; Lu, Q.; Chen, B.; Chen, J.; Huang, Y.; Ma, Q.; Tan, C.; Yang, J.; Cao, X.; et al. Self-Assembly of Single-Layer CoAl-Layered Double Hydroxide Nanosheets on 3D Graphene Network Used as Highly Efficient Electrocatalyst for Oxygen Evolution Reaction. Adv. Mater. 2016, 28, 7640-7645. [CrossRef] [PubMed]

34. Hunter, B.M.; Winkler, J.R.; Gray, H.B. Iron Is the Active Site in Nickel/Iron Water Oxidation Electrocatalysts. Molecules 2018, 23, 903. [CrossRef] [PubMed]

35. Wang, C.; Moghaddam, R.B.; Brett, M.J.; Bergens, S.H. Simple Aqueous Preparation of High Activity and Stability NiFe Hydrous Oxide Catalysts for Water Oxidation. ACS Sustain. Chem. Eng. 2017, 5, 1106-1112. [CrossRef]

36. Li, N.; Bediako, D.K.; Hadt, R.G.; Hayes, D.; Kempa, T.J.; von Cube, F.; Bell, D.C.; Chen, L.X.; Nocera, D.G. Influence of iron doping on tetravalent nickel content in catalytic oxygen evolving films. Proc. Natl. Acad. Sci. USA 2017, 114, 1486-1491. [CrossRef] [PubMed]

37. Li, Z.; Shao, M.; An, H.; Wang, Z.; Xu, S.; Wei, M.; Evans, D.G.; Duan, X. Fast electrosynthesis of Fe-containing layered double hydroxide arrays toward highly efficient electrocatalytic oxidation reactions. Chem. Sci. 2015, 6, 6624-6631. [CrossRef] [PubMed]

38. Xie, C.; Wang, Y.; Hu, K.; Tao, L.; Huang, X.; Huo, J.; Wang, S. In situ confined synthesis of molybdenum oxide decorated nickel-iron alloy nanosheets from $\mathrm{MoO}_{4}{ }^{2-}$ intercalated layered double hydroxides for the oxygen evolution reaction. J. Mater. Chem. A 2017, 5, 87-91. [CrossRef]

39. Görlin, M.; Ferreira de Araújo, J.; Schmies, H.; Bernsmeier, D.; Dresp, S.; Gliech, M.; Jusys, Z.; Chernev, P.; Kraehnert, R.; Dau, H.; et al. Tracking Catalyst Redox States and Reaction Dynamics in Ni-Fe Oxyhydroxide Oxygen Evolution Reaction Electrocatalysts: The Role of Catalyst Support and Electrolyte pH. J. Am. Chem. Soc. 2017, 139, 2070-2082. [CrossRef] [PubMed]

40. Zhang, F.; Shi, Y.; Xue, T.; Zhang, J.; Liang, Y.; Zhang, B. In situ electrochemically converting $\mathrm{Fe}_{2} \mathrm{O}_{3}-\mathrm{Ni}(\mathrm{OH})_{2}$ to $\mathrm{NiFe}_{2} \mathrm{O}_{4}-\mathrm{NiOOH}$ : A highly efficient electrocatalyst towards water oxidation. Sci. China Mater. 2017, 60, 324-334. [CrossRef]

41. Zou, X.; Liu, Y.; Li, G.-D.; Wu, Y.; Liu, D.-P.; Li, W.; Li, H.-W.; Wang, D.; Zhang, Y.; Zou, X. Ultrafast Formation of Amorphous Bimetallic Hydroxide Films on 3D Conductive Sulfide Nanoarrays for Large-Current-Density Oxygen Evolution Electrocatalysis. Adv. Mater. 2017, 29. [CrossRef] [PubMed]

42. Wu, Z.; Wang, Z.; Geng, F. Radially Aligned Hierarchical Nickel/Nickel-Iron (Oxy)hydroxide Nanotubes for Efficient Electrocatalytic Water Splitting. ACS Appl. Mater. Interfaces 2018, 10, 8585-8593. [CrossRef] [PubMed]

43. Hunter, B.M.; Hieringer, W.; Winkler, J.R.; Gray, H.B.; Müller, A.M. Effect of interlayer anions on [NiFe]-LDH nanosheet water oxidation activity. Energy Environ. Sci. 2016, 9, 1734-1743. [CrossRef]

44. Jia, Y.; Zhang, L.; Gao, G.; Chen, H.; Wang, B.; Zhou, J.; Soo, M.T.; Hong, M.; Yan, X.; Qian, G.; et al. A Heterostructure Coupling of Exfoliated Ni-Fe Hydroxide Nanosheet and Defective Graphene as a Bifunctional Electrocatalyst for Overall Water Splitting. Adv. Mater. 2017, 29. [CrossRef] [PubMed]

45. Lutterman, D.A.; Surendranath, Y.; Nocera, D.G. A self-healing oxygen-evolving catalyst. J. Am. Chem. Soc. 2009, 131, 3838-3839. [CrossRef] [PubMed] 
46. Xie, T.; Min, J.; Liu, J.; Chen, J.; Fu, D.; Zhang, R.; Zhu, K.; Lei, M. Synthesis of mesoporous $\mathrm{Co}_{3} \mathrm{O}_{4}$ nanosheet-assembled hollow spheres towards efficient electrocatalytic oxygen evolution. J. Alloy. Compd. 2018, 754, 72-77. [CrossRef]

47. Wang, H.-Y.; Hung, S.-F.; Chen, H.-Y.; Chan, T.-S.; Chen, H.M.; Liu, B. In Operando Identification of Geometrical-Site-Dependent Water Oxidation Activity of Spinel $\mathrm{Co}_{3} \mathrm{O}_{4}$. J. Am. Chem. Soc. 2016, 138, 36-39. [CrossRef] [PubMed]

48. Zhu, Y.P.; Ma, T.Y.; Jaroniec, M.; Qiao, S.Z. Self-Templating Synthesis of Hollow $\mathrm{Co}_{3} \mathrm{O}_{4}$ Microtube Arrays for Highly Efficient Water Electrolysis. Angew. Chem. 2017, 56, 1324-1328. [CrossRef] [PubMed]

49. Koroidov, S.; Anderlund, M.F.; Styring, S.; Thapper, A.; Messinger, J. First turnover analysis of water-oxidation catalyzed by Co-oxide nanoparticles. Energy Environ. Sci. 2015, 8, 2492-2503. [CrossRef]

50. Wang, Q.; Hu, W.; Huang, Y. Nitrogen doped graphene anchored cobalt oxides efficiently bi-functionally catalyze both oxygen reduction reaction and oxygen revolution reaction. Int. J. Hydrogen Energy 2017, 42, 5899-5907. [CrossRef]

51. Aijaz, A.; Masa, J.; Rösler, C.; Xia, W.; Weide, P.; Botz, A.J.R.; Fischer, R.A.; Schuhmann, W.; Muhler, M. $\mathrm{Co} @ \mathrm{Co}_{3} \mathrm{O}_{4}$ Encapsulated in Carbon Nanotube-Grafted Nitrogen-Doped Carbon Polyhedra as an Advanced Bifunctional Oxygen Electrode. Angew. Chem. 2016, 55, 4087-4091. [CrossRef] [PubMed]

52. Liu, Z.-Q.; Cheng, H.; Li, N.; Ma, T.Y.; Su, Y.-Z. $\mathrm{ZnCo}_{2} \mathrm{O}_{4}$ Quantum Dots Anchored on Nitrogen-Doped Carbon Nanotubes as Reversible Oxygen Reduction/Evolution Electrocatalysts. Adv. Mater. 2016, 28, 3777-3784. [CrossRef] [PubMed]

53. Xiao, C.; Li, Y.; Lu, X.; Zhao, C. Bifunctional Porous NiFe/ $\mathrm{NiCo}_{2} \mathrm{O}_{4} / \mathrm{Ni}$ Foam Electrodes with Triple Hierarchy and Double Synergies for Efficient Whole Cell Water Splitting. Adv. Funct. Mater. 2016, 26, 3515-3523. [CrossRef]

54. Guan, C.; Liu, X.; Ren, W.; Li, X.; Cheng, C.; Wang, J. Rational Design of Metal-Organic Framework Derived Hollow $\mathrm{NiCo}_{2} \mathrm{O}_{4}$ Arrays for Flexible Supercapacitor and Electrocatalysis. Adv. Energy Mater. 2017, 7, 1602391. [CrossRef]

55. Morales-Guio, C.G.; Liardet, L.; Hu, X. Oxidatively Electrodeposited Thin-Film Transition Metal (Oxy)hydroxides as Oxygen Evolution Catalysts. J. Am. Chem. Soc. 2016, 138, 8946-8957. [CrossRef] [PubMed]

56. Ji, X.; Hao, S.; Qu, F.; Liu, J.; Du, G.; Asiri, A.M.; Chen, L.; Sun, X. Core-shell CoFe $\mathrm{O}_{4} @$ Co-Fe-Bi nanoarray: A surface-amorphization water oxidation catalyst operating at near-neutral pH. Nanoscale 2017, 9, 7714-7718. [CrossRef] [PubMed]

57. Zhang, X.; Chen, Y.-S.; Kamat, P.V.; Ptasinska, S. Probing Interfacial Electrochemistry on a $\mathrm{Co}_{3} \mathrm{O}_{4} \mathrm{Water}$ Oxidation Catalyst Using Lab-Based Ambient Pressure X-ray Photoelectron Spectroscopy. J. Phys. Chem. C 2018, 122, 13894-13901. [CrossRef]

58. Reith, L.; Lienau, K.; Cook, D.S.; Moré, R.; Walton, R.I.; Patzke, G.R. Monitoring the Hydrothermal Growth of Cobalt Spinel Water Oxidation Catalysts: From Preparative History to Catalytic Activity. Chemistry 2018. [CrossRef]

59. Matsumoto, Y.; Yamada, S.; Nishida, T.; Sato, E. Oxygen evolution on $\mathrm{La}_{1-\mathrm{x}} \mathrm{Sr}_{\mathrm{x}} \mathrm{Fe}_{1-\mathrm{y}} \mathrm{Co}_{\mathrm{y}} \mathrm{O}_{3}$ series oxides. J. Electrochem. Sci. 1980, 127, 2360-2364. [CrossRef]

60. Zhu, Y.; Zhou, W.; Yu, J.; Chen, Y.; Liu, M.; Shao, Z. Enhancing Electrocatalytic Activity of Perovskite Oxides by Tuning Cation Deficiency for Oxygen Reduction and Evolution Reactions. Chem. Mater. 2016, 28, 1691-1697. [CrossRef]

61. Zhao, B.; Zhang, L.; Zhen, D.; Yoo, S.; Ding, Y.; Chen, D.; Chen, Y.; Zhang, Q.; Doyle, B.; Xiong, X.; et al. A tailored double perovskite nanofiber catalyst enables ultrafast oxygen evolution. Nat. Commun. 2017, 8, 14586. [CrossRef] [PubMed]

62. Su, C.; Duan, X.; Miao, J.; Zhong, Y.; Zhou, W.; Wang, S.; Shao, Z. Mixed Conducting Perovskite Materials as Superior Catalysts for Fast Aqueous-Phase Advanced Oxidation: A Mechanistic Study. ACS Catal. 2017, 7, 388-397. [CrossRef]

63. Xu, X.; Su, C.; Zhou, W.; Zhu, Y.; Chen, Y.; Shao, Z. Co-doping Strategy for Developing Perovskite Oxides as Highly Efficient Electrocatalysts for Oxygen Evolution Reaction. Adv. Sci. 2016, 3, 1500187. [CrossRef] [PubMed]

64. Zhu, Y.; Zhou, W.; Zhong, Y.; Bu, Y.; Chen, X.; Zhong, Q.; Liu, M.; Shao, Z. A Perovskite Nanorod as Bifunctional Electrocatalyst for Overall Water Splitting. Adv. Energy Mater. 2017, 7, 1602122. [CrossRef] 
65. Mefford, J.T.; Rong, X.; Abakumov, A.M.; Hardin, W.G.; Dai, S.; Kolpak, A.M.; Johnston, K.P.; Stevenson, K.J. Water electrolysis on $\mathrm{La}_{1-x} \mathrm{Sr}_{\mathrm{x}} \mathrm{CoO}_{3-\delta}$ perovskite electrocatalysts. Nat. Commun. 2016, 7, 11053. [CrossRef] [PubMed]

66. Lee, J.G.; Hwang, J.; Hwang, H.J.; Jeon, O.S.; Jang, J.; Kwon, O.; Lee, Y.; Han, B.; Shul, Y.-G. A New Family of Perovskite Catalysts for Oxygen-Evolution Reaction in Alkaline Media: $\mathrm{BaNiO}_{3}$ and $\mathrm{BaNi}_{0.83} \mathrm{O}_{2.5}$. J. Am. Chem. Soc. 2016, 138, 3541-3547. [CrossRef] [PubMed]

67. Black, A.P.; Suzuki, H.; Higashi, M.; Frontera, C.; Ritter, C.; De, C.; Sundaresan, A.; Abe, R.; Fuertes, A. New rare earth hafnium oxynitride perovskites with photocatalytic activity in water oxidation and reduction. Chem. Commun. 2018, 54, 1525-1528. [CrossRef] [PubMed]

68. Ng, J.W.D.; García-Melchor, M.; Bajdich, M.; Chakthranont, P.; Kirk, C.; Vojvodic, A.; Jaramillo, T.F. Gold-supported cerium-doped $\mathrm{NiO}_{x}$ catalysts for water oxidation. Nat. Energy 2016, 1, 16053. [CrossRef]

69. Li, M.; Yang, Y.; Ling, Y.; Qiu, W.; Wang, F.; Liu, T.; Song, Y.; Liu, X.; Fang, P.; Tong, Y.; et al. Morphology and Doping Engineering of Sn-Doped Hematite Nanowire Photoanodes. Nano Lett. 2017, 17, 2490-2495. [CrossRef] [PubMed]

70. Bates, M.K.; Jia, Q.; Doan, H.; Liang, W.; Mukerjee, S. Charge-Transfer Effects in Ni-Fe and Ni-Fe-Co Mixed-Metal Oxides for the Alkaline Oxygen Evolution Reaction. ACS Catal. 2016, 6, 155-161. [CrossRef]

71. Li, P.; Zeng, H.C. Sandwich-Like Nanocomposite of $\mathrm{CoNiO}_{x} /$ Reduced Graphene Oxide for Enhanced Electrocatalytic Water Oxidation. Adv. Funct. Mater. 2017, 27, 1606325. [CrossRef]

72. Zhuang, L.; Ge, L.; Yang, Y.; Li, M.; Jia, Y.; Yao, X.; Zhu, Z. Ultrathin Iron-Cobalt Oxide Nanosheets with Abundant Oxygen Vacancies for the Oxygen Evolution Reaction. Adv. Mater. 2017, 29. [CrossRef] [PubMed]

73. Li, W.; Sheehan, S.W.; He, D.; He, Y.; Yao, X.; Grimm, R.L.; Brudvig, G.W.; Wang, D. Hematite-Based Solar Water Splitting in Acidic Solutions: Functionalization by Mono- and Multilayers of Iridium Oxygen-Evolution Catalysts. Angew. Chem. 2015, 54, 11428-11432. [CrossRef] [PubMed]

74. Gholamrezaei, S.; Salavati-Niasari, M. Sonochemical synthesis of $\mathrm{SrMnO}_{3}$ nanoparticles as an efficient and new catalyst for $\mathrm{O}_{2}$ evolution from water splitting reaction. Ultrason. Sonochem. 2018, 40, 651-663. [CrossRef] [PubMed]

75. Yang, J.; Zhu, G.; Liu, Y.; Xia, J.; Ji, Z.; Shen, X.; Wu, S. Fe $\mathrm{O}_{4}$-Decorated $\mathrm{Co}_{9} \mathrm{~S}_{8}$ Nanoparticles In Situ Grown on Reduced Graphene Oxide: A New and Efficient Electrocatalyst for Oxygen Evolution Reaction. Adv. Funct. Mater. 2016, 26, 4712-4721. [CrossRef]

76. Weng, B.; Xu, F.; Wang, C.; Meng, W.; Grice, C.R.; Yan, Y. A layered $\mathrm{Na}_{1-x} \mathrm{Ni}_{\mathrm{y}} \mathrm{Fe}_{1-\mathrm{y}} \mathrm{O}_{2}$ double oxide oxygen evolution reaction electrocatalyst for highly efficient water-splitting. Energy Environ. Sci. 2017, 10, 121-128. [CrossRef]

77. Abbott, D.F.; Meier, M.; Meseck, G.R.; Fabbri, E.; Seeger, S.; Schmidt, T.J. Silicone Nanofilament-Supported Mixed Nickel-Metal Oxides for Alkaline Water Electrolysis. J. Electrochem. Soc. 2017, 164, F203-F208. [CrossRef]

78. Kanazawa, T.; Maeda, K. Chromium-substituted hematite powder as a catalytic material for photochemical and electrochemical water oxidation. Catal. Sci. Technol. 2017, 7, 2940-2946. [CrossRef]

79. Xing, X.; Liu, R.; Cao, K.; Kaiser, U.; Zhang, G.; Streb, C. Manganese vanadium oxide-N-doped reduced graphene oxide composites as oxygen reduction and oxygen evolution electrocatalysts. ACS Appl. Mater. Interfaces 2018. [CrossRef] [PubMed]

80. Antoni, H.; Morales, D.M.; Fu, Q.; Chen, Y.-T.; Masa, J.; Schuhmann, W.; Muhler, M. Oxidative Deposition of Manganese Oxide Nanosheets on Nitrogen-Functionalized Carbon Nanotubes Applied in the Alkaline Oxygen Evolution Reaction. ACS Omega 2018, 3, 11216-11226. [CrossRef]

81. Zhou, L.; Shinde, A.; Montoya, H.J.; Singh, A.; Gul, S.; Tano, J.; Ye, Y.; Crumlin, J.E.; Richter, M.H.; Cooper, J.K.; et al. Rutile alloys in the Mn-Sb-O system stabilize Mn3+ for OER in strong acid. ACS Catal. 2018, 8, 10938-10948. [CrossRef]

82. Najafpour, M.M.; Salimi, S.; Safdari, R. Nanosized manganese oxide supported on carbon black: A new, cheap and green composite for water oxidation. Int. J. Hydrogen Energy 2017, 42, 255-264. [CrossRef]

83. Najafpour, M.M.; Hołyńska, M.; Salimi, S. Applications of the "nano to bulk" Mn oxides: Mn oxide as a Swiss army knife. Coord. Chem. Rev. 2015, 285, 65-75. [CrossRef]

84. Morgan Chan, Z.; Kitchaev, D.A.; Nelson Weker, J.; Schnedermann, C.; Lim, K.; Ceder, G.; Tumas, W.; Toney, M.F.; Nocera, D.G. Electrochemical trapping of metastable $\mathrm{Mn}^{3+}$ ions for activation of $\mathrm{MnO}_{2}$ oxygen evolution catalysts. Proc. Natl. Acad. Sci. USA 2018, 115, E5261-E5268. [CrossRef] [PubMed] 
85. Liang, H.; Gandi, A.N.; Xia, C.; Hedhili, M.N.; Anjum, D.H.; Schwingenschlögl, U.; Alshareef, H.N. Amorphous NiFe-OH/NiFeP Electrocatalyst Fabricated at Low Temperature for Water Oxidation Applications. ACS Energy Lett. 2017, 2, 1035-1042. [CrossRef]

86. Zhang, W.; Wu, Y.; Qi, J.; Chen, M.; Cao, R. A Thin NiFe Hydroxide Film Formed by Stepwise Electrodeposition Strategy with Significantly Improved Catalytic Water Oxidation Efficiency. Adv. Energy Mater. 2017, 7, 1602547. [CrossRef]

87. Pi, Y.; Shao, Q.; Wang, P.; Lv, F.; Guo, S.; Guo, J.; Huang, X. Trimetallic Oxyhydroxide Coralloids for Efficient Oxygen Evolution Electrocatalysis. Angew. Chem. 2017, 56, 4502-4506. [CrossRef] [PubMed]

88. Liu, W.; Liu, H.; Dang, L.; Zhang, H.; Wu, X.; Yang, B.; Li, Z.; Zhang, X.; Lei, L.; Jin, S. Amorphous Cobalt-Iron Hydroxide Nanosheet Electrocatalyst for Efficient Electrochemical and Photo-Electrochemical Oxygen Evolution. Adv. Funct. Mater. 2017, 27, 1603904. [CrossRef]

89. Feng, J.-X.; Ye, S.-H.; Xu, H.; Tong, Y.-X.; Li, G.-R. Design and Synthesis of FeOOH/CeO 2 Heterolayered Nanotube Electrocatalysts for the Oxygen Evolution Reaction. Adv. Mater. 2016, 28, 4698-4703. [CrossRef] [PubMed]

90. Feng, J.-X.; Xu, H.; Dong, Y.-T.; Ye, S.-H.; Tong, Y.-X.; Li, G.-R. FeOOH/Co/FeOOH Hybrid Nanotube Arrays as High-Performance Electrocatalysts for the Oxygen Evolution Reaction. Angew. Chem. 2016, 55, 3694-3698. [CrossRef] [PubMed]

91. Zhang, B.; Zheng, X.; Voznyy, O.; Comin, R.; Bajdich, M.; García-Melchor, M.; Han, L.; Xu, J.; Liu, M.; Zheng, L.; et al. Homogeneously dispersed multimetal oxygen-evolving catalysts. Science 2016, 352, 333-337. [CrossRef] [PubMed]

92. Li, Y.; Zhao, C. Enhancing Water Oxidation Catalysis on a Synergistic Phosphorylated NiFe Hydroxide by Adjusting Catalyst Wettability. ACS Catal. 2017, 7, 2535-2541. [CrossRef]

93. Shin, H.; Xiao, H.; Goddard, W.A. In Silico Discovery of New Dopants for Fe-Doped Ni Oxyhydroxide $\left(\mathrm{Ni}_{1-x} \mathrm{Fe}_{\mathrm{x}} \mathrm{OOH}\right)$ Catalysts for Oxygen Evolution Reaction. J. Am. Chem. Soc. 2018, 140, 6745-6748. [CrossRef] [PubMed]

94. Dong, R.; Du, H.; Sun, Y.; Huang, K.; Li, W.; Geng, B. Selective Reduction-Oxidation Strategy to the Conductivity-Enhancing Ag-Decorated Co-Based 2D Hydroxides as Efficient Electrocatalyst in Oxygen Evolution Reaction. ACS Sustain. Chem. Eng. 2018, 6, 13420-13426. [CrossRef]

95. Suryawanshi, M.P.; Shin, S.W.; Ghorpade, U.V.; Kim, J.; Jeong, H.W.; Kang, S.H.; Kim, J.H. A facile, one-step electroless deposition of $\mathrm{NiFeOOH}$ nanosheets onto photoanodes for highly durable and efficient solar water oxidation. J. Mater. Chem. A 2018, 6, 20678-20685. [CrossRef]

96. Balram, A.; Zhang, H.; Santhanagopalan, S. Enhanced Oxygen Evolution Reaction Electrocatalysis via Electrodeposited Amorphous $\alpha$-Phase Nickel-Cobalt Hydroxide Nanodendrite Forests. ACS Appl. Mater. Interfaces 2017, 9, 28355-28365. [CrossRef] [PubMed]

97. Konkena, B.; Masa, J.; Botz, A.J.R.; Sinev, I.; Xia, W.; Koßmann, J.; Drautz, R.; Muhler, M.; Schuhmann, W. Metallic NiPS $3 @ N i O O H$ Core-Shell Heterostructures as Highly Efficient and Stable Electrocatalyst for the Oxygen Evolution Reaction. ACS Catal. 2017, 7, 229-237. [CrossRef]

98. Kuang, P.; Zhu, B.; Li, Y.; Liu, H.; Yu, J.; Fan, K. Graphdiyne: A superior carbon additive to boost the activity of water oxidation catalysts. Nanoscale Horiz. 2018, 3, 317-326. [CrossRef]

99. Lu, C.; Yang, Y.; Wang, J.; Fu, R.; Zhao, X.; Zhao, L.; Ming, Y.; Hu, Y.; Lin, H.; Tao, X.; et al. High-performance graphdiyne-based electrochemical actuators. Nat. Commun. 2018, 9, 752. [CrossRef] [PubMed]

100. Chen, J.; Shen, X.; Pan, Y.; Liu, C.; Hwang, S.Y.; Xu, Q.; Peng, Z. Synthesis of freestanding amorphous giant carbon tubes with outstanding oil sorption and water oxidation properties. J. Mater. Chem. A 2018, 6, 3996-4002. [CrossRef]

101. Wei, Y.; Wang, J.; Yu, R.; Wan, J.; Wang, D. Constructing $\mathrm{SrTiO}_{3}-\mathrm{TiO}_{2}$ Heterogeneous Hollow Multi-shelled Structures for Enhanced Solar Water Splitting. Angew. Chem. 2019, 58, 1422-1426. [CrossRef] [PubMed]

(C) 2019 by the authors. Licensee MDPI, Basel, Switzerland. This article is an open access article distributed under the terms and conditions of the Creative Commons Attribution (CC BY) license (http:/ / creativecommons.org/licenses/by/4.0/). 